\title{
VISITOR SATISFACTION WITH GUIDED PACKAGE TOURS IN THE NORTHERN TOURIST CIRCUIT OF TANZANIA
}

By

\section{Elisante Ombeni Leguma}

\author{
A thesis \\ submitted to Victoria University of Wellington in partial \\ fulfilment of the requirements for the degree of \\ Master of Tourism Management
}

Victoria University of Wellington

2013 


\begin{abstract}
The guided package tour is a special tourism product that is composed of many components that are organized and offered by a tour operator. The literature shows that many visitors prefer guided package tours because they are a convenient way of organising a holiday. Studies of visitor satisfaction with guided package tours are often conducted in developed economies, on coach tours in cities, and therefore less is known about guided package tours in developing economies where the principle attraction is wildlife and nature. This thesis investigates visitor satisfaction with guided package tours that feature safaris in the northern tourist circuit of Tanzania. The northern tourist circuit is the largest tourist destination in Tanzania that attracts more that $80 \%$ of international visitors in the country.
\end{abstract}

Quantitative research method is used in this study together with importance-performance analysis. Importance-performance analysis provides a structure for data analysis and the interpretation of research findings. This thesis explores the relative importance of different components of guided package tours; visitor satisfaction with different components of the guided package tour; the relationship between importance and performance of different components of the guided package tour; and the relationship between visitor satisfaction with the tour guide and overall satisfaction with the tour experience.

This research demonstrates that all components of the guided package tour are important to visitors, and visitors are very satisfied with the performance of the tour providers. Attractions, tour guides and transportation are considered very important and very satisfying components of the guided package tour in the northern tourist circuit. Visitor satisfaction with the tour guide makes the largest contribution to overall satisfaction with the tour experience. Similarly, visitor satisfaction with other components of the guided package tour contributes to overall satisfaction with the tour experience.

The findings of this study provide a better understanding of visitor satisfaction with guided package tours that feature safaris, and the application of importance-performance analysis in the study of visitor satisfaction in a rural wildlife area. The study provides 
several practical suggestions for guided package tour providers in the northern tourist circuit.

Keywords: Guided package tours; visitor satisfaction; importance-performance analysis; Tanzania. 


\section{ACKNOWLEDGEMENTS}

My academic journey at Victoria University of Wellington would not have been successful without these incredible people who touched my life in so many ways.

I'm so delighted to express my sincere gratitude to my incredible supervisors Dr Adam Weaver and Dr Julia Albrecht who provided guidance, support and critiques throughout this research. Adam, I appreciate your written feedback you gave for every piece of work you read. Julia, I thank for your positive critique and interest in my research. You are the best supervisors I could imagine. I am immensely proud of your job well done. I have learnt a lot from you. I take all the research skills you provided me with; you have set a foundation for my future career.

I am also very appreciative of the wonderful support I received from Dr Dalice Sim, the university's amazing statistical consultant.

I wish to express my sincere thanks to NZAID for awarding me a scholarship to pursue a Masters degree at Victoria University of Wellington. I feel humbled to have been awarded this scholarship because it has not only given me knowledge and skills but also a great experience in New Zealand. Also, my heartfelt thanks go to the School of Management for research funds without which this thesis would not have been successful.

My sincere gratitude extends to the Kilimanjaro International Airport, for permission to access visitors at the departure lounges and Kudu Safaris Ltd and Nomad Tanzania for distributing a questionnaire during the data collection phase of my thesis.

This journey would not have been as interesting without the encouragement and love of my fellow MTM students 2012/13: Amalina, Natalia and Peter. You guys are amazing. I owe my very best thanks to my friend Peter for being a true brother since we arrived in Wellington.

Also, many thanks to members of the academic staff from the Tourism Management Group (Prof. Douglas G. Pearce, Dr Christian Schott, Dr Ian Yeoman, \& Dr Karen Smith) for the knowledge and skills they demonstrated throughout the programme. 
Last, but not least, my family who I love, my parents, my brothers and my sisters for their love, support, prayers, and encouragement throughout my experience in New Zealand. I thank God for having such a wonderful family. 


\section{TABLE OF CONTENTS}

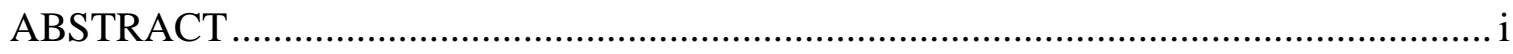

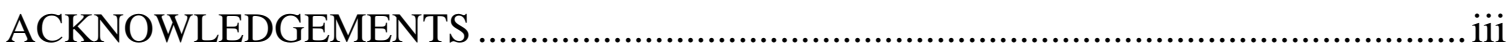

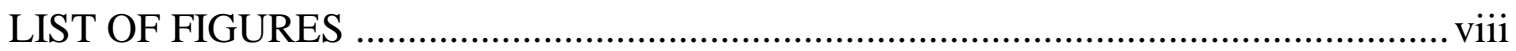

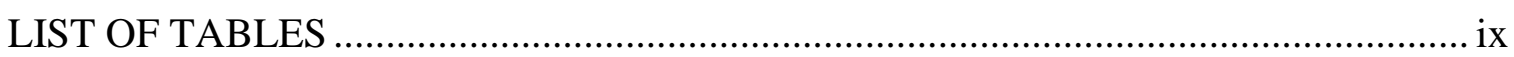

LIST OF ABBREVIATIONS ...............................................................................

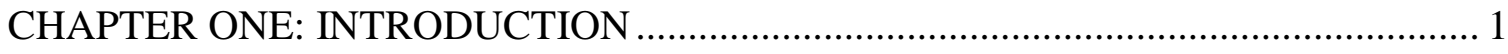

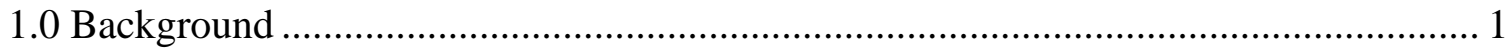

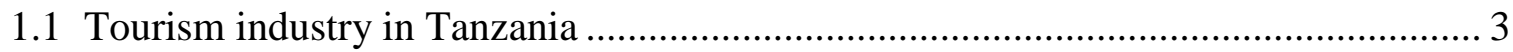

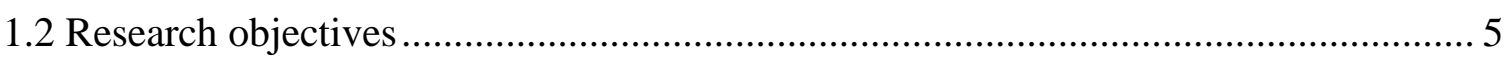

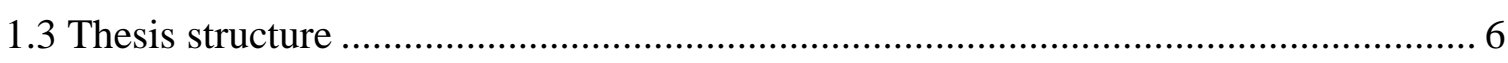

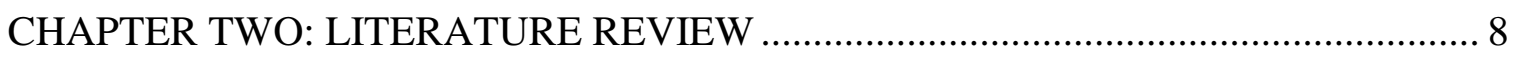

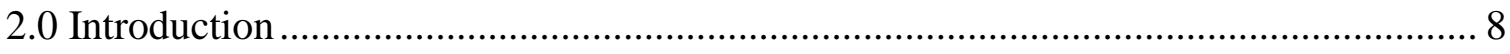

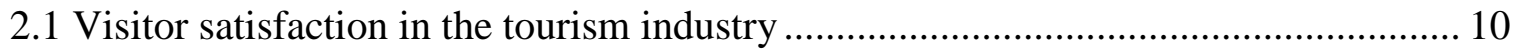

2.1.1 Factors affecting visitor satisfaction with tourism products and services ............ 11

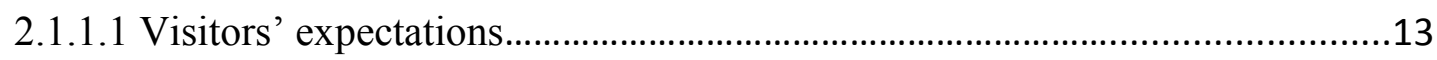

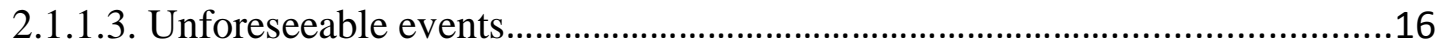

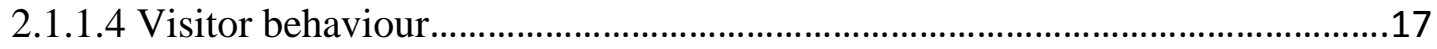

2.1.1.5 Visitors' perception of equity..................................................................... 18

2.1.2 Measurement of visitor satisfaction in the tourism industry ............................. 19

2.1.2.1 Different ways to measure satisfaction............................................................19

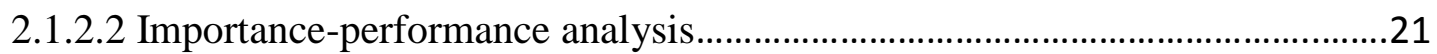

2.1.3 Visitor satisfaction in protected area tourism ................................................ 23

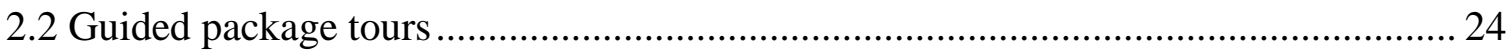

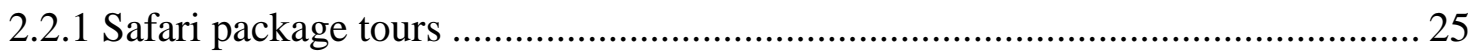

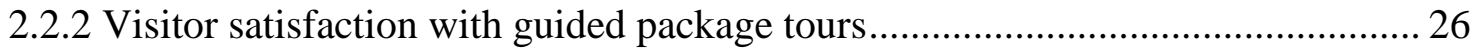

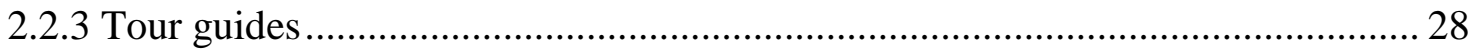

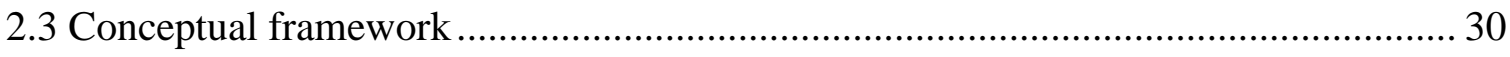

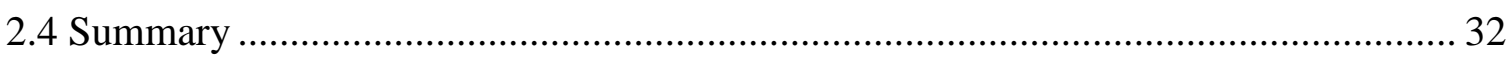

CHAPTER THREE: TOURISM IN THE CONTEXT OF TANZANIA ........................ 34

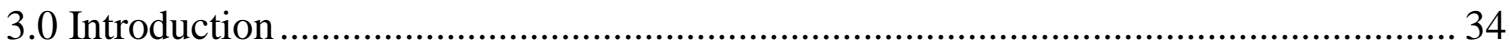

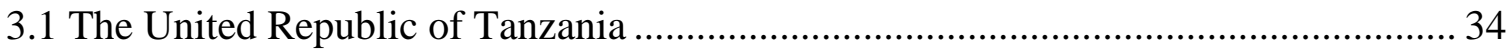




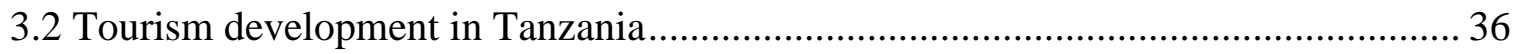

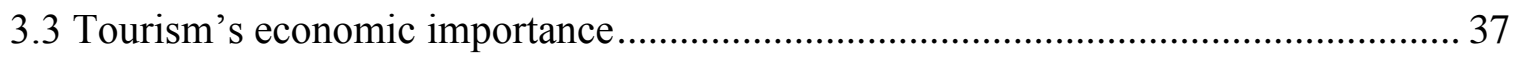

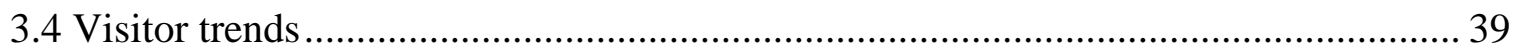

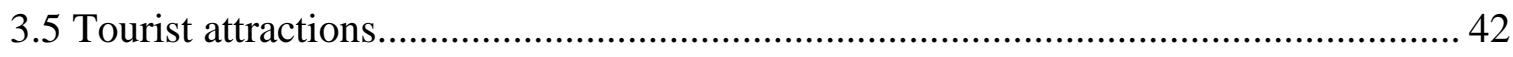

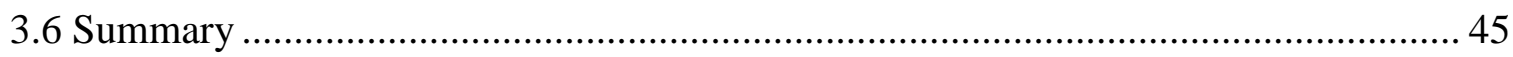

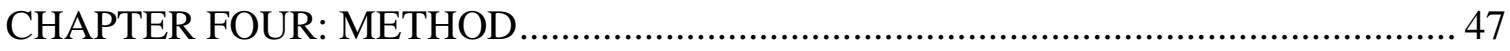

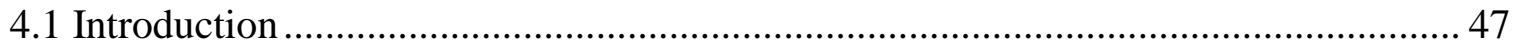

4.2 The northern tourist circuit of Tanzania................................................................ 48

4.2.1 The nature of safari package tours in the northern tourist circuit of Tanzania .... 51

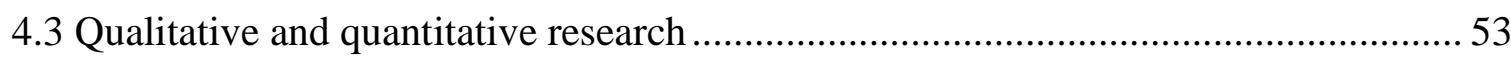

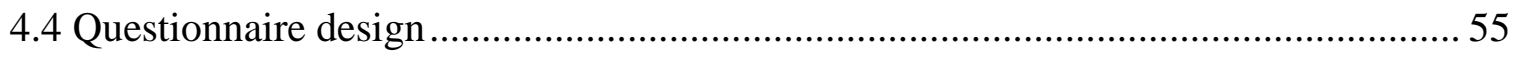

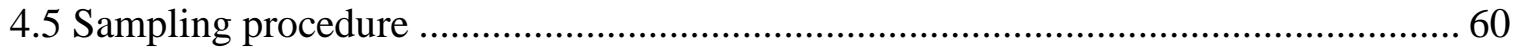

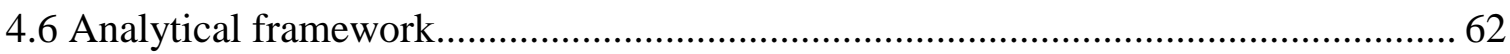

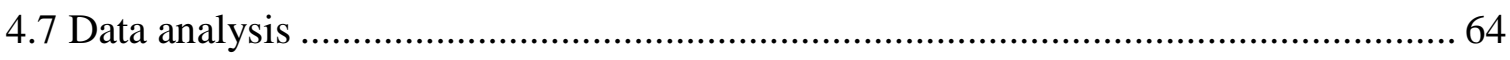

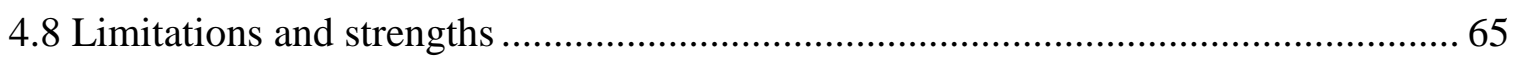

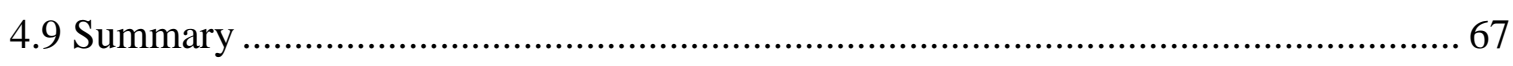

CHAPTER FIVE: THE IMPORTANCE AND PERFORMANCE OF DIFFERENT COMPONENTS OF GUIDED PACKAGE TOURS ................................................ 69

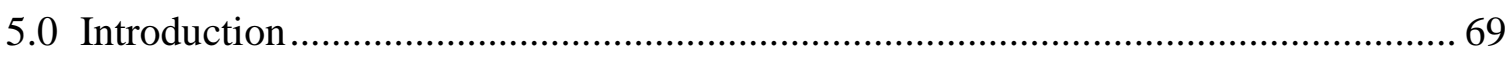

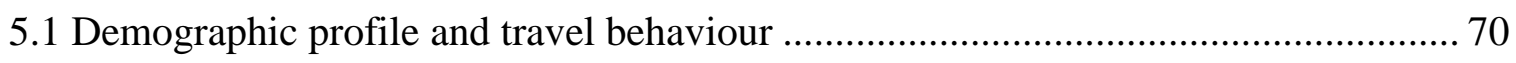

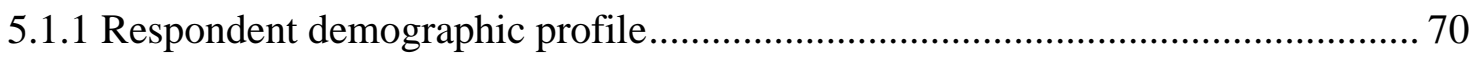

5.1.3 The duration of stay and purpose of visiting Tanzania ....................................... 72

5.2 The nature of guided package tours in the northern tourist circuit ........................... 73

5.2.1 Visitors' previous experience with guided package tours in Tanzania ................ 73

5.2.2 The length of guided package tours in the northern tourist circuit of Tanzania... 73

5.2.3 Overall visitor satisfaction with guided package tours...................................... 74

5.2.4 Visitor satisfaction with the availability of the Big Five ................................... 76

5.2.5: The most satisfying aspect of the guided package tour experience .................... 77

5.3 The importance of different components of a guided package tour........................... 79

5.4 The performance of different components of the guided package tour ..................... 83

5.5 Importance and performance of different components of the guided package tour ... 87

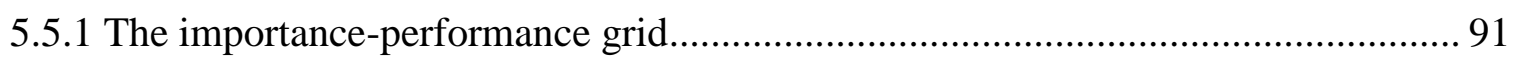

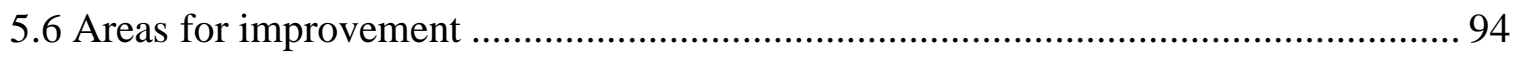

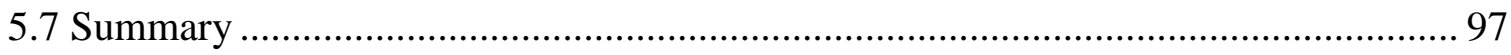


CHAPTER SIX: THE IMPORTANCE AND PERFORMANCE OF DIFFERENT ATTRIBUTES OF THE TOUR GUIDE ............................................................ 98

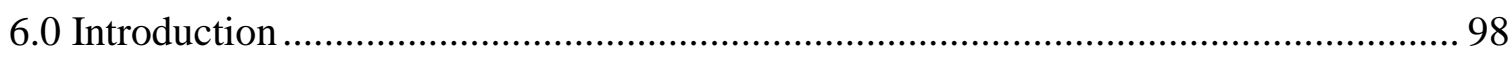

6.1 Visitor satisfaction with tour guides and overall satisfaction with the guided package

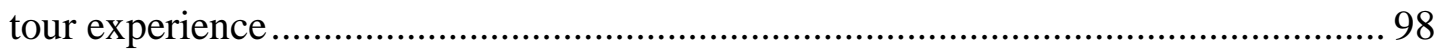

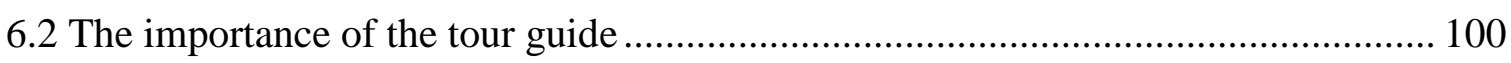

6.3 Visitor satisfaction with the performance of the tour guide.................................... 102

6.4 The importance and performance of the tour guide ............................................. 104

6.4.1 The importance-performance grid for the tour guide .................................... 107

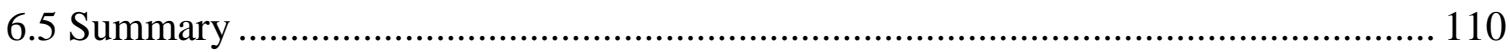

CHAPTER SEVEN: DISCUSSION, IMPLICATIONS AND CONCLUSION ............. 112

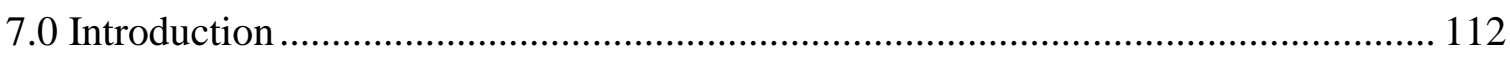

7.1 The relative importance of different components of guided package tours in terms of

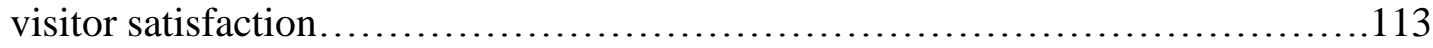

7.2 Visitor satisfaction with different components of guided package tours in the northern tourist circuit of Tanzania................................................. 115

7.3 The relationship between the importance and performance of different components of guided package tours in the context of visitor satisfaction with a guided package tour experience

7.4 The relationship between visitor satisfaction with the tour guide and overall visitor satisfaction with the guided package tour experience

7.4.1 The role of the tour guide in the guided package tour experience 123

7.5 The management implications of visitor satisfaction with the guided package tour in the northern tourist circuit of Tanzania

7.5.1 Management implications for the tour operators......................................... 127

7.5.2 Management implications for tour guides ................................................... 129

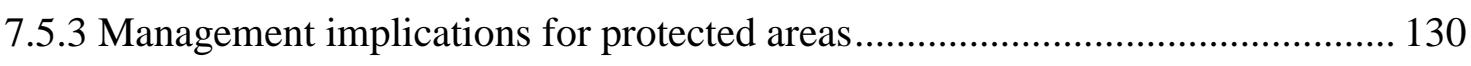

7.5.4 Management implications for food providers .............................................. 130

7.5.5 Management implications for accommodation providers ................................ 131

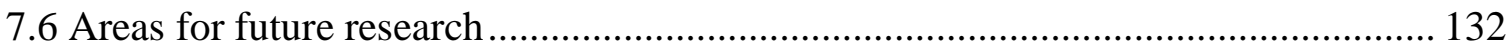

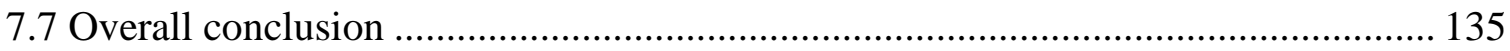

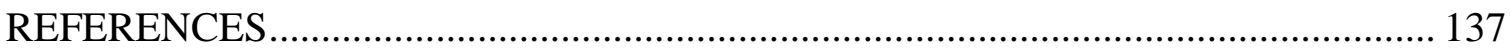

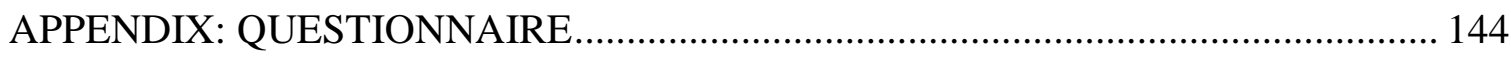




\section{LIST OF FIGURES}

Figure 2.1: Sources of stress for tourists.

Figure 2.2: Factors affecting visitor satisfaction with tourism products and services........................................................13

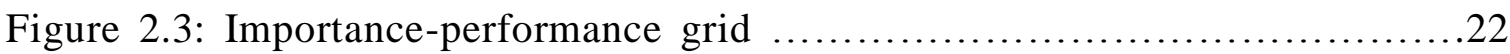

Figure 2.4: Components of a guided package tour...........................27

Figure 2.5: Visitor satisfaction with package tours: Conceptualizing importance and

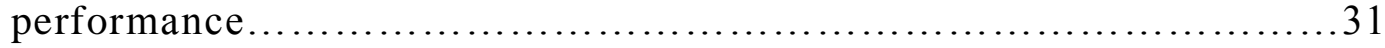

Figure 3.1: A map of The United Republic of Tanzania......................... 35

Figure 3.2: Tourists on a guided package tour in the Ngorongoro Crater............42

Figure 3.3: Empakaai Crater, a small crater located in the Ngorongoro Conservation Area ........................................................... 43

Figure 3.4: A sand beach in Zanzibar Island.................................44

Figure 4.1: Map of protected areas in Tanzania. The dotted line shows the protected areas (National Parks and Ngorongoro Conservation Area) that form the northern tourist circuit.

Figure 4.2: A sketch map showing routes used by international visitors in the northern tourist circuit of Tanzania...................................5 52

Figure 4.3: The importance-performance analysis: The analytical framework for measuring visitor satisfaction with guided package tours in the northern tourist circuit of Tanzania ...........................................63

Figure 5.1: Scatter plot for the mean importance-performance scores for different service attributes of the guided package tour......................... 91

Figure 5.2: Importance-performance grid for different service attributes of the guided package tour.

Figure 6.1: Scatter plot for the mean importance-performance scores for different attributes of the tour guide. 107

Figure 6.2: Importance-performance grid for different attributes of the tour guide. 108 


\section{LIST OF TABLES}

Table 3.1: International visitor arrivals and receipts in Tanzania.............................38

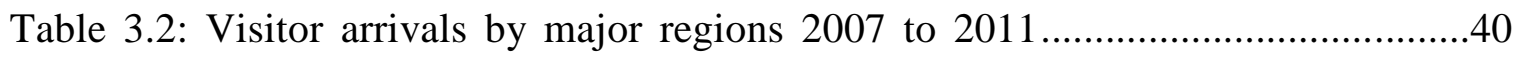

Table 4.1: List of protected areas in the northern tourist circuit of Tanzania.............50

Table 4.2: Attributes used to assess the importance and performance of different components of guided package tours........................................................57

Table 4.3: Attributes of tour guides used to assess the importance and performance

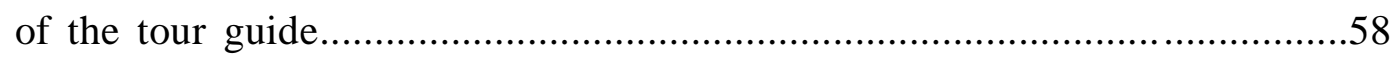

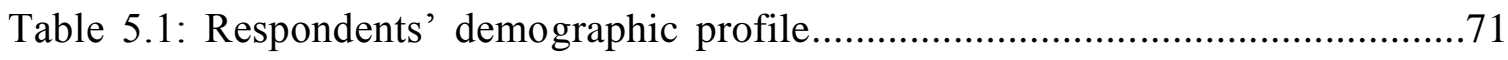

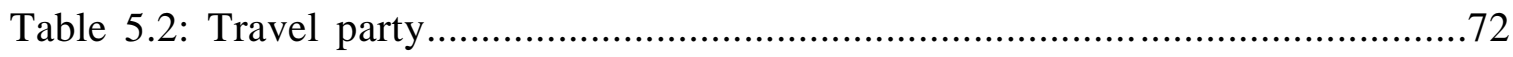

Table 5:3: Purpose of visit and duration of stay in Tanzania...................................73

Table 5.4: The length of the guided package tours in the northern tourist circuit of

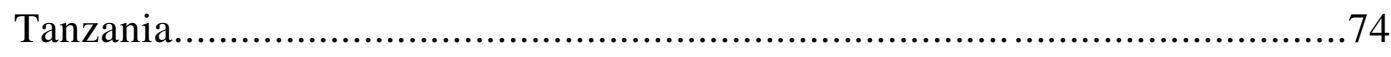

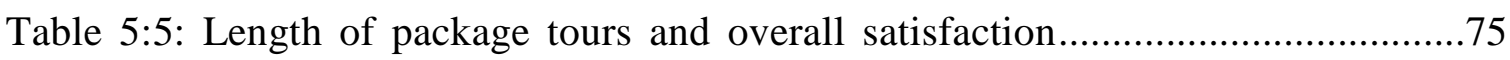

Table 5.6: Satisfaction with guided package tours: First-time and repeat tour takers.

Table 5.7: Visitor satisfaction with the availability of the Big Five. .77

Table 5.8: The most satisfying aspect of the guided package tour .78

Table 5.9: The importance of different components of the guided package tour.......80

Table 5.10: The importance of different service attributes of the guided package tour

Table 5.11: Visitor satisfaction with the performance of different service attributes of the guided package tour.

Table 5.12: Visitor satisfaction with the performance of different service attributes of the guided package tour.

Table 5.13: Paired $t$-test for the importance and performance of different components of the guided package tour.

Table 5.14: Paired $t$-test for the mean importance and mean performance of different service attributes of the guided package tour..... 
Table 5.15 Areas to be improved.

Table 6.1: Correlations between visitor satisfaction with different components of the guided package tour and overall satisfaction with the tour experience........99

Table 6.2: The importance of different attributes of the tour guide.........................101

Table 6.3: Visitor satisfaction with the performance of different attributes of tour

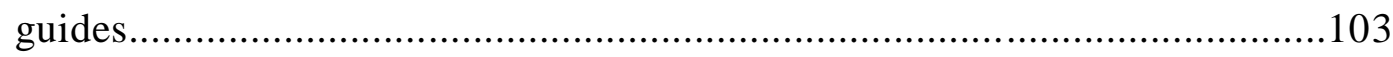

Table 6.4: Paired $t$-tests for the importance and performance of different attributes of

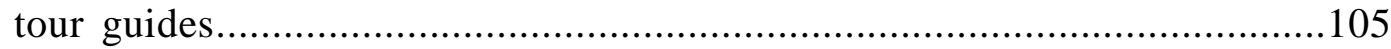




\section{LIST OF ABBREVIATIONS}

$\mathrm{BOT}=$ Bank of Tanzania

GDP $=$ Gross Domestic Product

ICT = Information and Communication Technology

IPA = Importance-Performance Analysis

MNRT $=$ Ministry of Natural Resources and Tourism

NBS $=$ National Bureau of Statistics

TANAPA $=$ Tanzania National Parks Authority

TTB $=$ Tanzania Tourist Board

TTCR $=$ Travel $\&$ Tourism Competitive Report

UNESCO = United Nations Educational, and Scientific Cultural Organization

UNWTO = United Nations World Tourism Organization

URT = United Republic of Tanzania

$\mathrm{WEF}=$ World Economic Forum

WFTGA $=$ World Federation of Tourist Guide Associations

WHC $=$ World Heritage Convention

ZCT $=$ Zanzibar Commission for Tourism 


\section{CHAPTER ONE: INTRODUCTION}

\subsection{Background}

Package tours are a type of tour where all important services are organised or provided by a tour operating company. Bowie and Chang (2005, p. 304) define package tours as "a complex service product which is synthetic and involves the assembly of a multitude of components". In the guided package tour setting, tour operators determine the physical elements of the tour such as the accommodation, food, airline to be used, the itinerary and the ground transportation (Bowie \& Chang, 2005; Geva \& Goldman, 1991; McMullan \& O’Neill, 2010; Xu \& Chan, 2010). Also, visitors in the guided package tour are accompanied by a tour guide who leads the tour, interacts with visitors and links visitors with different service providers (Geva \& Goldman, 1991; Huang, Hsu \& Chang, 2010; Wang, Hsieh \& Huan, 2000). One of the main objectives of package tour companies is to offer a satisfying guided package tour experience. Visitor satisfaction with guided package tours is shaped by a range of services offered during the tour. Bowie and Chang $(2005$, p. 317) in a study of visitor satisfaction with a guided package tour that had a mix of international tourists found that

customers' satisfaction is composed of hard tangible elements and soft intangible service. It is the combination of, on one hand, the service performance of the tour leader and the tour operator and, on the other, the customers' anticipation and perceptions of the vacation, their expectations prior to the tour, their attitudes and behaviour (past travel experience) and their perceptions of equity and unforeseeable events during service encounters.

However, visitors will not always experience satisfaction with services offered by a package tour company because of factors beyond the company's control (Bowie \& Chang, 2005). These factors include problems with foreign language, performance of service staff, difficulty over money, weather at the destination, illness during the tour and relationships with other guided package visitors (Swarbrooke \& Horner, 1999). Also, it is a challenge to maintain high satisfaction with the guided package tour experience because visitors access services from different sectors during the tour. 
Visitor satisfaction is a crucial aspect for the tourism industry as it is likely that high levels of visitor satisfaction lead to increased repeat visitation among the current tourists and word-of-mouth recommendations which consequently reduce marketing costs (Yüksel \& Yüksel, 2001). Likewise, Swarbrooke and Horner (1999, p. 238) added that satisfying customers in tourism is vital because "dealing with complaints is expensive, time-consuming and bad for the organization's reputation". The review conducted by Pizam and Ellis (1999) shows that much visitor satisfaction research is conducted in industrialized countries and very little is undertaken in Africa, the Middle East, South America and a large portion of Asia.

Most of the current studies of visitor satisfaction with guided package tours are conducted in Asia (Chang, 2006; Chang \& Chiu, 2008; Chen, Hwang \& Lee, 2006; Huang, Hsu \& Chang, 2010; Wang, Hsieh \& Huan, 2000; Wang et al., 2007; Wang et al., 2012; Xu \& Chan, 2010). Many researchers have focused on the role of the tour leader (Bowie \& Chang, 2005; Chang, 2006) and tour guides (Geva \& Goldman, 1991; Holloway, 1981; Huang, Hsu \& Chang, 2010; Wong, 2001) as well as coach tours mainly in cities; one study (Chen, Hwang \& Lee, 2006) has examined guided package tours in national parks.

Furthermore, visitor satisfaction is a crucial aspect in the tourism industry based on the nature of tourism products. Bowen and Clarke (2002, p. 302) argue that "tourism is a high-involvement, high-risk product to its customers, tourism is a product partly constituted by the dreams and fantasies of customers; and tourism is an extended experience with no predictable critical evaluation point". For example, buying holidays involves "no tangible investment, a purchase that is not spontaneous, considerable expenditure in relation to earned income and expenditure that involves saving and planning" (Pizam \& Mansfeld, 1999, p.18). As a result of the nature of tourism products, understanding visitor satisfaction has become a pivotal concern for many tour operators while the measuring of visitor satisfaction has been a great challenge to many researchers because tourists are sensitive customers who can easily be disappointed. Pizam and Ellis (1999) added that visitors' needs, the objective of travelling, expectations together with their previous experience have a significant impact on their level of satisfaction. Also, the heterogeneity of tourism products and tourists themselves are likely to affect their satisfaction. 


\subsection{Tourism industry in Tanzania}

Tourism is a fast growing industry in Tanzania that accounts for $17 \%$ of Gross Domestic Product (GDP) and 25\% of the total export earnings (BOT, 2011; Runyoro \& Kideghesho, 2010). It is among the leading sectors in generating foreign currency, export earnings and employment (Kweka, 2004). The contribution of the tourism industry to the Tanzanian economy has steadily grown over the past decades. Earnings from the tourism industry have risen from US\$13.39 million in 1970 to US\$1,353.29 million in 2011 (MNRT, 2011). The tourism industry plays a significant role in poverty alleviation in Tanzania. This is in spite of its vulnerability to environmental, economic, social and political factors (Runyoro \& Kideghesho, 2010). The tourism industry in Tanzania is wildlife based and mostly concentrated in the northern tourist circuit (MNRT, 2002; Okello \& Yerian, 2009). International tourism is more developed than domestic tourism (Runyoro \& Kideghesho, 2010). International visitor arrivals have grown from 8,949 in 1960 to 867,994 in 2011 (MNRT, 2011). The majority of international visitors travel to Tanzania for wildlife safaris particularly in the northern tourist circuit. This circuit encompasses Arusha National Park, Lake Manyara National Park, Mount Kilimanjaro National Park, Serengeti National Park, Tarangire National Park and the Ngorongoro Conservation Area. The northern tourist circuit is a popular destination in Africa, especially the plains of the Serengeti as they are well known as a result of

nature documentaries like Serengeti Shall Not Die, Wild Africa, People of the Forest, The Chimps of Gombe, and Hollywood entertainment (The Lion King, Tarzan, Hatari, George of the Jungle) and true-life movies (Out of Africa, Gorillas in the Mist, Born Free) with their perfect romantic and nostalgic vision of unexplored and time-frozen wild Eden (Salazar, 2006, p. 839).

These protected areas have an abundance of wildlife ranging from small to large mammals, natural features (Mount Kilimanjaro, Mount Meru, Ngorongoro Crater) and a key archaeological site of human kind (Olduvai Gorge) that form the backbone of the Tanzanian tourism industry (MNRT, 2002; Nelson, 2012; Okello \& Yerian, 2009; Runyoro \& Kideghesho, 2010). It is in this regard that Tanzania is seeking to promote a tourism industry that will be environmentally sustainable, ecologically friendly, economically feasible and socially acceptable (MNRT, 1999). 
The majority of international visitors who visit the northern tourist circuit travel with guided package tours (Mitchell, Keane \& Laidlaw, 2009; MNRT, 2002; Okello \& Yerian, 2009). There are more than 600 ground tour operators in the northern tourist circuit who organize and sell tour packages either directly to international visitors or indirectly using overseas wholesalers (Mkumbo, 2010). The common guided package tour offered includes attractions, accommodation, ground transport, food, tour guiding services (interpretation of nature, locating wildlife for viewing, informing visitors about wildlife and history as well as managing visitors' interactions with local communities during the tour) and pre-arrival arrangements (Mkumbo, 2010; Okello \& Yerian, 2009). The main objective of tour operators is to be successful businesses by earning a profit, and part of that involves satisfying customers who will either come back in the future or spread positive word of mouth. Visitor satisfaction with guided package tours in the rural African context has received less attention from researchers. Pearce (2005, p. 163) argues that the "literature ignores a fundamental starting point-satisfaction is simply a postexperience attitude, and attitudes are not fixed or tangible parameters".

The majority of studies of visitor satisfaction with guided package tours have been conducted in developed economies, and less is known about package tours in developing countries. Many researchers have studied visitor satisfaction with package tours in the context of coach tours, particularly in cities, and little is known about rural areas where the main attractions are landscapes and wildlife in their natural environment. Also, research on visitor satisfaction in rural wildlife areas has focused on attractions and the implications for conservation (Okello \& Grasty, 2009; Okello \& Yerian, 2009). Visitor satisfaction with guided package tours conducted in rural wildlife areas has seldom been studied. This study is focusing on assessing components of safari guided package tours that determine visitor satisfaction with the tour.

The importance-performance analysis (IPA) has been widely used in tourism and the hospitality industry (Azzopardi \& Nash, 2013; Liu et al., 2010; Lück, 2011; Oh, 2001). This framework measures the importance of different attributes of the tour to visitors, and visitors' perception of the performance of tour providers (Azzopardi \& Nash, 2013). Visitors' judgment of the importance of different attributes of the tour is affected by their expectations (Liu et al., 2010). Performance is influenced by the 
extent to which the attribute is important to visitors. The framework does not only measure different aspects of the tour but also many other things, such as accommodation, transport, and even companies and attributes outside the tourism and hospitality industries. In fact, the very first study of the IPA looked at car dealers. In spite of its ability structure data analysis, presentation of research findings and identification of management implications, there is no researcher who has applied the IPA method to assess visitor satisfaction with safari guided tours. This study uses IPA as the analytical framework to measure satisfaction. In the context of this study, performance refers to satisfaction.

\subsection{Research objectives}

This study focuses on the satisfaction of international visitors with guided package tours in the northern tourist circuit of Tanzania with the following specific objectives:

1. To assess the relative importance of different components of guided package tours in terms of visitor satisfaction.

2. To determine visitor satisfaction with the performance of different components of guided package tours in the northern tourist circuit of Tanzania.

3. To assess the relationship between the importance and performance of different components of guided package tours in the context of visitor satisfaction with a guided package tour experience.

4. To assess the relationship between visitor satisfaction with the tour guide and overall satisfaction with a guided package tour experience.

5. To determine the management implications of visitor satisfaction with guided package tours in the northern tourist circuit of Tanzania.

The results from this study will help to fill the gap in the visitor satisfaction literature in the context of developing countries. It will also provide a broad understanding of guided package tours that include safaris. The study will possibly be useful to package tour operators as it will provide more information on areas that need more 
attention with respect to satisfaction and may provide insight about how to improve or maintain the level of satisfaction.

\subsection{Thesis structure}

This thesis has seven chapters. Chapter one presents the introduction of this thesis; it provides an overview of visitor satisfaction with tourism products and services. It discusses visitor satisfaction with guided package tours and identifies research gaps. This chapter presents the research objectives underlying this study. It highlights the contribution of this study.

Chapter two provides the literature review. This chapter discusses in more detail issues raised in the introductory part of this thesis. This chapter defines visitor satisfaction from different points of views; it discusses visitor satisfaction with tourism products and factors affecting visitor satisfaction with tourism products and services. It elaborates on visitor satisfaction measurement in the tourism industry, and discusses visitor satisfaction in protected areas. This chapter further elaborates on guided package tours, and discusses visitor satisfaction with the guided package tour experience. This chapter also presents the conceptual framework underpinning this study and concludes with the key research gaps.

Chapter three presents the tourism industry in the context of Tanzania The chapter analyses tourism development in Tanzania, it points out the major changes since independence, and it discusses the importance of the tourism industry to the Tanzanian economy. The chapter presents the progress made in the last ten years as well as challenges that the industry is facing. It further elaborates on visitor trends, major markets and attractions.

Chapter four addresses methods of this study. This chapter describes the study site (the northern tourist circuit of Tanzania), and the nature of guided package tours in the northern tourist circuit of Tanzania. This chapter describes the approach used in the study and points out the strengths and weaknesses of various ways of examining visitor satisfaction with guided package tours. It discusses the research design, 
sampling procedure, the analytical framework and data analysis. The strengths and limitations of this study will be presented in this chapter.

Chapter five presents research findings on the importance and performance of different components of guided package tours. This chapter addresses the first three research objectives. It presents respondents' demographic profile and travel behaviour and the nature of the guided package tour in the northern tourist circuit of Tanzania. The chapter goes on to assess the importance and performance of different components of the guided package tour. The chapter further examines the relationship between the importance and performance of different components of the guided package tour using IPA and paired $t$-tests.

Chapter six addresses the fourth research objective of this study. This chapter examines the relationship between visitor satisfaction with tour guides and overall satisfaction with the guided package tour experience by using Pearson's correlation coefficient ( $r$ ). The chapter further assesses the importance and performance of different service attributes of the tour guide by using IPA and paired $t$-rests.

Chapter seven is the discussion and conclusion. This chapter discusses the key research findings from Chapter Five and Six. It presents the management implications of visitor satisfaction with the guided package tour (the fifth research objective), and areas for future research. 


\section{CHAPTER TWO: LITERATURE REVIEW}

\subsection{Introduction}

In a competitive world, one of the most important objectives of service providers is satisfying and retaining current and past customers (Pizam \& Ellis, 1999). Customer satisfaction is a complex phenomenon in the study of consumer behaviour as customers are heterogeneous and they come with different needs and goals. Crompton and Love (cited by Yüksel \& Yüksel, 2001, p.50) contend that "even though there is a consensus that customer satisfaction is central to success in the delivery of tourist and leisure services, satisfaction remains an elusive, indistinct and ambiguous construct". There are many definitions of visitor satisfaction as researchers have studied satisfaction in different sectors such as attractions, accommodation, transportation, restaurants and tour operators by using different methodologies. Visitor satisfaction can be defined as an individual cognitiveaffective state derived from the post-consumption experience (Ross \& Iso-Ahola, 1991). In this context, researchers define visitor satisfaction in the context of the post-consumption experience. In this paradigm visitor satisfaction is studied by comparing visitors' expectations before consumption of tourism products with postconsumption experiences. Also, other researchers refer to visitor satisfaction as both the cognitive and the emotional response derived from the consumption experience (Bowen \& Clarke, 2002; Yüksel \& Yüksel, 2001). According to the World Tourism Organization (WTO) (1985) cited by Pizam and Ellis (1999, p.327) customer satisfaction is referred to as a "psychological concept that involves the feeling of well-being and pleasure that results from obtaining what one hopes for and expects from an appealing product or service". From this perspective, satisfaction is defined in the context of the quality of the product or service offered.

Quality is viewed as an attitude perceived by customers based on the long-term evaluation process while customer satisfaction is more of the immediate response based on the service encounters (Yüksel \& Yüksel, 2001). Quality "is in the eye of the beholder", it is based on his or her expectations, previous experience and the motivation of purchase of a particular product and service (Swarbrooke \& Horner, 
1999, p.237). McMallon and O'Neill (2010, p.30) add that "service quality and satisfaction can be conceptualized as the difference between what a consumer expects to receive and his or her perception of actual delivery". Service quality relies on the visitors' expectations based on word-of-mouth recommendations, motivation of travel, established rating criteria and consumer reports, while customer satisfaction is based on the individual experience of the product or service. As a result of the complexity of visitor satisfaction, researchers have used different methodologies to study visitor satisfaction with tourism products and services which results in different definitions of visitor satisfaction.

The study of visitor satisfaction has gained more attention from researchers and practitioners as a salient factor for tourism development. High levels of visitor satisfaction have the following impacts: increasing the number of repeat visitations, influencing word-of-mouth recommendations and reducing customer complaints which are likely to undermine the organisation's reputation (Okello \& Grasty, 2009; Swarbrooke \& Horner, 1999). Visitor satisfaction studies help service providers to understand visitors' perception of the product or service offered (Arabatzis \& Grigoroudis, 2010). This information is crucial for service providers in assessing their strengths and weaknesses during service delivery. Visitor satisfaction studies provide visitors with an opportunity to give feedback to the service providers on products or services that are important to them and how providers performed during delivery.

The literature review is composed of two main parts. The first part contains the work done on visitor satisfaction in the tourism industry. It identifies factors affecting visitor satisfaction, and highlights different techniques that have been used to measure visitor satisfaction with tourism products and services and discusses the use of IPA. Finally visitor satisfaction in the context of protected areas will be discussed in this sub-section. The second part of the literature review will discuss visitor satisfaction with guided package tours. This part will discuss in general the nature of guided package tours, and highlight safari package tours. Then different components of guided package tours (accommodation, attractions, pre-arrival services, restaurant, tour leaders and tour guides, and transport) will be discussed. The literature review 
will conclude with identifying key gaps in the literature that this study is planning to fill.

\subsection{Visitor satisfaction in the tourism industry}

Studies of visitor satisfaction with tourism products demand special attention because of the nature of tourism products. Bowen and Clarke (2002) provide a useful analysis of the nature of tourism products, stating that they are intangible, inseparable, heterogeneous and perishable in nature. With reference to intangibility, "services are viewed as performances or actions rather than objects" (p.301). Inseparability refers to simultaneous production and consumption, and there are interactions between consumers and suppliers during the production process. With regards to heterogeneity, "service is largely connected with the vagaries of human interaction between and among service contact employees and customers" (p.302). Perishability refers to "services that cannot be saved, stored, resold or returned" (p.302). The nature of tourism products is significantly different to ordinary products because, to a large extent, tourists buy experiences which are largely intangible in nature. In a similar manner, Bowen and Clarke (2002, p.302) add that "tourists may have to force judgment into a shorter timeframe than for other purchases with a similar financial outlay or degree of involvement in decision making". Thus, understanding how visitors are satisfied with tourism products becomes a major concern for tour providers.

When tourists purchase tourism products they expect their experience to be special and memorable. After consumption of tourism products, visitors tend to compare their expectations before consumption of the tourism products with their postconsumption experience to determine their satisfaction (Yüksel \& Yüksel, 2001). Geva and Goldman (1991) concluded that visitor satisfaction with a tour experience is determined by activities that a visitor has actively participated in during his or her tour. Similarly, in the destination context, Arabatzis and Grigoroudis (2010) contend that evaluation of visitor satisfaction with a tourist destination depends on the comparison between the visitors' expectations before arriving at the destination, and the experiences and images they come into contact with during the consumption of 
tourism products. Yüksel and Yüksel (2001) add that visitor satisfaction with their experience from the destination visited is determined by all tourism products they consumed during their vacation, and the sense with which they perceive the level of service in relation to the price paid. However, it can be argued that the price of the tourism products and services plays a big role in accounting for the quality of the service offered, but has less of a contribution to visitor satisfaction. Okello and Yerian (2009) emphasize that visitor satisfaction can be determined by individual's cognition and feelings about the experience undertaken.

Moreover, studies of visitor satisfaction have revealed that repeat visitation to the same destination is associated with high levels of satisfaction (Arabatzis \& Grigoroudis, 2010). Maintaining high levels of visitor satisfaction is likely to create a positive image and attitude toward tourism products and services. This is in spite of the argument raised by Pizam and Ellis (1999) that visitor satisfaction is not a universal phenomenon; it differs significantly as a result of visitors' experiences, motivation for travel, and needs. These factors affect visitor satisfaction with the tour experience despite travel behaviour (free independent traveller or package group traveller).

\subsubsection{Factors affecting visitor satisfaction with tourism products and services}

Visitor satisfaction is affected by a number of factors ranging from service providers to visitors themselves. Swarbrooke and Horner (1999) identify two major factors that affect visitor satisfaction during their holiday. These factors include too much stress and lack of arousal resulting in boredom and dissatisfaction. The stress (Figure 2.1) is likely to be caused by external or interpersonal elements that are beyond providers' control. 


\section{Figure 2.1: Sources of stress for tourists}

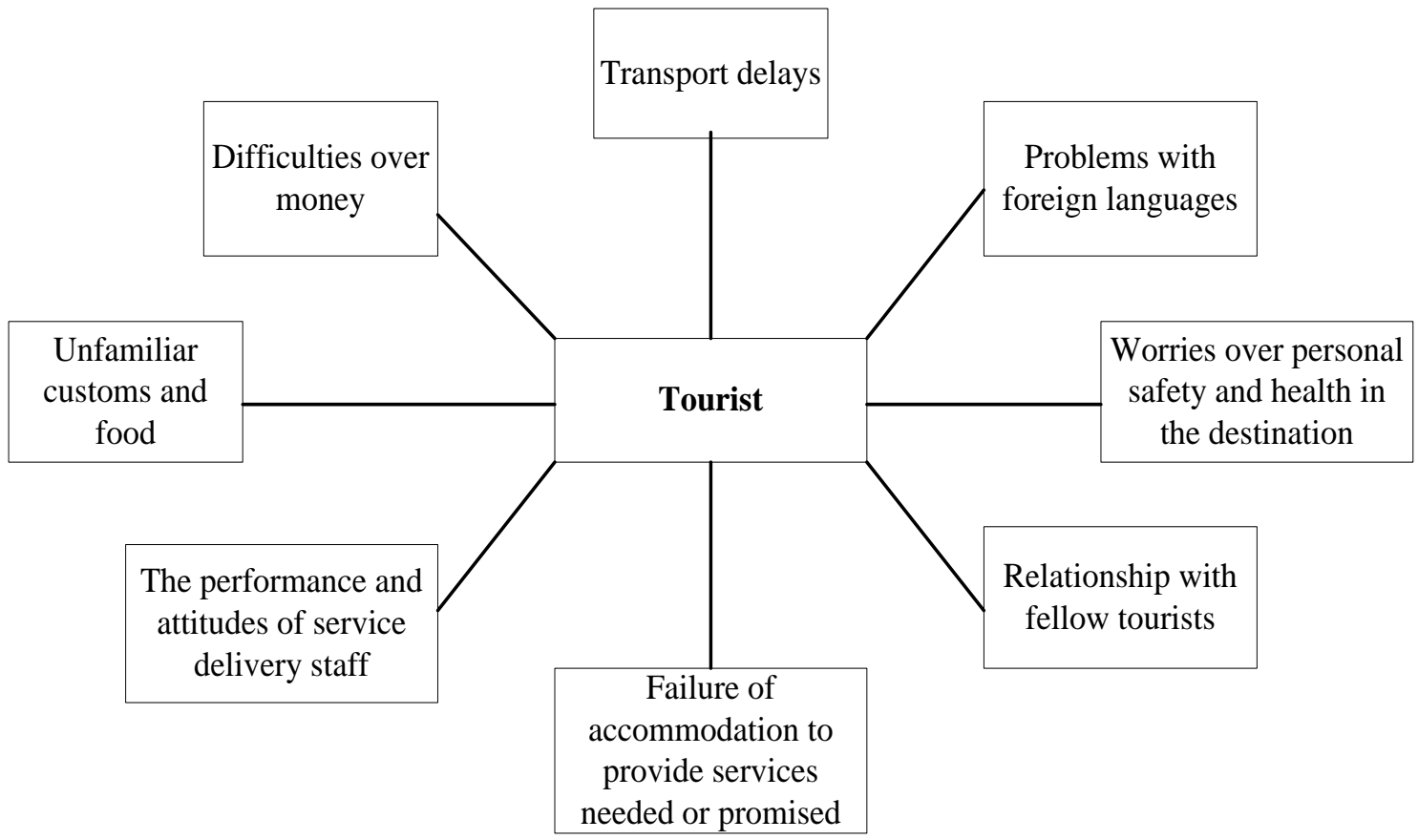

Source: Swarbrooke and Horner (1999, p. 244)

Bowie and Chang (2005) conclude that visitor satisfaction is determined by visitors' expectations, previous experience, visitor behaviour during the tour, the perception of equity, and unforeseeable events (Figure 2.2). Visitors' expectations, previous experience, visitors' behaviour during the tour and the perception of equity are internal factors while unforeseeable events together with sources of stress for tourists are external factors. These factors affect visitors at three different stages of the tour (pre-tour, on tour and post-tour). Visitors' expectations and previous experience affect visitor satisfaction at the pre-tour stage. During the tour, visitors' expectations, previous experience, visitors' behaviour, the perception of equity and unforeseeable events and visitors' stress tend to affect their satisfaction. At the post-tour stage, visitors' experience shapes visitor satisfaction. Also these factors together with tourism product and service characteristics are likely to result in visitor satisfaction, partial satisfaction or visitor dissatisfaction with tour experience (Swarbrooke \& Horner, 1999). The evaluation of visitor satisfaction becomes a complicated and interesting research topic to explore because visitors are heterogeneous in nature and their perceptions and expectations tend to change over time. The following sections 
discuss the five key factors that affect visitor satisfaction: visitors' expectations, the visitors' experience, unforeseeable events, visitors' behaviour, and visitors' perception of equity.

\section{Figure 2.2: Factors affecting visitor satisfaction with tourism products and services}

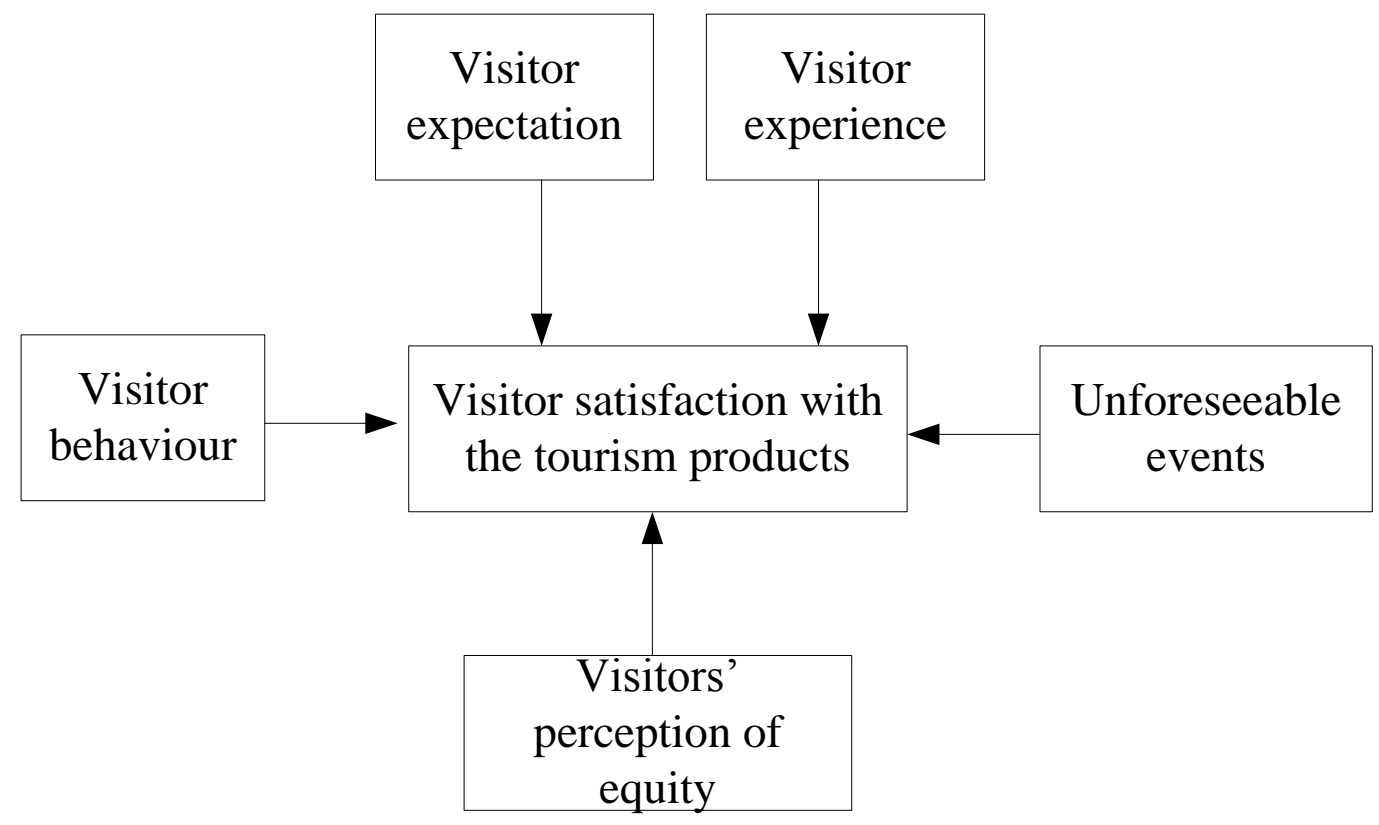

Source: Derived from Bowie and chang (2005), Pizam and Ellis (1999), Swarbrooke and Horner (1999), Yüksel and Yüksel (2001).

\subsubsection{Visitors' expectations}

Visitors' expectations are important in that they help us to understand visitor satisfaction with tourism products and services. Pizam and Ellis (1999, p.328) refer to expectations as "mutable internal standards" developed from numerous factors including goals, objectives, needs and previous experiences with established standards. Expectations help to understand the visitors' motivation for travel or consumption of tourism products and services. Furthermore visitors' expectations can either be normative or predictive expectations: normative expectations refer to visitors' belief of what should happen in the imminent consumption experience while predictive expectations refer to what will happen in the impending 
consumption experience (Yüksel \& Yüksel 2001). Whether normative or predictive, expectations are the pre-consumption attitude a visitor has before purchase and consumption of tourism products (Bowie \& Chang, 2005). Visitors' expectations can easily be studied before the consumption process. In the last two decades, visitors' expectations have increased as a result of technological innovations among the service providers and the improvement of living standards among visitors (Swarbrooke \& Horner, 1999). Technological innovations have simplified the flow of information about tourism products and services which shape visitors' expectations. Likewise, the improvement in standard of living has changed visitors' demand from consumption of tourism products to the consumption of experiences. Furthermore, in the study of tourist satisfaction within protected areas in Tanzania, Okelo and Yerian (2009) concluded that visitors' expectations result from previous travel experience, word-of-mouth recommendations, printed and electronic media, the internet, films, wildlife documentaries and advertisements about tourism products and services.

Studies of visitor satisfaction with tourism products have used expectations in the measurement of satisfaction. Bowen and Clarke (2002) argue that visitor satisfaction can be derived from a comparison between observed service experiences against visitors' expectations. However, Bowie and Chang (2005) contend that visitors' expectations may be biased or superficial as a result of visitors' previous travel experiences and the lack of clear information about tourism products and services which result in an unfair comparison. It is clear that visitor satisfaction with tourism products and services can be affected by visitors' expectations, but the level at which expectations affect satisfaction is not clear. Arabatzis and Grigoroudis (2010) found that visitor satisfaction tend to increase with an increase in meeting expectations, as the more visitors feel that their expectations are reached, the higher the level of satisfaction. Visitors' expectations are likely to change during their consumption of tourism products and services. It is important to understand the attributes of tourism products or services that are important to visitors and how visitors perceive their performance during the tour in order to understand their levels of satisfaction. Pizam and Ellis (1999) stress that visitors' expectations are psychological phenomena that can easily be altered by external factors. Therefore, to rely on visitors' expectations 
as the only measure of visitor satisfaction without comparing them with experiences is likely to provide insufficient information.

It can be argued that understanding product and service performance can only be done after experiencing the product or service in question. It is imperative to understand visitors' expectations as it is a simple way of understanding visitors' travel motivation.

\subsubsection{Visitor experience}

The visitor experience is an important aspect in the tourism industry as most tourism products are in the form of experiences and these experiences become available after consumption of these products. Quan and Wang (2004) refer to visitors' experiences as peak experiences and supporting experiences derived from the consumption of tourism products and services. Peak experiences emanate from the main attractions while supporting experiences are derived from transportation, hotel and restaurants. Studies of visitor satisfaction with tourism products have revealed that previous experiences have an impact on individuals' attitudes and expectations towards the next purchase (Bowie \& Chang, 2005). It can be argued that previous experiences form a benchmark for visitors' expectations of impending consumption experiences. Bowie and Chang (2005) add that visitors with previous travel experience have a greater ability to control their expectations than visitors without such experience. Visitors without travel experience tend to develop high expectations based on the pre-travel information, word-of-mouth recommendations and advertisements which do not always give the true picture of the tourism product or service.

Nevertheless, it is not clear how a visitor judges his/her experience in relation to the consumed tourism products or services. Quan and Wang (2004) claim that visitors' experiences are in sharp contrast to ordinary experiences, because visitors tend to travel with an objective of experiencing something different from their normal life. In most cases the tourism industry is focusing on the provision of memorable experiences to visitors rather than the consumption of goods and services during the holiday. Quan and Wang (2004) stress that in a package tour the overall visitors' experiences might be affected by supporting experiences even if the visitor had 
positive peak experience of the main attractions. Thus evaluating visitor satisfaction with package tours by focusing on visitors' experiences with a few components of the package is likely to affect the results. Visitors on the one hand might have unsatisfactory experiences with the restaurant or hotel and on the other hand excellent experiences with the tour guide/tour leader or attraction visited. This phenomenon is likely to be caused by unforeseen events such as a restaurant staff strike which is beyond tour operators' control but affects visitor satisfaction.

\subsubsection{Unforeseeable events}

Unforeseeable events include all unplanned events that are likely to occur during the service encounter. Swarbrooke and Horner (1999) emphasise that unforeseeable events are likely to cause visitors dissatisfaction with the tour experience but tour operators have no control over these events. In the study of international guided package tours, Bowie and Chang (2005) found that delayed flights, bad weather, shortage of staff in hotels, loss of luggage, illness, non-punctuality among the tour members, tour members' attitudes and language constraints are some of the unforeseeable events that are likely to affect visitor satisfaction with guided package tours. However, the extent to which visitors adapt to these factors and the way in which tour operators handle the situation has a great influence on visitor satisfaction. Okello, D'Amor and Manka (2008) report that most of the visitors who are visiting protected areas in Kenya come with high expectations of seeing the big cats (lions, leopards and cheetahs) and observing their unique behaviours such as hunting, mating and social interaction. However, unforeseeable events such as weather, migration of animals between national parks and distribution patterns might prevent visitors from observing those animals' behaviour that form part of visitor satisfaction. Pizam and Ellis (1999), Yüksel and Yüksel (2001) and Bowie and Chang (2005) contend that visitor satisfaction cannot be achieved by simply narrowing the gap between expectation and performance but it can be achieved focusing on how visitors are adapting to unpredictable circumstances during their tour. 
Despite being the source of visitors' dissatisfaction, some uncontrollable factors might act as a source of arousal during the tour and influence visitor satisfaction positively. For example the serendipitous moment of watching a leopard hunting during the daytime in Serengeti national park, or a surprise from a tourist celebrating his/her birthday during the holiday. These moments are outside tour operators' control but they have a great influence on visitor satisfaction.

\subsubsection{Visitor behaviour}

Visitor behaviour is an important aspect that determines the way visitors purchase, consume and evaluate different tourism products and services. The way in which other visitors behave during the tour is likely to affect levels of satisfaction amongst tour group members. Ross and Iso-Ahola (1991) support the assumption that behaviour is expected to produce personal satisfaction. Visitor behaviour can be influenced by visitors' culture, travel experience, demographic characteristics and holiday atmosphere (Bowie \& Chang, 2005). Pizam and Ellis (1999, p.335) emphasize that "culture has an impact on perception, problem solving and cognition and often leads to differences in satisfaction levels for a single product between different global customers". Visitors are heterogeneous in nature and managing their behaviour during the tour imposes a challenge to tour operators especially when they travel in the same vehicle for a long time during the tour. Moreover, in the study of seniors' perception of service features of package tours, Wang et al. (2012) concluded that Taiwanese senior visitors demand care and more attention from the tour leader and tour guide during the tour. This phenomenon may irritate other tourists who prefer less attention during the scenic tour.

Moreover, Bowie and Chang (2005) report that in guided package tours visitors tend to change their behaviour by imitation, interaction or the setting. This phenomenon affects their perception of different products and services which consequently affects their level of satisfaction. Also, Swarbrooke and Horner (1999) argue that visitors have different feelings, standards and prejudices which make them judge issues that are perceived to be important to them subjectively. This phenomenon is likely to affect the way in which visitors rank their satisfaction with different products and 
services as their judgment might be biased as a result of the influence of tour group members. For example, in a Taiwanese package tour Wang, Hsieh and Huan (2000) found that Taiwanese travellers were complaining about a tour leader's procedures of collecting tips during the tour to Italy. The complaining behaviour among the tour members about tourism products or services is likely to affect the tour groups' perception about the product or service in question. Understanding the way in which visitors behave and their perceptions of equity in the context of service offered during the tour contributes significantly to maintaining their levels of satisfaction.

\subsubsection{Visitors' perception of equity}

Equity is another concept in the tourism industry that plays an important role in determining visitor satisfaction. Visitors, whether independent or part of package tours, compare what they receive with what they paid for. Bowen and Clarke (2002) refer to equity as a sense of fairness between the input and output of tour providers with their own inputs and outputs. Yüksel and Yüksel (2001) emphasise that during satisfaction formation, visitors tend to compare input/output combinations in terms of fairness. Visitors' perception of fairness during the tour is likely to affect their satisfaction especially when travelling in a group. For example, Chang and Chiu (2008) found that in a guided package tour, visitors tend to tip less when they feel that there is unequal treatment or less attention from tour leader/tour guide during the tour. Furthermore, visitors' travelling as part of a package tour spend more time together and they have a great opportunity to compare what they paid for and what they receive during the tour in terms of fairness.

Visitors' perception of fairness is affected by a number of factors such as visitors' cultural background, travel experience and expectations (Bowie \& Chang, 2005). For example, in a group package tour, Wang, Hsieh and Huan (2000) found that visitors with travel experience were very aware of coach seating arrangements and the need to rotate during the tour in order to have equal opportunities for a better view. This phenomenon is likely to affect visitor satisfaction when members of the tour refuse the idea of seat rotation. Bowie and Chang (2005) revealed that equitable treatment of visitors during the tour is likely to contribute to their level of satisfaction. 
Managing group dynamics especially in a guided package tour is a challenge to tour leaders and tour guides as visitors prefer to receive fair treatment during the tour, unfair treatment is likely to cause visitor dissatisfaction.

\subsubsection{Measurement of visitor satisfaction in the tourism industry}

Visitor satisfaction is a complicated attribute to measure in the study of tourist behaviour. Different frameworks have been used to measure visitor satisfaction with tourism products. Yüksel and Yüksel (2001) argue that the expectancydisconfirmation model, the SERVQUAL model, congruity evaluation, and IPA are frameworks that have been widely used by researchers to study customer satisfaction in the context of tourism and hospitality. These models have been developed based on cognitive psychology (Pizam \& Ellis, 1999). For example, Okello, D’Amour and Manka (2008) used the expectancy disconfirmation model while Arabatzis and Grigoroudis (2010), Geva and Goldman (1991), Kao et al. (2008), Liu et al. (2010) used IPA developed by Martilla and James (1977). Lück (2011) used IPA to study visitor satisfaction with backpacker accommodation in Fiji. Furthermore Chen, Hwang and Lee (2006), Lee et al. (2007), Wang et al. (2012) use the SERVQUAL model in the study of visitor satisfaction with guided package tours.

\subsubsection{Different ways to measure satisfaction}

In the expectancy-disconfirmation model, visitors purchase tourism products with pre-purchase expectations about the anticipated performance (Yüksel \& Yüksel, 2001). Once the product is purchased and consumed, visitors tend to compare their post consumption experience with pre-purchase expectations; disconfirmation/dissatisfaction occurs when the performance of the product is less than expectation and confirmation/satisfaction occurs when the performance exceeds the product expectation (McMullan \& O’Neill, 2010; Pizam \& Ellis, 1999). However, Yüksel and Yüksel (2001, p.70) argue that it is not always the case that visitors will be satisfied when product performance exceeds expectations; "some visitors may be satisfied with the service experience, even when the performance 
falls short of their predictive expectation but above the minimum tolerable level". Also the expectancy-disconfirmation model cannot accommodate the dynamic nature of expectations "as visitors' initial expectations of a product or service might be substantially different from their expectations, if measured after a service experience, which involve several encounters, as in the case of many hospitality and tourism services"(Yüksel \& Yüksel, 2001, p.70). For example, in a guided package tour, visitors encounter different services offered by different providers which become hard for visitors to compare pre-purchase expectations with post-consumption experiences. Pizam and Ellis (1999) contend that the expectancy-disconfirmation model can only work efficiently on the established standards.

The SERVQUAL model (an acronym for service quality) is another technique that has been widely used in measuring service quality and visitor satisfaction. The main assumption of this model is that service quality is determined by customer satisfaction, which is a function of consumers' previous experience and cognition (Chen, Hwang \& Lee, 2006). In the same way, service quality is a gap between the perception of the service providers and visitors' expectations (Pizam \& Ellis, 1999). The SERVQUAL model uses the five dimensions of service quality (tangibility, reliability, responsiveness, assurance and empathy) in measuring visitor satisfaction (Swarbrooke \& Horner, 1999). Chen, Hwang and Lee (2006) argue that the SERVQUAL model is an ideal evaluation technique which encompasses visitors' knowledge, sociological and psychological parameters together with managers' cognition. In this model, visitors have an opportunity to evaluate product and service performance at the same time. However, Wang et al. (2007) argue that this model is effective in some sectors-for example banks, restaurants, hotels, travel agents and other sectors that involve short term service encounters rather than long term encounters like guided package tour.

Congruity evaluation is another method used to measure visitor satisfaction in the tourism industry. The congruity evaluation model uses visitors' expectations as a reference point in determining visitor satisfaction (Sirgy et al., 1995). The expectations can be based on what a visitor hopes is realistic or ideal, what one deserves, morally acceptable and significant to other visitors. Nevertheless, this method relies more on visitors' expectations without taking into account other factors like unforeseeable events that can affect visitors' expectation and satisfaction. 


\subsubsection{Importance-performance analysis}

IPA was developed by Martilla and James (1977) with the objective of helping management to understand the practical implications of research findings. IPA has been widely used by researchers in hospitality and tourism research (Lück, 2011; Oh, 2001). Wade and Eagles (2003) applied the IPA method to examine the importance and performance of tours and accommodation in two national parks in Tanzania. Wade and Eagles (2003, p.209) recommend that IPA is a basic technique to use in protected area tourism as it acts as a "baseline diagnostic tool to provide insight into the relationship between satisfaction dynamics and the importance that specific visitor groups assess to various aspects of the service offering". Arabatzis and Grigoroudis (2010) add that in protected areas, IPA has been used to evaluate facilities such as accommodation, campsites and visitor information centres. However IPA has not been used to specifically study visitor satisfaction with safari guided package tours in protected areas.

The framework presents results in four quadrants (Figure 2.3). Concentrate Here (includes the attributes that customers think are extremely important to their purchase decision making but their performance is fair), Keep Up The Good Work (excellent performance of all extremely important attributes), Low Priority (this includes all attributes that customers perceive have less importance in their decision making and the company has fair performance) and Possible overkill (excellent performance of the company on attributes perceived to have less importance to customers). Martilla and James (1977, p.79) contend that the "presentation of results on the importance performance grid facilitates management interpretation of the data and increases their usefulness in making strategic marketing decisions". The IPA guides resource allocations as it highlights the strengths and weaknesses of the company in service provision. 


\section{Figure 2.3: Importance-performance grid}

\begin{tabular}{l|l} 
A: Concentrate Here & B: Keep Up The Good Work \\
Fair & Exportant \\
\hline Performance & Performance \\
C: Low Priority & D: Possible Overkill \\
Slightly & \\
Important
\end{tabular}

Source: Martilla and James (1977)

Liu et al. (2010, p.860) comment that the main assumption in IPA is that "consumer's levels of satisfaction in the attributes examined are based on the consumers' expectations and evaluation on the performance of products or service". Kao et al. (2008) argue that tourists might change their expectation during a tour and some might confuse their importance and performance attributes when both surveys are conducted simultaneously. On the contrary Arabatzis and Grigoroudis (2010) conclude that visitor satisfaction is an unstable measure of consumer behaviour that changes over time. The significance of IPA is centred on determining the relative levels of importance and performance of products and services (Martilla and James, 1977). Therefore, IPA is the ideal approach to use in the study of visitor satisfaction with guided package tours as it helps to identify the relative importance and performance of different components of the package tour as perceived by visitors. 
This technique provides an overview on areas of strength, improvement and areas that receive too much attention from management (Lück, 2011).

\subsubsection{Visitor satisfaction in protected area tourism}

Wildlife tourism is an area of "overlap between nature based tourism, ecotourism, consumptive use of wildlife, rural tourism, and human relations with animals" (Reynolds \& Braithwaite, 2001, p.32). Wildlife tourism is a major tourism attraction that is attracting many international visitors to Tanzania. Tanzania has devoted $30 \%$ of its land for protection of wildlife (Kideghesho \& Runyoro, 2010). Many international visitors visit protected areas with the objective of observing wildlife in its natural habitat and to see undisturbed landscapes (Okello, D’Amour \& Manka 2008). Despite wildlife and undisturbed landscapes, visitors who are visiting these protected areas are interested in indigenous culture (Okello \& Yerian, 2009). The satisfaction of international visitors who are visiting protected areas relies on how their expectations are fulfilled. Reynolds and Braithwaite (2001, p.33) contend that visitor satisfaction with wildlife tourism is determined by tangible factors which "include service and contextual factors such as comfort and design of facilities, the number of people involved and the weather. The intangible quality modifiers include the duration of the event, the exhilaration felt and the authenticity of the experience". It is a combination of the controllable and non-controllable factors by the park or protected areas management.

Studies of visitor satisfaction in protected areas have focused on the importance of tourist attraction to visitors' experience (Okello, D'Amour \& Manka, 2008; Okello \& Grasty, 2009 Okello \& Yerian, 2009) attractions and accommodation (Arabatzis $\&$ Grigoroudis, 2010) and the role of park management (Fletcher \& Fletcher, 2003). Wade and Eagles (2003) found that studies of visitor satisfaction in protected areas have focused on performance-only measurement and less emphasis has been put on the importance of different products and services to visitors. Arabatzis and Grigoroudis (2010) argue that satisfaction of visitors visiting protected areas can be measured indirectly through the stimulus they receive from the protected area visited and their experience during the service encounter. Similarly, Okello and Yerian 
(2009) contend that emotional connections with the destination (attractions, facilities and services) during the tour determine the level of visitor satisfaction. Visitors' experiences and their level of satisfaction in the protected area are likely to be affected by their previous experience from visiting similarly protected areas as a reference point for comparison, their prior knowledge and their ability to learn, articulate and link these experiences together (Arabatzis \& Grigoroudis, 2010).

Visitor satisfaction with wildlife has a high likelihood of contributing to sustainable tourism and conservation of wildlife. Eagle (2001, p.13) argues that "park visitation and nature based tourism are critical components for fostering support for parks and conservation of the biological and cultural heritage contained within them". Therefore, understanding visitor satisfaction with guided package tours in protected areas would help park managers to prepare strategies that would enable guided package visitors to contribute to different conservation activities during the tour.

\subsection{Guided package tours}

A package tour is a special tourism product composed of many components that are organised and offered together by a tour operator (Bowie \& Chang, 2005; Xu \& Chan, 2010). The components of a package tour include pre-arrival services, accommodation, restaurants, transport, attractions, and the tour guide/tour leader (Wang, Hsieh \& Huan, 2000; Xu \& Chan, 2010). In guided package tours, visitors are accompanied by a tour leader or tour guide during their tour contrary to independent travel whereby a visitor travels by him/herself (Wang, Hsieh \& Huan, 2000). Package tour services vary significantly based on visitors' preferences and the objectives of travel. Cohen (1985) reports that the main goal for all guided package tour operators is to offer tour packages that meet tourists' expectations. Similarly, Xu and Chan (2010) add that the majority of visitors opt for a guided package tour setting with expectations of having a wonderful tourism experience. The guided package tour is increasingly becoming an important market segment. Wang et al. (2012) report that guided package tours are a popular model of travel for Asians.

Enoch (1996, p.601) argues that the guided package tour is a "rational and effective" way of organizing a holiday as it provides an opportunity to visit many attractions in 
a short timeframe. A guided package tour is "less expensive" way of travelling as costs of transportation are shared among the members of a tour unlike independent travel. In guided package tours, visitors purchase a "predesigned itinerary" which cannot be altered by any member of the tour. Also, a guided package tour is "not flexible" because after it has been purchased visitors have to receive what they paid for and tour operators have to deliver what they agreed to. There are lots of benefits of travelling under guided package tours as even when something goes wrong there is someone to be held accountable.

\subsubsection{Safari package tours}

Safari tourism is the major tourism product in the northern tourist circuit of Tanzania. There are two types of safaris in Tanzania; photographic safaris and hunting safaris, both conducted in the natural environment. Hunting safaris are practiced in game reserves, game controlled areas, open areas, forest reserves, wetlands and areas outside protected areas (MNRT, 2007). This type of safari involves consumptive use of wildlife. Photographic safaris are conducted in National Parks and the Ngorongoro Conservation Area (MNRT, 2007). It is a major form of tourism in the northern tourist circuit of Tanzania. The majority of international visitors taking a safari tour in the northern tourist circuit of Tanzania travel on a guided package tour (Mitchell, Keane \& Laidlaw, 2009; Okello \& Yerian, 2009).

A typical guided package tour includes accommodation, attractions, hotels, prearrival services, tour guiding and park fees (Mkumbo, 2010; Okello \& Yerian, 2009). The cost of the guided package tour differs depending on the attractions to be visited, duration and level of services. Studies about satisfaction with safari package tours have assessed international visitor satisfaction with attractions as a component of the guided package tour (Okello \& Grasty, 2009; Okello \& Yerian, 2009). Visitor satisfaction with different components of the safari package tour and how visitor satisfaction with different components contributes to overall satisfaction with the tour experience have not been studied. 


\subsubsection{Visitor satisfaction with guided package tours}

An important focus of package tour companies is to gain more profit, and satisfying customers with the service offered. Visitors will not always experience satisfaction with services offered by a package tour company because of factors beyond the company's control (Figure 2.1). Bowie and Chang (2005, p.317), as already noted earlier in this thesis, argue that

visitor satisfaction is composed of hard tangible and soft intangible service. It is a combination of, on one hand the customers' anticipation and perception of the vacation, their expectation prior to the tour, their attitudes and behaviour (past travel experience) and their perceptions of equity and unforeseeable events during service encounters.

Likewise, Geva and Goldman (1991, p.178) emphasise that tour companies determine the more tangible elements of the tour, "the airline used, hotels and meals, the itinerary, the local transportation and similar services". The study of tourism distribution channels in the northern tourist circuit by Mkumbo (2010) observed that booking of flights, accommodation, transport to the attractions are made available by tour operating companies and it is the role of these companies to make sure that visitors finish their holiday satisfied.

Evaluation of visitor satisfaction with guided package tours is a complex process because of the composition of guided package tours. A guided package tour is composed of both physical service features of the tour operator and intangible services provided by personnel such as tour leaders or tour guides (Huang, Hsu and Chan, 2010). Also, in guided package tours, visitors interact with different sectors, for example transport, accommodation, restaurants and attractions (Figure 2.4). This phenomenon creates a challenge in determining visitor satisfaction with guided package tours as it is hard for visitors to remember the performance of every component and compare it with their expectations. Bowen and Clarke (2005) add that it is hard to maintain the same levels of visitor satisfaction in an environment that involves many service encounters. In spite of the complexity of determining visitor satisfaction with guided package tours, Wang et al. (2007) report that the success of guided package tour operators can be influenced by their ability to collect information about visitor satisfaction and the use of this information to improve 
service delivery. But visitor satisfaction with the guided package tour is affected by visitors' previous experiences, expectations, and visitors' behaviour during the tours, and unforeseeable events (Bowen \& Clarke, 2005).

\section{Figure 2.4: Components of a guided package tour}

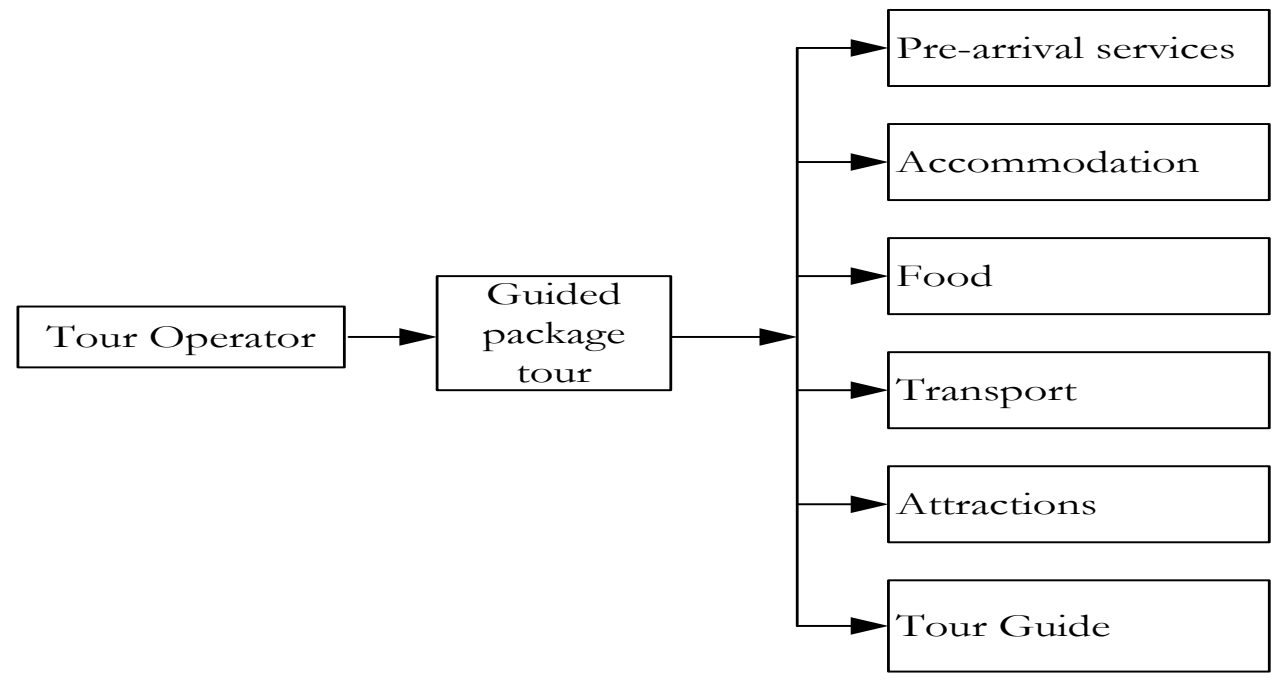

Source: Wang, Hsieh and Huan (2000), Bowie and Chang (2005)

Studies of visitor satisfaction with guided package tours have explored the content of guided package tours (Enoch, 1996; Wang et al., 2012; Xu \& Chan, 2010) visitor satisfaction measurement (Geva \& Goldman, 1991), the role of tour leaders (Bowie \& Chang, 2005; Chang, 2006) and tour guides (Huang, Hsu \& Chan, 2010; Wang, Hsieh \& Huan, 2000) in package tours. Furthermore, the majority of researchers have focused on the role of tour leader/tour guide during the tour. However, less attention have been paid to visitor satisfaction with different components of guided package tours and how satisfaction with the components of the package tour affects overall visitor satisfaction with a tour experience. Likewise, the guided package tour literature shows that the majority of researchers have studied visitor satisfaction with guided package tours in Asia, Europe and the USA. Similarly the review conducted by Pizam and Ellis (1999) reveals that customer satisfaction studies have been conducted in developed countries and little is known about visitor satisfaction in less developed countries. It can be argued that the visitor satisfaction literature has not 
adequately addressed the increasing complexities and uncertainties of package tours composed of a mixture of international visitors with different expectations and experiences in the context of wildlife based tourism. Similarly, the current literature has addressed the impact of the tour guide or tour leader in shaping visitors' experience with a guided package tour.

\subsubsection{Tour guides}

The study of the tour guide as a component of the guided package tours has received significant attention from researchers. The majority of them have studied the performance of tour guides and their influence in the context of visitor satisfaction with package tour experiences. A tour guide is "a person who guides visitors in the language of their choice and interprets the cultural and natural heritage of an area which person normally possesses an area-specific qualification usually issued and/or recognised by the appropriate authority" (WFTGA, 2003). Likewise, Pond (1993, p.2) defines a tour guide as a person "who leads the way through an environment in which his followers lack orientation or through a socially defined territory to which they have no access". Tour guides play a big role in the tourism industry as they enhance the destination image and ensure safe passage for visitors. The importance of the tour guide can been seen directly from the brochure, as most tour operators include the tour guide's professional details or some information about guiding in order to assure visitors that the tour guide is experienced in the industry (Cohen, 1985). The roles of tour guides includes interpretation of tourism attractions, mediator between visitors and local communities (Leclerc \& Martin, 2004; Reisinger \& Steiner, 2006), customer care, entertainment, a source of information and knowledge, a pathfinder and ambassador (Ap \& Wong, 2001; Bowie \& Chang, 2005; Cohen, 1985; Holloway, 1981; Pond, 1993; Xu \& Chan, 2010). The role of the tour guide is professional; it relies on knowledge and the ability to transfer this knowledge to visitors. In a package tour, visitors are accompanied by the tour leader and tour guide each with their own role to play. The term tour guide and tour leader are often used interchangeably.

A tour leader is a person who leads a tour; he/she acts as a liaison between the tour company and tourist (Bowie \& Chang, 2005). Holloway (1981, p.380) adds that the 
generic role of tour leader includes "shepherding and marshalling tourists and seeing their needs during the tour". The work of the tour leader is more challenging because it demands not only knowledge but also wisdom because the tour leader switches his/her role during the tour depending on the circumstances (Bowie \& Chang, 2005). For example, a tour leader may take a counseling role when members of a tour quarrel. They play a significant role in controlling visitors' expectations of impending consumption experiences during the tour.

Studies of tour guiding have concentrated on the importance of tour guides in enhancing authentic tourism experiences (Ap \& Wong, 2001; Huang, Hsu \& Chan, 2010; Leclerc \& Martin, 2004; MacDonnell, 2001; Pond, 1993; Reisinger \& Steiner, 2006). The evaluation of the importance of tour guides in a tour has been based on their professional skills, customer care attitude and their ability to communicate (Wong, 2001). The way in which the tour guide communicates with visitors, interprets the natural and cultural resources, manages interactions between local communities and tourists contributes significantly to visitor satisfaction with a tour experience. For example, in wildlife tourism, Reynolds and Braithwaite (2001) contend that tour guides' knowledge about wildlife contributes significantly to visitor satisfaction with the tour experience in the park. Likewise, tour guides' knowledge about local culture is very important as it helps the tour guide to perform their role as cultural broker (Huang, Hsu \& Chan, 2010; McDonnell, 2001; Reisinger $\&$ Steiner, 2006). Tour guide work ethic is a salient feature of the tour guide that determines visitor satisfaction with tour guides. In the study of the nature of local tour guides in Hong Kong, Ap and Wong (2001) found that poor attitudes toward work, cheating and forcing tourists to do shopping in order to get commissions are unethical acts of tour guides. The unethical practices of tour guides can potentially damage their reputation and the quality of service they are giving to tourists.

Research on visitor satisfaction with tour guide has also focused on the ability of tour guides to transmit information to visitors (McDonnell, 2001; Wong, 2001). Tour guides take care of customers' needs during the tour and create positive visitor attitudes towards the tour guide. However, Geva and Goldman (1991) argue that visitor satisfaction with tour guides' performance has no relation with their satisfaction with tour operators despite the fact that the tour guide is part of the tour 
operating companies. Studies of visitor satisfaction with tour guiding in the guided package tour setting have been overshadowed by the role of tour leader. Researchers have studied the performance of a tour leader and his or her influence on visitor satisfaction with a guided tour (Bowie \& Chang, 2005; Chang, 2006; Geva \& Goldman, 1991). Few studies have been conducted to assess the role of the tour guide in enhancing visitors' experience with guided package tours (Huang, Hsu \& Chan, 2010). This is in spite of the argument presented by Huang, Hsu and Chan (2010) that tour guides are an integral part of the tourism industry that help to enhance visitor experience with a tourism product or destination.

\subsection{Conceptual framework}

The conceptual frameworks play a significant role in showing the relationship between different concepts that are used in the study. A conceptual framework helps to structure the research design, identify different parameters to be measured and determine the scope of the research (Pearce, 2012). The conceptual framework in this study (Figure 2.5) is derived from the literature review and it is in a form of a Venn diagram. It conceptualizes the IPA in the study of visitor satisfaction with guided package tours. This framework shows the relationship between importance and performance, factors affecting visitor satisfaction and different components of the guided package tour. 
Figure 2.5 Visitor satisfaction with package tours: Conceptualizing importance and performance

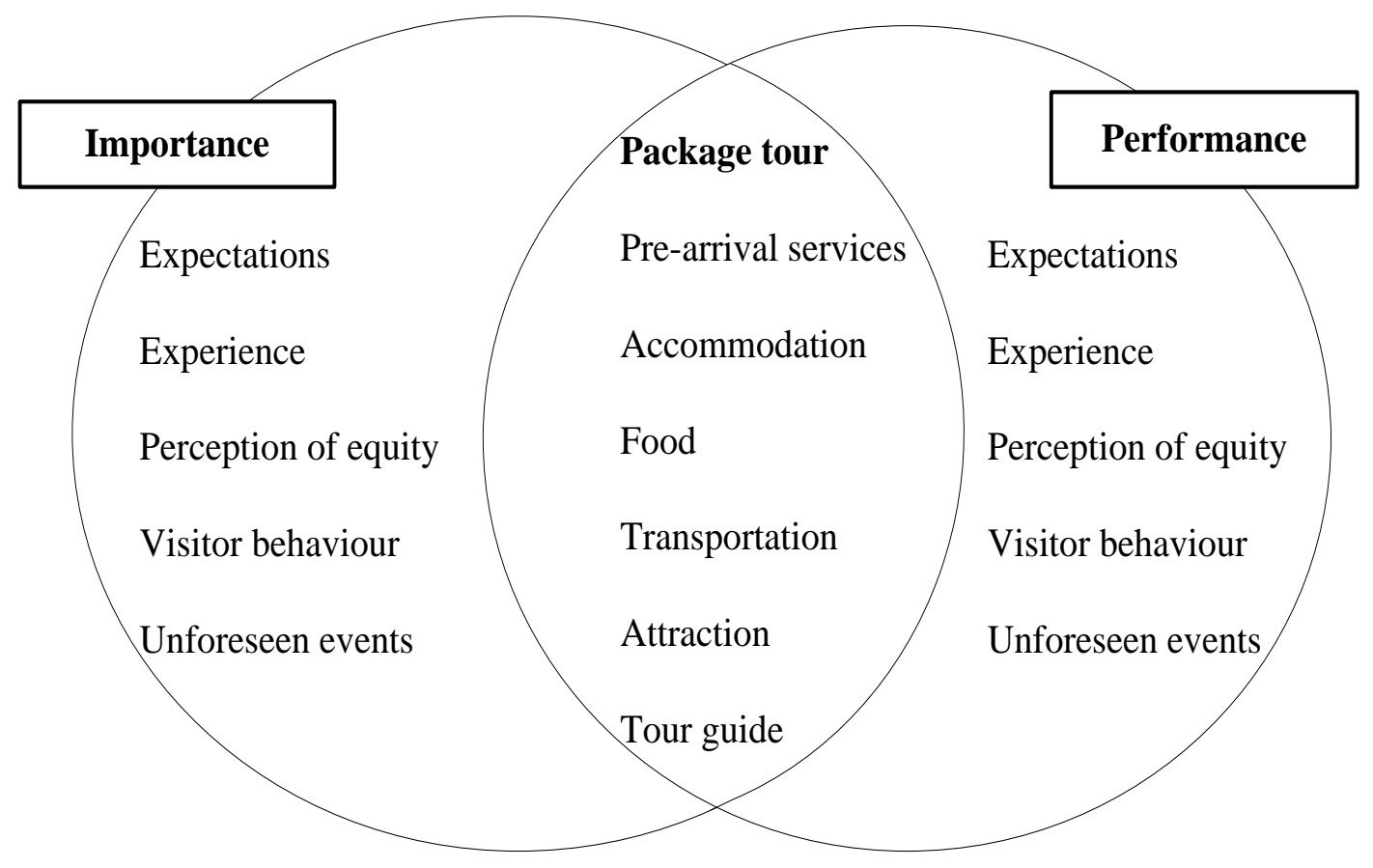

Tour operators offer a guided package tour composed of pre-arrival services, hotels, restaurants, transport, attractions and the tour guide. Visitor satisfaction with different components of the guided package tour is determined by the importance of these components to visitors and visitor perceptions about the performance of tour providers during the tour. The way in which visitors assess the importance and performance of different components of the guided package tour is affected by visitor experiences, visitors' expectations, visitor behaviour, perception equity and unforeseeable events during the tour. Visitor satisfaction is conceptualized as an overlap between the importance and performance of different components of the guided package tours.

Martilla and James (1977, p.77) argue that customer satisfaction "is a function of both expectations related to certain important attributes and judgment of attribute performance". Moreover, the importance of these attributes can be derived from visitors' memory while performance can be determined by visitors' experiences (Liu et al., 2010). Arguably, visitor satisfaction is a positive visitor experience. Oh (2001) 
stresses that visitors' evaluation of attribute performance is likely to be affected by how important the visitor thinks the attribute is to him or her. This conceptual framework work will structure the assessment of the relative importance and the performance of each component of the package tour. It will also help to identify the underlying factors that determine visitors' perceptions of importance and performance of each component of the package tour.

\subsection{Summary}

Visitor satisfaction with tourism products and services is an interesting and complicated phenomenon to study because tourism products and service are intangible, inseparable, heterogeneous and perishable in nature (Bowen \& Clarke, 2002). Also, visitors are heterogeneous in nature; they purchase tourism products with different goals and objectives. Likewise, in the guided package tour, visitors access services from different providers; this phenomenon makes satisfaction measurement a complicated topic to investigate. Similarly, satisfaction as a psychological phenomenon is affected by a number of factors such as visitors' expectations, visitor behaviour, visitor experiences, perception of equity and unforeseen events. These factors affect visitors' perceptions of the importance and evaluation of the performance of different components of the guided package tour.

The literature shows that studies of the visitor satisfaction with guided package tours are conducted in developed economies and less is known about developing ones where the principle attractions are wildlife and nature. The majority of researchers have studied satisfaction in the context of coach tours, in cities, and less is known about safaris in rural areas. Studies of visitor satisfaction with the guided package tour have assessed the role of tour leader/tour guide in enhancing visitor satisfaction with the tour experience. However, visitor satisfaction with other components of the guided package tour has received less attention. Also, the relative contribution of different components of the guided package tour to overall satisfaction with the tour experience in the context of safaris has not yet been investigated.

IPA has been applied by researchers and managers to investigate various problems in the tourism industry. This method acts as a diagnostic tool in the identification of 
areas that are performing well, areas that need improvements, areas of low priority and areas where the organisation is spending more resources but they have less impact on visitors satisfaction (Azzopardi \& Nash, 2013; Liu et al., 2010; Martilla \& James, 1977; Oh, 2001). This technique facilitates the preparation of strategies and distribution of scarce resources to meet organisational objectives. This technique has not yet been applied to assess visitor satisfaction with guided package tours in rural wildlife areas.

The literature has identified various issues about visitor satisfaction with guided package tours. The identified research gapes are contextual, methodological, product oriented and regional. By using the conceptual framework derived from the literature (Figure 2.5) the identified gaps will be addressed. Chapter Three will present the study area where this research was conducted. The methods used to address these research gaps will be discussed in Chapter Four. The research methods to a great extent have been shaped by the conceptual framework underpinning this study. 


\section{CHAPTER THREE: TOURISM IN THE CONTEXT OF TANZANIA}

\subsection{Introduction}

This chapter addresses the tourism industry in Tanzania. This chapter provides the reader with more information about the tourism industry in Tanzania. It has six sections. The first section introduces Tanzania more generally. The second section analyses tourism development in Tanzania; it points out the major changes since independence. The third section discusses the importance of the tourism industry to the Tanzanian economy. This section shows the progress made in the last ten years as well as challenges that the industry is facing. The fourth section analyses visitor trends in the last ten years; it compares the major markets for Tanzanian tourism. The fifth section presents the attractions. The sixth and final section identifies major challenges for the tourism industry in Tanzania.

\subsection{The United Republic of Tanzania}

The United Republic of Tanzania was formed in 1964 as a union between The Republic of Tanganyika and Republic of Zanzibar. Tanzania is located in East Africa between latitude $1^{\circ}$ and $11^{\circ}$ South, and longitude $30^{\circ}$ and $40^{\circ}$ East (URT, 2012). Tanzania covers an area of $945,234 \mathrm{~km}^{2}$ which includes the mainland and the islands of Zanzibar (Unguja and Pemba) (Figure 3.1). Tanzania has a population of 44,929,434 people (NBS, 2013). Tanzania is a member of the East African Community (EAC) that comprises five countries: Burundi, Kenya, Rwanda, Uganda and Tanzania. Tanzania is also a member of other regional blocks and has strong diplomatic links to neighbouring countries. 


\section{Figure 3.1: A map of The United Republic of Tanzania}

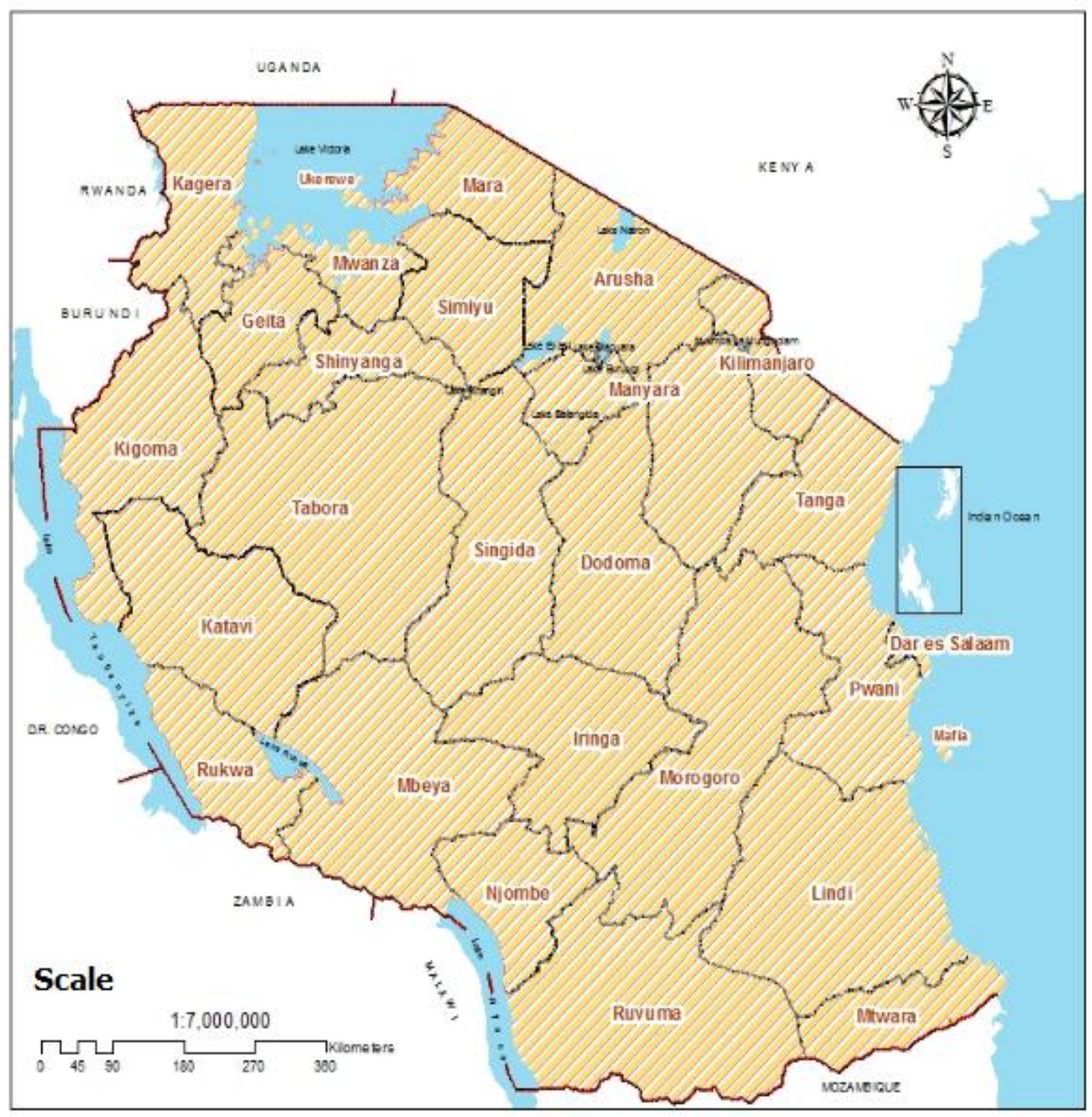

Source: National Bureau of Statistics (2013, used with permission)

Tanzania is focusing on improving production and the livelihood of the people. In its five year plan (2011/2012 to 2015/2016) released in June 2012, Tanzania is aiming to develop five key sectors of its economy. These include infrastructure development (energy, transport infrastructure, water and sanitation, information communication and technology, agriculture (increase of food production and exports), industrial development (investing in manufacturing industries and promoting public-private partnerships), human resource development (in science, technology and innovation) and tourism, trade and financial services (URT, 2012). In terms of contributions to 
GDP, agriculture contributes 27.8\%, industry $24.2 \%$ and services $48 \%$ (Global Finance, 2012). The agriculture sector employs many Tanzanians and it is regarded as the backbone of the economy. The service sector comprises tourism, hospitality, transportation, education, financial services and other small sectors. Tourism has reported faster growth in the last two decades (Nelson, 2012). The industry accounts for $17 \%$ of GDP (Runyoro \& Kideghesho, 2010). The growth of the tourism industry in Tanzania is to some extent influenced by global trends of the tourism industry.

\subsection{Tourism development in Tanzania}

The tourism industry in Tanzania experienced a very slow growth rate just after independence (1961). The focus of the country was on the conservation of wildlife and its habitat in terms of tourism. The effort of Tanzania in conservation of wildlife was realised in the Arusha Manifesto released in 1961 by the president Mwalimu J.K Nyerere:

The survival of our wildlife is a matter of grave concern to all of us in Africa. These wild creatures amid the wild places they inhabit are not only important as a source of wonder and inspiration but are an integral part of our natural resources and of our future livelihood and well being... (MNRT, 2007, p.2)

Tanzania had few investments in the tourism industry in the first three decades after independence, and the majority of these investments were owned by the socialist government (Tanzania Invest, 2011). However, in the 1990s, Tanzania went through economic reformation which changed its economic policy from one of socialist policies to a free market economy (Nelson, 2012). Runyoro and Kideghesho (2010) elaborate that socialist economic policies were restricting foreign investment which made it difficult for local investors who had less capital, experience and expertise to thrive in a competitive world. The liberal economic policies adopted in the 1990s opened doors for foreign investors to invest in various sectors, including tourism (Nelson, 2012). The role of the government remained on preparation and implementation of laws and policies and creating a conducive environment for investment in the tourism industry. 
Tanzania experienced fast growth in the tourism industry after the economic reforms. In 1991, Tanzania enacted a National Tourism Policy with an objective of ensuring sustainable tourism development (MNRT, 2002). The National Tourism Policy gave rise to the formation of the Tanzania Tourist Board (TTB) which was formally known as the Tanzania Tourism Cooperation. The National Tourism Policy was reviewed in 1999 in order to create more opportunities for investment as well as protection of the environment. The main objective for the revised national tourism policy is:

to promote the economy and livelihood of the people, essentially poverty alleviation, through encouraging the development of sustainable and quality tourism that is culturally and socially acceptable, ecologically friendly, environmentally sustainable, and economically viable (MNRT, 1999 , p. 5).

Furthermore, a gradual increase in tourism facilities has continued to attract more visitors from those who visit the country out of curiosity to holiday and leisure visitors. Nelson (2012) argues that the number of visitor arrivals has increased by ten percent per annum during the first decade of economic liberalization. The tourism industry has continued to grow as a result of the friendly business environment created after liberalization. For example, the numbers of rooms in hotels and tented campsites have increased from 8,500 in 1995 to 15,000 rooms in 2010 (MNRT, 2011). Similarly, the number of ground tour operators has increased from 200 in 1999 to more than 500 in 2010 (MNRT, 2011). Also there has been a remarkable improvement in the air service sector after liberalization - for example, availability of direct flights to Tanzania (KLM and British Airways) and a number of international airlines (India Airways, Kenya Airways, Swiss Airways, Emirates Airlines, Gulf Air, Ethiopia Airways, and South African Airways) indirectly flying to Tanzania via regional hubs (Tanzania Invest, 2011).

\subsection{Tourism's economic importance}

The tourism industry has continued to be among the vital sectors in terms of job creation, poverty alleviation, generation of tax revenue for the government, and as a source of foreign currency (MNRT, 2002). The tourism industry provides an 
opportunity for investments from small and medium enterprises to large business. Tourism has strong linkages with other sectors such as agriculture, sports, health, and education. Earnings from the tourism industry have increased by $85 \%$ from US\$730.00 million in 2002 to US\$1,353.29 million in 2011, an annual average growth rate of six percent (Table 3.1). However, tourist receipts have dropped from US\$1,288.76 million (7.2\%) in 2008 to US\$1,159.82 million in 2009 (Table 3.1). The decline in tourism receipts was exacerbated by the global economic crisis (Runyoro \& Kideghesho, 2010). The economic recession, oil crisis, climate change and political unrest have affected the industry (TTCR, 2011). The economic recession has adversely affected the tourism industry as it is largely depending on international visitors mainly from Europe and America (BOT, 2011). In 2010 the tourism industry reported growth of $8.2 \%$ from US\$1,159.82 million in 2009 to US\$1,254.5 million in 2010 (Table 3.1). The increase in tourist receipts in 2010 resulted from the global economic recovery in Europe and North America together with promotion of the Tanzanian tourism industry in Asia and other African countries (BOT, 2011). In spite of the increase in the number of visitors from Asia and Africa, Europe and North America remain the top markets for Tanzanian tourism (Tanzania Review, 2011).

Table 3.1: International visitor arrival and receipts in Tanzania

\begin{tabular}{|l|c|c|c|}
\hline Year & Number of visitors & Annual change (\%) & $\begin{array}{c}\text { Receipts (US\$ } \\
\text { millions) }\end{array}$ \\
\hline 2002 & 575,000 & 9.52 & 730.00 \\
\hline 2003 & 576,000 & 0.17 & 731.00 \\
\hline 2004 & 582,807 & 1.18 & 746.02 \\
\hline 2005 & 612,754 & 4.80 & 823.05 \\
\hline 2006 & 644,124 & 5.12 & 950.00 \\
\hline 2007 & 719,031 & 11.62 & $1,198.76$ \\
\hline 2008 & 770,376 & 7.14 & $1,288.76$ \\
\hline 2009 & 714,367 & -7.27 & $1,159.82$ \\
\hline 2010 & 782,699 & 9.50 & $1,254.50$ \\
\hline 2011 & 867,994 & 10.89 & $1,353.29$ \\
\hline
\end{tabular}

Source: MNRT (2011) 
In 2011 the tourism industry generated about US\$1,353.29 million from international tourist receipts (MNRT, 2011). Earnings generated from international tourism are expected to grow by $26.8 \%$ from US\$1,353.29 million in 2011 to US $\$ 2,459.35$ million in 2021 (Tanzania Review, 2011). With regard to the employment opportunities, the tourism industry produced approximately 377,000 jobs in 2011 (Tanzania Review, 2011). The industry is expected to produce 497,000 jobs by 2021, an increase of 32\% from 2011 (Tanzania Review, 2011). This trend shows the prosperity of the tourism industry in supporting economic growth through the provision of employment and generation of national income.

Despite enormous success in the last two decades, the Travel and Tourism Competitive Report (TTCR) released in 2011 revealed that the business environment and infrastructure development is still a challenge for the development of the tourism industry in Tanzania (WEF, 2011). According to TTCR 2011, Tanzania ranks number 127 out of 139 countries with regard to the business environment and infrastructure development. Some areas that Tanzania is performing poorly include: air transportation infrastructure, ground transport infrastructure (low-quality roads), ICT infrastructure, human capital and unreliable power supply (WEF, 2011). Overall, Tanzania ranked $110^{\text {th }}$ of the 139 countries in the global tourism competitive indices in 2011 which is a 12 point drop from the $98^{\text {th }}$ position in 2009. In Africa, Tanzania ranked $11^{\text {th }}$ of the 39 African countries assessed.

\subsection{Visitor trends}

Tanzania attracts visitors from all around the world. In the last five years, trends of visitor arrivals show that visitors from Africa are accounting for $48 \%$ of all visitors followed by Europeans (32\%) and Americans (ten percent). Visitors from East Asia and the Pacific, the Middle East and South East Asia are accounting for ten percent of all visitors to Tanzania (Table 3.2). Table 3.2 shows a decrease in visitor arrivals from East Asia and the Pacific and South Asia regions in 2011. The decline in visitor arrivals from these regions is explained by the earthquake, tsunami and the nuclear crisis that hit Japan in March 2011 (UNWTO, 2011). Visitor arrival trends show that Europe and America are the leading markets for Tanzanian tourism outside of Africa. The 2010 international visitors' exit survey report shows that the major 
sources of tourists to Tanzania are Italy, the United Kingdom, the United States of America, Germany and Australia. The report further shows that Austria, Zambia and India are emerging markets. Moreover, international tourist arrivals have increased by $51 \%$ from 575,000 in 2002 to 867,994 in 2011 . This is in spite of a seven percent decline in international visitor arrivals in 2009 as a result of the global economic recession (Table 3.1). The increase in international visitor arrivals has been influenced by the improvement of tourist facilities, the increase in the number of airlines flying directly and indirectly to Tanzania, promotion of the Tanzanian tourism industry overseas and a peaceful environment created by a stable democratic government (Nelson, 2012).

Tanzania is aiming to attract 1.5 million tourists by 2015 which is almost double the number of current annual visitor arrivals (Tanzania Invest, 2012). However, the increase in visitor arrivals will be determined by the stabilization of the global economy, peace in the Middle East and North Africa, vigorous advertisement and promotion of Tanzanian tourism, infrastructure development (roads, railway, airports and ICT) and conservation of wildlife.

Table 3.2: Visitor arrivals by major regions 2007 to 2011

\begin{tabular}{|c|c|c|c|c|c|c|c|}
\hline Year & Africa & $\begin{array}{c}\text { America } \\
\mathbf{S}\end{array}$ & $\begin{array}{c}\text { East } \\
\text { Asia } \\
\text { and the } \\
\text { Pacific }\end{array}$ & Europe & $\begin{array}{c}\text { Middle } \\
\text { East }\end{array}$ & $\begin{array}{c}\text { South } \\
\text { Asia }\end{array}$ & Total \\
\hline 2007 & 305,748 & 80,699 & 29,760 & 274,964 & 11,180 & 16,970 & 719,321 \\
\hline 2008 & 373,053 & 87,835 & 32,442 & 245,873 & 10,377 & 20,889 & 770,469 \\
\hline 2009 & 343,283 & 67,896 & 31,155 & 239,292 & 11,121 & 21,620 & 714,367 \\
\hline 2010 & 392,137 & 70,558 & 42,520 & 242,828 & 10,521 & 24,135 & 782,699 \\
\hline 2011 & 450,782 & 92,503 & 39,867 & 248,940 & 15,281 & 20,621 & 867,994 \\
\hline
\end{tabular}

Source: MNRT (2011)

Moreover, domestic tourism is less developed in Tanzania compared to developed countries. Runyoro and Kideghesho (2010) argue that there are few domestic visitors who visit national parks compared to the number of international visitors. This is in 
spite of the argument raised by Philemon (2009) that domestic tourists have increased from 350,000 to 650,000 as a result of a vigorous promotional campaign led by the Ministry of Natural Resources and Tourism together with the Tanzania Tourist Board. The author claims that the promotional campaign was targeting Tanzanians more generally, and specifically those in higher learning institutions to visit local attractions. However, growth in domestic tourism cannot solely be attributed to richness in attractions, but economic development and growth in per capita income. Tanzania is among the poorest countries in the world and many Tanzanians are living in absolute poverty. There are a few Tanzanians who can afford to travel. This phenomenon creates a challenge to the tourism industry which aims at developing domestic tourism in order to decrease overdependence from international tourism.

The majority of international visitors to Tanzania travel with package tours and a few travel as free independent travellers (MNRT, 2012). Many of the international visitors travel with package tours simply because it is a convenient way of organising a holiday (Figure 3.3). The average stay for package visitors is eight nights and ten nights for non-package visitors (MNRT, 2012). About $81.1 \%$ of international visitors visit Tanzania for holiday and leisure, $8.5 \%$ visiting friends and relatives, $4.7 \%$ for business, $1.8 \%$ for conferences (MNRT, 2012). Moreover, many of the international visitors are 25-44 years old (51.3\%) or 45-64 years old (29.3\%). There are a few senior visitors (5.8\%) and young visitors (1.3\%) who visit Tanzania (MNRT, 2012). The 2010 international visitors' survey report shows that about $48.1 \%$ of international visitors to Tanzania travel alone, $31 \%$ travel with their spouses. Visitors who travel with friends and relatives are accounting for $11.1 \%$ while a few international visitors travel with their children. 


\section{Figure 3.2: Tourists on a guided package tour in the Ngorongoro Crater}

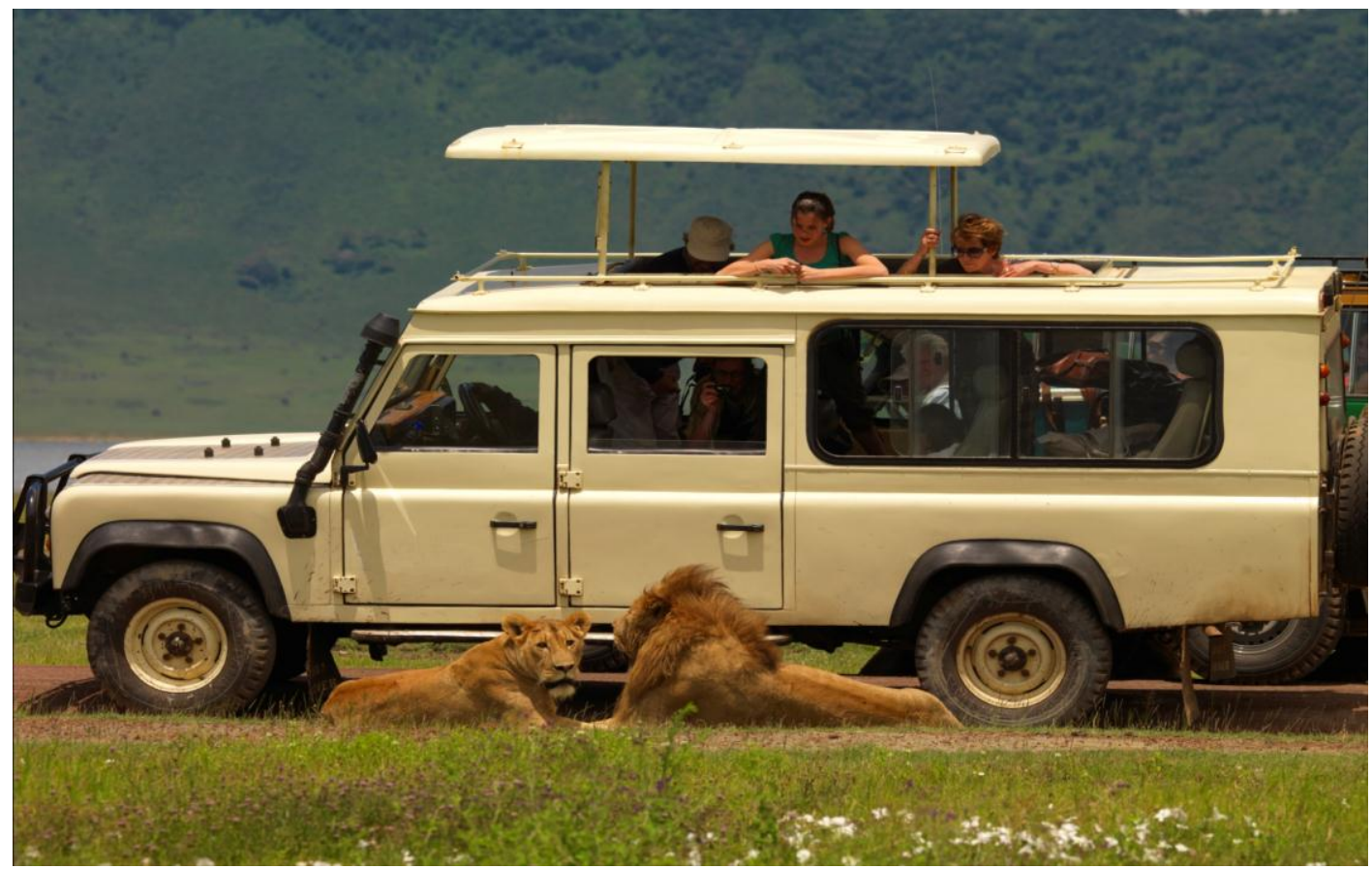

Source: Ngorongoro Conservation Area (2012)

In spite of being the major option for organizing a holiday in the northern tourist circuit of Tanzania, there is no study that has been conducted to assess how visitors are satisfied with services offered in a package tour.

\subsection{Tourist attractions}

Tanzania is one of the more popular tourist destinations in the southern Sahara. Some of the attractions that make Tanzania a popular destination include wildlife in their natural habitat, historical sites, pristine scenery (Figure 3.4), undisturbed beaches, a diverse culture, museums and crafts (MNRT, 2002). The tourism industry in Tanzania is largely wildlife-based, and wildlife forms $60-70 \%$ of all tourism products in Tanzania (Runyoro \& Kideghesho, 2010). Tanzania has devoted $30 \%$ of its land for conservation of wildlife and natural resources (Runyoro \& Kideghesho, 2010). Tanzania has 16 National Parks, 33 Game Reserves, 48 Game Controlled Areas and Ngorongoro Conservation Area (Tanzania Review, 2011). Two Nationals Parks (Kilimanjaro and Serengeti) and Selous Game Reserve are named UNESCO Natural World Heritage Sites (WHC, 2012). Ngorongoro Conservation Area is both named as a UNESCO World Cultural and Natural Site (WHC, 2012). The conserved 
areas are rich in both flora and fauna in the context of the number of known species. There are 132 species of amphibians, 1,056 species of birds, 331 species of fish, 375 species of mammals and 355 species of reptiles (Runyoro \& Kideghesho, 2010). The 2011 Travel and Tourism Competitive Report (TTCR) illustrates that Tanzania holds the second position in the world with regard to natural resource competitiveness.

Figure 3.3: Empakaai Crater, a small crater located in the Ngorongoro Conservation Area

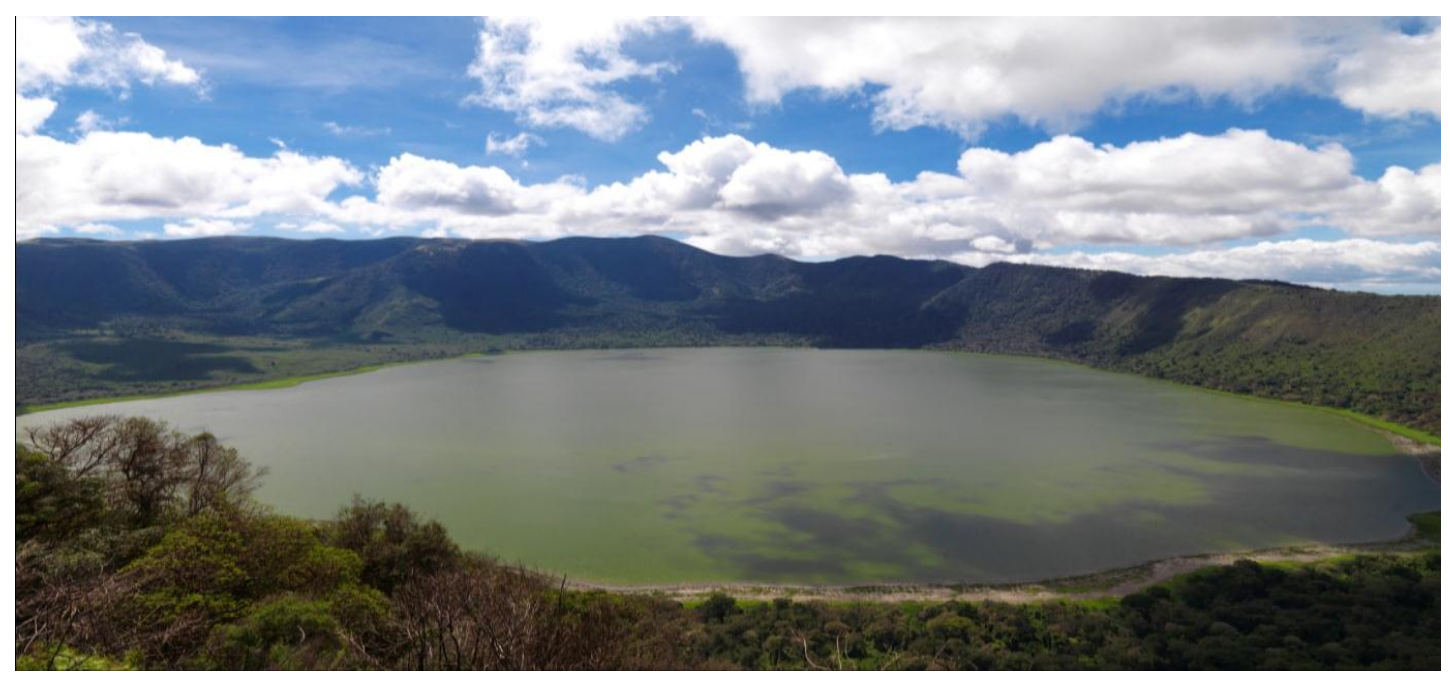

Source: Ngorongoro Conservation Area Authority (2012)

The main motivation for the majority of international visitors to Tanzania is to see wildlife in their natural habitat (MNRT, 2012). The tourism industry in Tanzania is well developed in the northern tourist circuit of Tanzania more so than other areas in the country (Tanzania Invest, 2012). The northern tourist circuit extends from Lake Victoria in the west to Tanga region in the east. This circuit comprises some of the most popular protected areas in Tanzania and in the world. These are Arusha National Park, Lake Manyara National Park, Mount Kilimanjaro National Park, Serengeti National Park, Tarangire National Parks and the Ngorongoro Conservation Area (including Olduvai Gorge, an archaeological site associated with the origins of humankind) (MNRT, 2002). These attractions are the backbone of Tanzania's tourism as they attract more than $80 \%$ of international visitors to Tanzania (Okello \& Yerian, 2009). For example, the Ngorongoro Conservation Area attracts more than $40 \%$ of visitors who visit Tanzania (Charnley, 2005; Okello \& Yerian, 2009). Apart from these well established attractions, the northern tourist circuit has also Mkomazi 
National Park, Usamabara Mountains, Amboni Caves, Pemba Channel and the coast of Tanga (Tanzania Invest, 2012). Similarly, Mount Kilimanjaro (5,895 metres, and the highest mountain in Africa) and Mount Meru attract mountaineering visitors and safari visitors. Mitchelle, Keane and Laidlaw (2009) reported that Mount Kilimanjaro attracts more than 40,000 international visitors every year.

Beaches are another tourism resource in Tanzania that attract many tourists, particularly in the Zanzibar islands and the coast of Tanzania (Figure 3.5). Zanzibar is a popular destination for beach holidays in the Indian Ocean (Tanzania Invest, 2012). The leading markets for beach tourism are Italy and the United Kingdom (MNRT, 2012). The major activities associated with beach tourism include boating, diving, snorkelling and sun-bathing.

\section{Figure 3.4: A sand beach in Zanzibar Island}

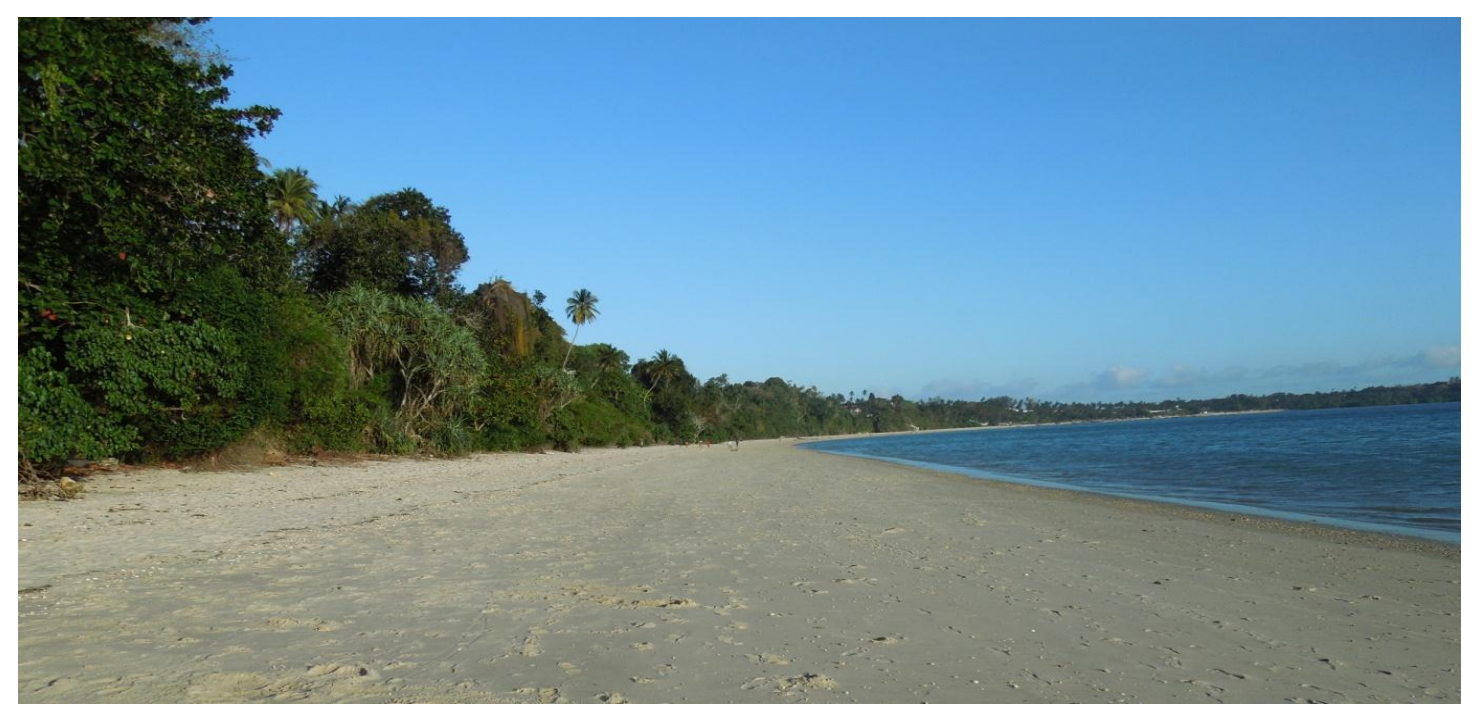

Source: The author (2012)

Moreover, in terms of cultural heritage, Tanzania has three UNESCO World Cultural Heritage Sites: Kondoa Rock-Art sites, Ruins of Kilwa Kisiwani and Ruins of Songo Mnara and Stone Town of Zanzibar (WHC, 2012). Alongside the world heritage sites, Maasai culture, Makonde carvings and friendly Tanzanian people are the country's cultural resources (MNRT, 2002).

As a result of the diversity of attractions, the Tanzania Tourist Board (TTB) and Zanzibar Commission for Tourism (ZCT) have changed the destination brand for 
Tanzania several times. Some of the brands for Tanzania tourism over the past two decades are: "Tanzania, the land of Kilimanjaro and Zanzibar" (1993), "Tanzania, unsurpassed Africa" (1997), "Tanzania, authentic Africa”, (2003), “Tanzania, the land of Kilimanjaro and Zanzibar" (2006), "Tanzania, the land of Kilimanjaro, Zanzibar and Serengeti” (2008) (MNRT, 2012). Nevertheless, "Tanzania: Feel great with friends" is a newly proposed destination brand for Tanzania that integrates the beauty of the country and friendliness of the people (MNRT 2012).

\subsection{Summary}

Tourism is a fast growing industry in Tanzania that contributes significantly to the economy through the creation of employment, generation of foreign currency and poverty alleviation. The global trend of visitor arrivals shows that the industry will continue to grow despite challenges that the industry is facing. This chapter has identified poor infrastructure development (roads, railway and airports), low levels of technological development, unstable electricity supply, lack of skilled human capacity to manage the industry and low quality services at the hotels and restaurants as major barriers to development of the tourism industry in Tanzania.

The industry is well developed in the northern tourist circuit of Tanzania as a result of infrastructure development, marketing and promotion of attractions in this circuit. Also, international tourism is more developed than domestic tourism because the majority of Tanzanians are poor; they do not have disposable income to spend for travelling. Even those who can afford travel still perceive tourism as a luxury for foreigners.

The tourism industry of Tanzania is largely depending on international tourism. The majority of international visitors visit Tanzania to see wildlife in its natural habitat. Guided package tours are the major way of organizing a holiday for most of international visitors. Guided package tours limit interaction between visitors and host communities as in most cases access to visitors is limited by tour operators. The nature of the guided package tour in the northern tourist circuit provides a score for assessing visitor satisfaction using questionnaires rather than interviews. Chapter 
Chapter three: Tourism in the context of Tanzania

Four will present the method of this study and discuss more about questionnaire development, dissemination and analysis of data. 


\section{CHAPTER FOUR: METHOD}

\subsection{Introduction}

Studies of visitor satisfaction with tourism products and services have taken different approaches depending on the objectives of the study, the place, and the nature of the population to be studied. As noted earlier, studies of visitor satisfaction with guided package tours are mostly conducted in the developed world and less is known about developing countries of which the principal attraction is wildlife in their natural environment. Also, studies of visitor satisfaction with guided package tours have assessed the role of the tour guide/tour leader in enhancing visitor satisfaction with the guided package tour experience. This study assesses visitor satisfaction with all components of a guided package tour and determines the relative importance of different components of package tours in terms of visitor satisfaction. It also assesses the relationship between the importance and performance of different components of package tours in the context of visitor satisfaction with a package tour experience. Moreover, this study focuses special attention on the relationship between visitor satisfaction with the tour guide and overall satisfaction with a package tour experience. This study focuses on the demand side, particularly international visitors because international tourism is more developed than domestic tourism in Tanzania (Runyoro \& Kideghesho, 2010).

This chapter presents the method employed in this study. It gives an overview of the northern tourist circuit of Tanzania which is the study site for this research. The chapter highlights the tourist attractions located at the site and the importance of this circuit to the tourism industry in Tanzania. It elaborates on the nature of guided package tours in the northern tourist circuit of Tanzania. The chapter discusses qualitative and quantitative research methods and points out the strengths and drawbacks of each method and states why quantitative research methods are better in the context of this study. Furthermore, the questionnaire design and sampling procedure used to obtain respondents and ways used to disseminate questionnaires during data collection are discussed. The importance-performance analysis (IPA) 
which is the analytical framework that underpins the data analysis is elaborated on in this chapter together with the data analysis process. Also, the strengths and limitations of this study are presented. Understanding visitor satisfaction with guided package tours would provide more information to tour operators and other stakeholders in the tourism industry on what makes a satisfying guided package tour experience in the northern tourist circuit of Tanzania.

\subsection{The northern tourist circuit of Tanzania}

The study was conducted in the northern tourist circuit of Tanzania. As discussed in Chapter Three, this circuit stretches from the Tanga region to Lake Victoria in the west. This circuit has spectacular natural landscapes, diversity of wildlife ranging from snakes and lizards to the Big Five, and archaeological sites which make this area important ecologically, economically and socially. The area contains major national parks and the Ngorongoro Conservation Area which together form the heart of the tourism industry in Tanzania. The parks located in this circuit include Arusha National Park, Lake Manyara National Park, Mkomazi National Park, Mount Kilimanjaro National Park, Serengeti National Park, Tarangire National Parks and the Ngorongoro Conservation Area (including Olduvai Gorge, an archaeological site associated with the origins of humankind and Ngorongoro Crater) Figure 4.1 (MNRT, 2002). Furthermore, the great East African Rift Valley and other volcanic features make the northern tourist circuit unique and an interesting destination to visit. These attractions are the backbone of Tanzania's tourism as they attract more than $80 \%$ of the total number of visitors to Tanzania (Okello \& Yerian, 2009). These attractions attract not only visitors to the northern tourist circuit but also small to large companies which contribute significantly to the national economy. Entry to these National Parks and the Ngorongoro Conservation Area is subject to fees ranging from US\$35 to US\$60. 
Figure 4.1: Map of protected areas in Tanzania. The dotted line shows the protected areas (National Parks and the Ngorongoro Conservation Area) that form the northern tourist circuit.

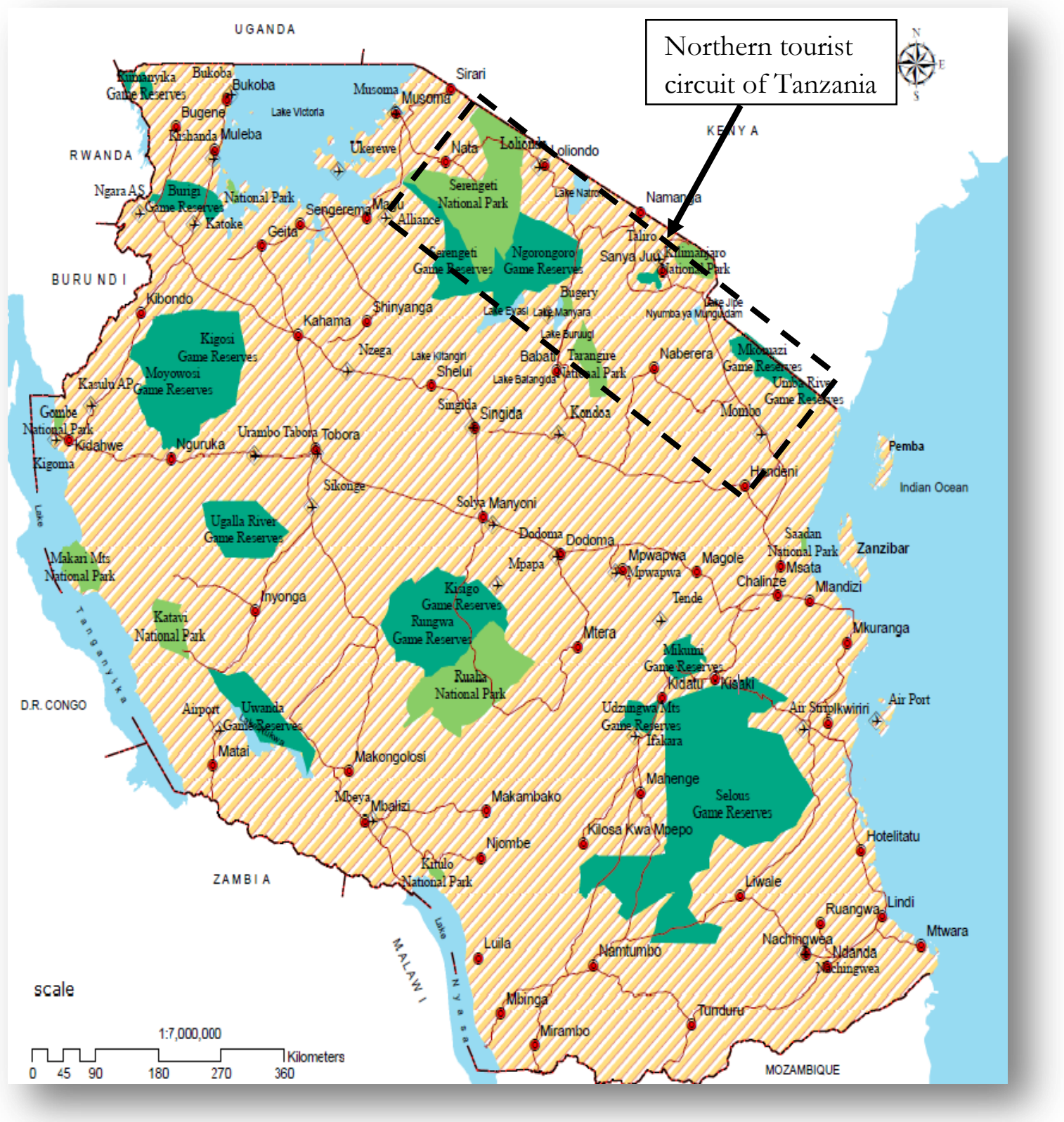

Source: National Bureau of Statistics (2013, used with permission)

Even though these protected areas are located in the same tourist circuit, they differ in terms of species of wildlife, scenery, conservation status, size and year of establishment (Table 4.1). The Ngorongoro Conservation Area differs with National Parks in one major aspect; it is the only protected area in Tanzania that allows a coexistence between semi-nomadic Maasai pastoralists, livestock and wildlife 
(Charnley, 2005). National Parks restrict human activities; they are strictly conserved for the wildlife. National Parks allow recreation activities (game viewing, hiking, canoeing and sport fishing) and management operations (MNRT, 2012).

Table 4.1: List of protected areas in the northern tourist circuit of Tanzania

\begin{tabular}{|l|c|c|c|}
\hline \multicolumn{1}{|c|}{ Name of the protected area } & $\begin{array}{l}\text { Year of } \\
\text { establishment }\end{array}$ & $\begin{array}{c}\text { Size in } \\
\mathbf{k m}^{\mathbf{2}}\end{array}$ & $\begin{array}{c}\text { Visitor Numbers } \\
\text { from 2006-2011 }\end{array}$ \\
\hline Arusha National Park & 1960 & 552 & 334,516 \\
\hline Kilimanjaro National Park & 1972 & 1,668 & 265,276 \\
\hline Lake Manyara National Park & 1960 & 330 & 897,102 \\
\hline Mkomazi National Park & 2006 & 3,542 & 2,895 \\
\hline Ngorongoro Conservation Area & 1957 & 8,292 & $1,218,593$ \\
\hline Serengeti National Park & 1940 & 14,763 & $1,338,193$ \\
\hline Tarangire National Park & 1970 & 2,850 & 548,589 \\
\hline
\end{tabular}

Source: Okello and Yerian (2009); MNRT (2011)

Arusha city (the safari capital of Tanzania) is located in the northern tourist circuit. This city is also the headquarters of the East African Community. Arusha City was established as a German garrison in 1900, it hosts the United Nations International Criminal Tribunal for Rwanda (ICTR) (Salazar, 2006). It is a gate way to the major protected areas in the northern tourist circuit. The northern tourist circuit is a potential tourism destination in Tanzania because it receives a range of visitors from holiday travellers to conference visitors. The majority of international visitors who are visiting this circuit travel with safari package tours (Mitchell, Keane \& Laidlaw, 2009). Conducting research in this tourist circuit provides an opportunity to meet with international guided package visitors from around the world and collect their views about what makes a satisfying guided package tour experience in a rural wildlife area. 


\subsubsection{The nature of safari package tours in the northern tourist circuit of Tanzania}

The northern tourist circuit of Tanzania offers a variety of touristic experiences such as safaris, mountain climbing and cultural tourism. About $70 \%$ of international visitors to the northern tourist circuit travel with package tours (MNRT, 2012). Ground tour operators in the northern tourist circuit organize different tourism products in a package. Such packages are then sold directly to tourists or indirectly to overseas wholesalers who then sell them to tourists (Mkumbo, 2010). There are three main groups of package tourists in this circuit, the first group and the largest one book for safari packages in-particular, game viewing. The second group consists of a combination of safari and mountain climbing adventure package tourists. The third group contains only adventure package tourists in-particular, mountaineering. Most mountaineering visitors book Mt Kilimanjaro and Mt Meru adventure packages.

The main entry points to the northern tourist circuit are Arusha (Namanga border from Nairobi; and Arusha Airport) and Kilimanjaro (through Kilimanjaro International Airport and by road) (MNRT, 2011). About $80 \%$ of visitors to the northern tourist circuit visit the Tarangire, Lake Manyara and Serengeti, and the Ngorongoro conservation area (Ngorongoro Crater and Olduvai Gorge) (MNRT, 2011). Few international visitors visit Mkomazi National Park as their principle safari destination. Arusha and Kilimanjaro National Parks are special for mountaineering visitors. The way in which tour operators organize tour packages reflects the nature of visitors and the type of experience to be achieved. There are many routes that visitors can take depending on their budget, duration of stay and desired levels of experience (Figure 4.2). The common safari packages last for six days and five nights, and features Lake Manyara, Serengeti and Tarangire National Parks and the Ngorongoro Conservation Area (Mitchell, Keane \& Laidlaw, 2009). These package tours cost an average of US $\$ 2,500$ as charged by local tour operators (http://www.ewpnet.com/kprices.htm) 
Figure 4.2: A sketch map showing routes used by international visitors in the northern tourist circuit of Tanzania

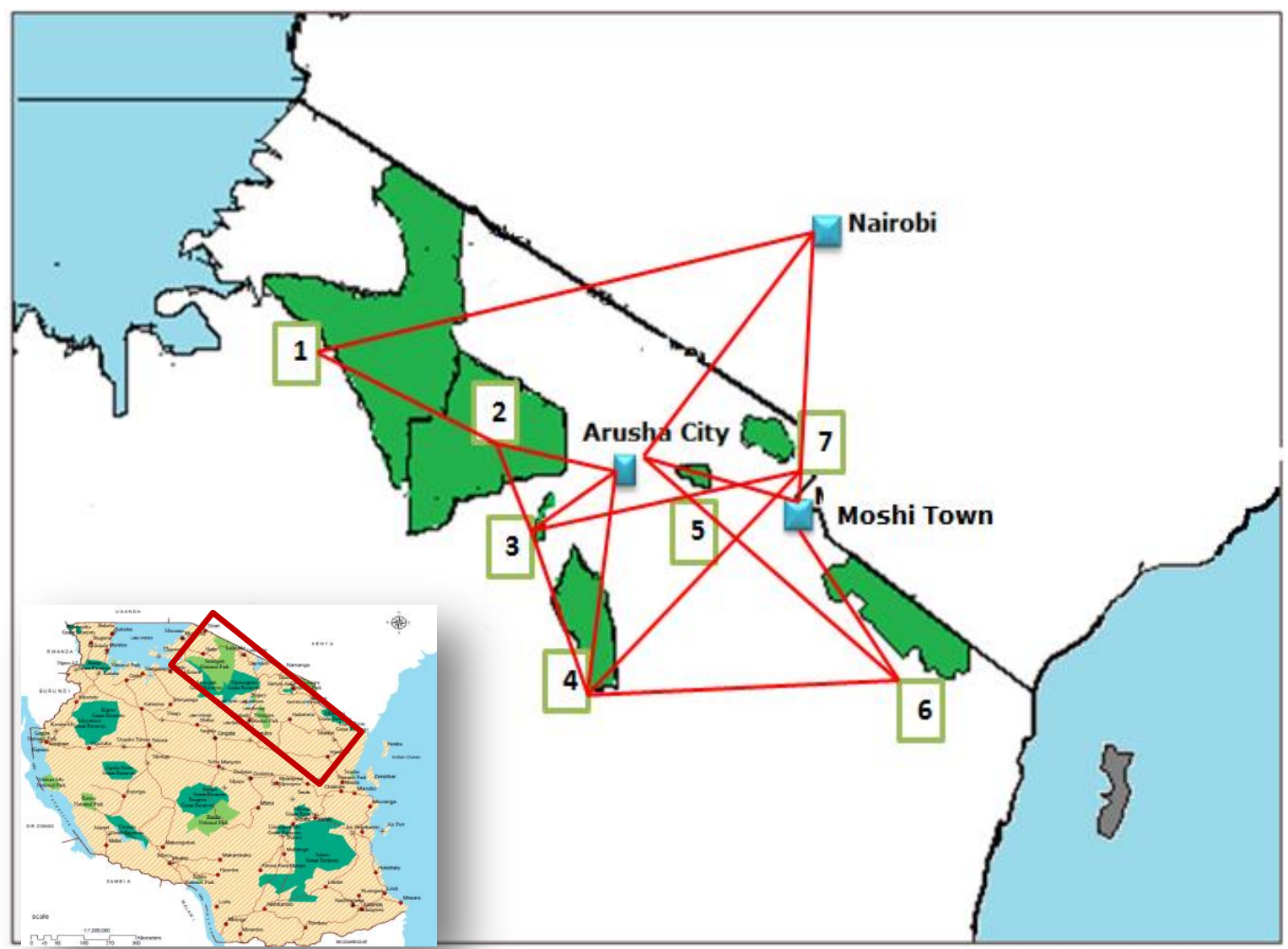

Source of insert map: National Bureau of Statistics (2013, used with permission)

Key: 1=Serengeti National Park; 2= Ngorongoro Conservation Area; 3=Lake Manyara National Park; 4=Tarangire National Park; 5=Arusha National Park; 6=Mkomazi National Park; 7=Mount Kilimanjaro National Park.

Guided package visitors in the northern tourism circuit spend most of their time in the protected areas for game viewing. This phenomenon creates limited chances of meeting with guided package visitors to collect their views about the tour experience. It is with regard to this that this study was conducted using the quantitative method. This method provides opportunity for the researcher to collect data during a very short timeframe. Also, the quantitative method provides a 
structural way of assessing the importance and performance of different components of guided package tours.

\subsection{Qualitative and quantitative research}

Studies of visitor satisfaction with tourism products have been conducted using a quantitative research approach particularly by using questionnaire surveys (Geva \& Goldman, 1991; Huang, Hsu \& Chan, 2010; McMullan \& O’Neill, 2010; Okello \& Grasty, 2009; Okello \& Yerian, 2009; Ross \& Iso-Ahola, 1991; Wang, Hsieh \& Huan, 2000; Wong, 2001; Xu \& Chan, 2010). Bowen and Clarke (2002) commented that the use of questionnaire surveys is economical, less time consuming, and can cover a wide range of situations in a large sample population. Veal (2006) emphasizes that questionnaire surveys provide a transparent set of research procedures used to gather information, analysis and interpretation. Pizam and Ellis (1999, p.326) suggest that customer satisfaction can be assessed by using "subjective or soft measures of quality (customer satisfaction surveys and questionnaires) which focus on the perceptions and attitudes of the customer rather than more concrete objective criteria". Finn, Elliott-White and Walton (2000) recommend that surveys are the most powerful source of information for tourism analysis, planning and decision making. Veal (2006, p.146) adds that questionnaire surveys provide an avenue for the collection and recording of information about "attitudes, meanings and perceptions of a population as a whole" unlike qualitative methods which are more effective on an individual basis. However, Walle (1997) argues that quantitative methods are often incapable of dealing with crucial issues facing the tourism industry in meaningful and pragmatic ways. Also, it is difficult to collect detailed information about the nature of travellers, their emotions and perception of tourism products and services.

Although quantitative research methods seem to be appropriate, Chang (2006, p.100) in a study of customer satisfaction with tour leaders' performance in guided package tours in Taiwan, argues that a qualitative research approach is appropriate for assessing visitor satisfaction as "the comments of respondents, observation and the 
in-depth interview can produce a richness of information on the aspects of service provision or improvement". Interviewees have the opportunity to describe situations (ones they are either satisfied or dissatisfied with) in great detail. However, Finn, Elliott-White and Walton (2000) and Veal (2006) contend that respondents will only provide information that they think is of interest to the interviewer. Also, attitudes and opinions of the interviewer may affect the interviewee's response to some questions during the interview process. Finn, Elliott-White and Walton (2000) add that misrepresentation of interviewers to interviewee, misinterpretation of questions by interviewees, demographic characteristics of interviewers and interviewees may create bias during the interview and affect the data collection process.

Arguably, it remains a challenge to assess visitor satisfaction with guided package tours whether by using qualitative or quantitative research approaches because satisfaction is a psychological phenomenon which can be altered by the external environment. Also, Ritchie, Burns and Palmer (2005, p.37) argue that for a "broadranging, psychologically complex field such as tourism, there is no singular pertinent research modality". Researchers should use research methods that provide a structured way to examine a problem (eg. importance and performance analysis).

In view of the nature of package tours in the northern tourist circuit of Tanzania discussed previously, it is difficult to conduct face to face in-depth interviews with members of package tours because researchers' access to them is limited by the tour operator and in most cases visitors in package tours have a short timeframe for an interview. Also Finn, Elliott-White and Walton (2000) contend that in a package tour setting visitors are travelling in a group, a phenomenon that creates difficulties in obtaining individual responses. Taking into account these logistical challenges associated with qualitative research in the northern tourist circuit, this study uses a quantitative research approach. Also, a quantitative research approach provides a structured way to examine the importance and performance of different components of package tours. A questionnaire is used to collect primary data. It should be noted that questionnaire surveys are a quick and effective way of reaching the required sample. Surveys help to generate information from a representative of the sample population to be studied. Likert scale questions were used in this study. The 
components of guided package tours (pre-arrival services, accommodation, restaurants, transport, attractions, and the tour guide) used by Bowie and Chang (2005) and Wang, Hsieh and Huan (2000) were used in assessing visitor satisfaction. Also these components are similar to those obtained from a comprehensive assessment of safari tour operators' websites.

The use of questionnaires was appropriate in assessing visitor satisfaction with guided package tours because the set of questions were designed to assess the relative importance of different components of guided package tours in terms of visitor satisfaction. The same set of questions was used to determine visitor satisfaction with different components of guided package tours in the northern tourist circuit of Tanzania. The use of similarly phrased statements for the assessment of both importance and performance helped respondents to provide consistent responses for each component of the package tour. For instance, respondents were asked: how important are the following components of a guided package tour (prearrival services, accommodation, food, transportation, attractions and tour guide) to your satisfaction with a tour experience. A similar phrase was used for satisfaction: how satisfied are you with different components of the package tour (pre-arrival services, accommodation, food, transportation, attractions and the tour guide). Instructions were bolded at every sub section of the questionnaire (Appendix). The use of a questionnaire survey was ideal for collecting information from a sample that represented a larger population of English-speaking international guided package visitors in the northern tourist circuit.

\subsection{Questionnaire design}

The questionnaire used in this study has four sections. The first section surveys visitors' length of stay, and travel behaviour. It assessed duration of stay, the objective of travel and possible repeat visitation. The second section assessed the current package tour; it included visitors' previous experience with package tours, the length of the current package tour, the importance of different components of package tours to visitor satisfaction with a tour experience and the performance of different components of the package tour. Nineteen attributes (Table 4.2) of the six main components of a guided package tour were assessed in terms of their 
importance to visitor satisfaction and how tourism providers performed to offer a satisfying guided package tour experience. The components and attributes of the package tours are derived from Bowie and Chang (2005), Wang, Hsieh and Huan (2000), Wang et al. (2007), Wang et al. (2012), and Xu and Chan (2010). This section also surveyed overall visitor satisfaction with the package tour experiences, and satisfaction with the availability of the Big Five in the protected areas visited. It included open-ended questions about the views of visitors on areas that need improvement and aspects that made their experience satisfactory. These open-ended questions at the end of the section are crucial in determining respondents' feelings about the topic in question. 
Table 4.2: Attributes used to assess the importance and performance of different components of guided package tours

\begin{tabular}{|c|c|c|}
\hline $\begin{array}{l}\text { Components of the package tour (in bold) } \\
\text { Attributes of the package tour (not in bold) }\end{array}$ & Importance & Performance \\
\hline Pre-arrival services & \multirow{25}{*}{$\begin{array}{c}\text { Measured } \\
\text { using } \\
\text { 5-point } \\
\text { Likert Scale }\end{array}$} & \multirow{25}{*}{$\begin{array}{l}\text { Measured } \\
\text { using } \\
\text { 5-point } \\
\text { Likert Scale }\end{array}$} \\
\hline Availability of airport pickup service & & \\
\hline Provision of information about the country & & \\
\hline Provision of information about the package tour & & \\
\hline Accommodation & & \\
\hline Quality of hotel facilities & & \\
\hline Location of the hotel & & \\
\hline Reasonable price & & \\
\hline Food & & \\
\hline Variety of food & & \\
\hline Attitude of restaurant staff & & \\
\hline Clean restaurant environment & & \\
\hline Transportation & & \\
\hline Condition of the sightseeing vehicles & & \\
\hline Professional and experienced driver & & \\
\hline Open roof car for ease of game viewing & & \\
\hline Attractions & & \\
\hline Abundance of wildlife in the parks & & \\
\hline $\begin{array}{l}\text { The availability of the Big Five (Buffalo, } \\
\text { Elephant, Leopard, Lion and Rhinoceros) }\end{array}$ & & \\
\hline The Maasai culture & & \\
\hline $\begin{array}{l}\text { Natural features (e.g. Ngorongoro crater, } \\
\text { Mt Kilimanjaro) }\end{array}$ & & \\
\hline Tour guide & & \\
\hline Tour guide speaks my language & & \\
\hline Tour guide has good communication skills & & \\
\hline Tour guide has a sense of humour & & \\
\hline
\end{tabular}

Source: Bowie and Chang (2005), MNRT (2012), Wang, et al. (2007)

The third section of this questionnaire surveyed the importance of different attributes of the tour guide and the extent to which visitors were satisfied with the tour guide's performance on every attribute. This section had 12 importance attributes and 12 performance attributes (Table 4.3) derived from Huang, Hsu and Chan (2010) and Wong (2001). These attributes are divided into four main categories: tour guides' communication skills, customer relations, professional skills and work ethic. The last 
section of the questionnaire solicited the demographic information from respondents which included their origins, gender, age, and travel style. Pizam and Ellis (1999) remind readers that visitors' demographic profiles are very important in the study of visitor satisfaction as this information helps one to understand visitors' behaviour. Demographic information is vital during the data analysis as it provides a basic criterion for classification of respondents. In this study questionnaires completed by respondents aged below 18 were discarded.

Table 4.3: Attributes of tour guides used to assess the importance and performance of tour guides

\begin{tabular}{|c|c|c|}
\hline Attribute of tour guide & Importance & Performance \\
\hline Knowledge about wildlife & \multirow{12}{*}{$\begin{array}{l}\text { Measured } \\
\text { using } \\
\text { 5-point } \\
\text { Likert Scale }\end{array}$} & \multirow{12}{*}{$\begin{array}{c}\text { Measured } \\
\text { using } \\
\text { 5-point } \\
\text { Likert Scale }\end{array}$} \\
\hline Focusses on the safety of the tour members & & \\
\hline Communication skills & & \\
\hline Professional ethic & & \\
\hline Care of customers' needs & & \\
\hline Good language skills & & \\
\hline Knowledge about local culture & & \\
\hline Time management skills & & \\
\hline $\begin{array}{l}\text { Able to manage interaction between tourists } \\
\text { and local communities }\end{array}$ & & \\
\hline Good presentation and interpretation skills & & \\
\hline $\begin{array}{l}\text { Capable of handling customers' complaints } \\
\text { properly }\end{array}$ & & \\
\hline Sense of humour & & \\
\hline
\end{tabular}

Source: Ap and Wong (2001); Wong (2001); Huang, Hsu and Chan (2010)

Questions in each section were arranged in a systematic manner. Every section had an introduction which provided respondents with an insight about terminologies used and what the researcher is expecting them to do. Finn, Elliott-White and Walton (2000) observed that during surveys, most respondents agreed to participate only if their confidentiality is assured by the researcher. In view of this observation, ethical and confidentiality issues were clearly presented on the information sheets which were attached to every questionnaire. Ethics approval to undertake this research was obtained from Victoria University of Wellington's Pipitea Human Ethics Committee. 
Questions were designed to conform to the IPA which is the framework that underpins this study. Similarly phrased statements are used to assess the importance and performance of different components of the guided package tour (Table 4.2). In the same way, similar statements are used to examine the importance and performance of different attributes of the tour guide (Table 4.3). The 5-point Likert scale is used to measure the importance and performance of different components of package tours and tour guides in the context of visitor satisfaction. Firstly, the 5point Likert scale ( $5=$ Very important: $1=$ Not important at all) is used to examine the importance of different components of guided package tours in the context of this study. The same scale is used to assess the importance of different attributes of the tour guide in the context of visitor satisfaction with the tour guides. Secondly, another 5-point Likert scale (5=Very satisfied: $1=$ Very dissatisfied) is used to measure the performance of different components of the package tour. Likewise, the same scale is used to assess visitor satisfaction with the performance of tour guides.

The 5-point Likert scales have been widely used in the tourism industry especially in the study of consumer behaviour and visitor satisfaction with tourism products. Finn, Elliott-White and Walton (2000, p.96) contend that 5-point scales are "probably the most frequently employed, easiest to understand and sufficient for most purposes". It is easy for respondents to complete a questionnaire because they have few options to compare. However, Pearce (2005) argues that visitors tend to score higher on a 5point Likert (four out of five) simply because they do not want to admit that they wilfully made wrong choice.

The questionnaire was pre-tested by asking tourism management Honours students to assess the clarity and format of questions, time needed to complete the questionnaire and clarity of instructions given on the information sheet. Finn, ElliottWhite and Walton (2000) remind tourism researchers that pre-testing of questionnaires is a very important part of research design because it helps to understand whether respondents understand the questions and whether they will be able to provide the intended response. 


\subsection{Sampling procedure}

This study collected information about the satisfaction of international visitors taking a package tour in the northern tourist circuit of Tanzania. Three study sites were identified: Tarangire National Park, the Ngorongoro Conservation Area, and Kilimanjaro International Airport. Tarangire National Park and the Ngorongoro Conservation Area are the major starting and ending points for safari package tours in the northern tourist circuit. The Kilimanjaro International Airport is the exit point for the majority of international visitors to the northern tourist circuit of Tanzania. Airports are strategic points to meet visitors travelling on package tours because their accessibility is not limited by a tour operating company. There is no overlap between respondents from three study sites, as data was collected in two phases. The first phase was at the Ngorongoro Conservation Area and Tarangire National Park which took four weeks (from 16 July to 12 August 2012). The second phase was conducted for three weeks at Kilimanjaro International Airport (from 23 August to 8 September 2012). Twenty nine tour operating companies that offer guided safari package tours in the northern tourist circuit of Tanzania were identified. These operators were contacted by email and asked to participate in the study by granting permission to distribute a questionnaire to visitors taking their tour. Only three tour operating companies (Fair Travel Tanzania, Kudu Safaris Ltd and Nomad Tanzania) agreed to participate in the study. The researcher met with the management of package tour operators who agreed to participate in the study and explained the objectives of the study. However, Fair Travel Tanzania declined to participate in the study because most of the company's visitors were arriving at the end of September. It would be impractical for the researcher to gain access to these visitors because his fieldwork was ending by then.

Tour guides/tour drivers were given the task of handing questionnaires to visitors at the end of the tour. Visitors were briefly introduced to the objectives of the study in a sightseeing vehicle and invited to participate by a tour guide/tour driver. The questionnaire was administered to all passengers on board at the end of the tour. Pizam and Ellis (1999) suggest that questionnaires containing questions about visitors' profile, motivation of travel, their lifestyles, frequency of visitation, 
behaviour and attitudes should be distributed to all visitors regularly or after completing their experience. At Kilimanjaro International Airport, respondents were sampled systematically at the international departure lounges. Every third person crossing the security check was approached and asked whether he/she visited Tanzania with a package tour. Those who replied 'yes' were introduced to the purpose of the study and asked to participate by completing a questionnaire. Since international flights took 30 minutes to 1 hour to board after the final security check, respondents had enough time to complete the questionnaire. However, only passengers aged 18 years and above were allowed to complete the questionnaire. Respondents were required to self-complete the questionnaire and place it into a box provided in the sightseeing vehicle/international departure lounge. Respondents' contact details (name, phone number, email address or contact address) were at all times unknown to the researcher. The questionnaire took 10-15 minutes to complete. Respondents' consent was obtained through their agreement to complete the questionnaire. Data was collected during a period of seven weeks (July to September) from 8:30 am to 4:30 pm.

In total, four hundred and eighteen international guided package visitors were asked to participate in this study. Three hundred and eight questionnaires were completed in total. After eliminating partially completed questionnaires and those completed by visitors less than 18 years old, 250 questionnaires were left for analysis (158 from Kilimanjaro International Airport, 69 from Nomad Tanzania and 23 from Kudu Safari Ltd), a response rate of $60 \%$. The availability of resources, the objectives of the study, the nature of the variables used, data analysis and population size are some practical considerations identified by Finn, Elliott-White and Walton (2000) that are used to determine the selection of the sample size. Also Ritchie, Burns and Palmer (2005) argue that in any research the main determining factor for the sample size is cost and time. The sample size of 250 respondents used in this study was considered sufficient. This research was conducted as part of a Master of Tourism Management degree limited to only 12 months of study. Furthermore, 250 respondents were deemed enough to perform correlation analysis to assess the relationship between visitor satisfaction with the tour guide and overall visitor satisfaction with the package tour experience. 


\subsection{Analytical framework}

The term analytical framework can be understood as "a set of relationships that do not lead to specific conclusions about the world of events but can serve in organizing in a preliminary way the object of the enquiry" (Pearce, 2012, p.13, citing Pacquet, 1993). An analytical framework helps to structure data analysis and the presentation of research findings in a logical and meaningful way. There are different types of analytical frameworks depending on the type and volume of data to be analysed and the objectives of the study. The analytical framework of this study is in the form of quadrant matrix. Pearce (2012, p.84) contends that these types of frameworks "have been used as analytical frameworks in tourism research to diagnose, classify, position and otherwise analyse a wide variety of phenomena". IPA examines the attribute of enquiry twice: the importance of the attribute to customers and the performance of the service providers (Lück, 2011). IPA developed by Martilla and James (1977) is used to structure data analysis. This framework is derived from the conceptual framework that underpins this study (Figure 2.5). The conceptual framework links the importance of the different components of the package tour and how tour operators performed. IPA has been widely used by researchers in various fields such as banking, education, healthcare, leisure and recreation, travel and tourism, marketing, management (Tonge et al., 2012). IPA helps to present results in a two-dimensional grid which is straight forward to interpret (Martilla \& James, 1977). The grid produces four quadrants which imply four possible outcomes (Figure 4.3). Concentrate Here shows low performance on the extremely important attributes. This implies low visitor satisfaction with the tour operator or service provider's performance. Keep Up The good Work shows excellent performance on extremely important attributes. Visitors are satisfied with the service provider's/tour operator's performance. The Low Priority quadrant illustrates poor company performance on the attributes that are not important to visitors. Possible Overkill illustrates excellent performance on attributes that are less important to visitors. Arabatzis and Grigoroudis (2010, p.167) contend that IPA helps to "indicate strong and weak points of customer satisfaction and define the required improvement efforts". The IPA grid shows clearly where tour operators are required to put more effort to increase or maintain levels of visitor satisfaction (Lück, 2011). 
Figure 4.3: The importance-performance analysis: The analytical framework for measuring visitor satisfaction with guided package tours in the northern tourist circuit of Tanzania.

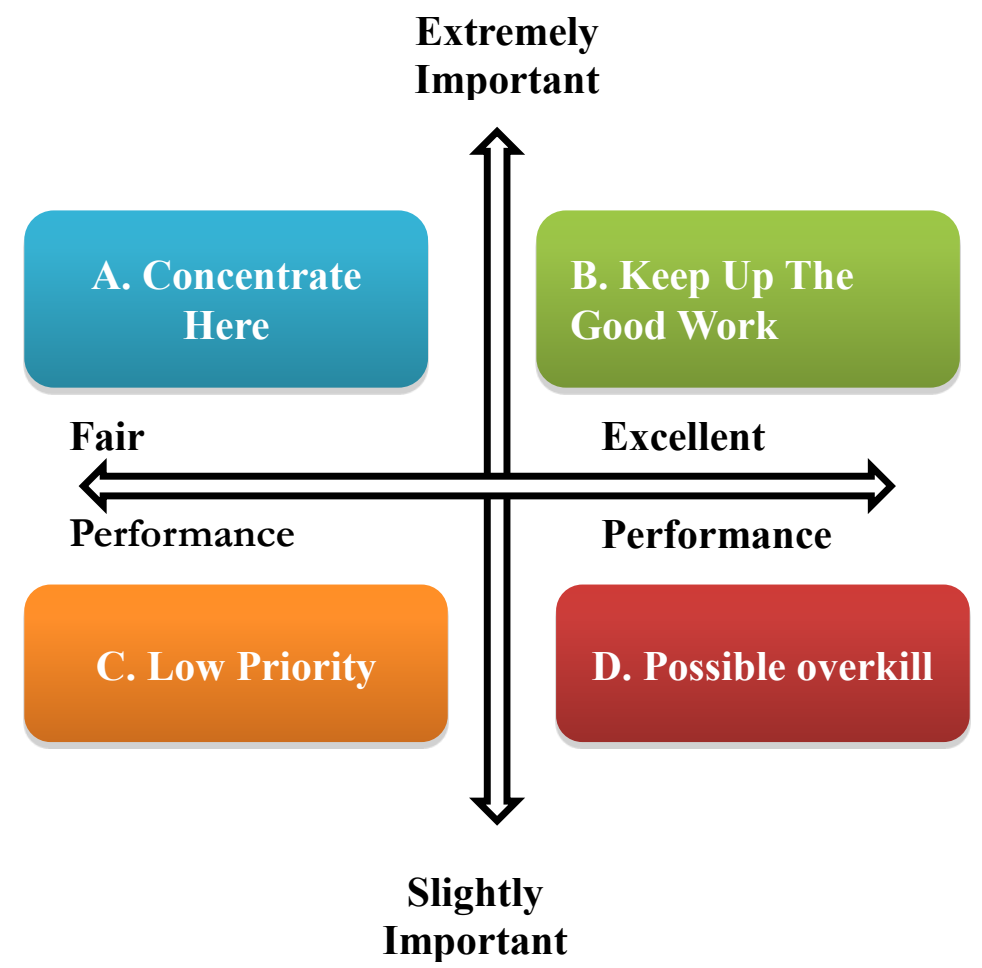

Source: Martilla and James (1977)

Two importance-performance matrices are employed to assess the importance and performance in the context of this study. The first matrix is used to assess the importance and performance of the different components of the package tours. The second matrix is used to examine the importance and performance of different attributes of the tour guides. Martilla and James (1977) clarify that IPA measures the relative but not absolute levels of the importance and performance of different attributes to determine satisfaction. The management implications of different levels of satisfaction with the tour guide are derived directly from the four quadrants of the importance-performance matrix. Yüksel and Yüksel (2001, p.68) add that "proper customer satisfaction research is likely to provide information on service attributes that are considered important by customers, the relative importance of the attributes in customer decision-making, and how well an organization is currently meeting its 
customer needs". Therefore using the importance-performance matrix could provide tour operators with a glimpse into areas that need to be improved based on the customers' need.

\subsection{Data analysis}

The data collected was analysed by using the Statistical Package for the Social Sciences version 19 (SPSS). The completed questionnaires were coded and entered into an SPSS datasheet. All responses on the 5-point Likert scale were coded. For importance ratings the coding was as follows, $5=$ very important, $4=$ important, $3=$ not sure, $2=$ not important, $1=$ not important at all. For performance ratings the coding was 5 = very satisfied, $4=$ satisfied, $3=$ neither satisfied nor dissatisfied, $2=$ dissatisfied, 1 = very dissatisfied. Descriptive statistics (mean, standard deviation and percentages) were calculated. This type of analysis was conducted to assess the visitors' length of stay and travel behaviour, the current package tour, tour guide and visitors' profile (see Appendix). Cross-tabulation was performed to examine overall visitor satisfaction with the package tour experience against the age of respondents, the length of the package tour, travel behaviour and travel experience. Furthermore, answers from the open-ended questions were studied by the researcher and common themes that emerged were grouped together.

The mean importance and performance of different components of the package tour and the attributes of the tour guides were calculated. These means were plotted in the importance-performance grid to determine visitor satisfaction and management implications of different levels of visitor satisfaction with different components of a package tour and tour guide. Pearce (2012) argues that there is no rule of thumb on the number and type of attributes to be incorporated into the IPA matrix. Attributes are selected based on the nature and objective of the study, the tool used to collect data and the type of decision that the organization is planning to make. Arabatizs and Grigorudis (2010) contend that the importance-performance matrix shows what a customer wants (importance) and what a customer receives (performance).

Pearson's correlation coefficient (r) was employed to assess the relationship between visitor satisfaction with different components of package tours and overall 
satisfaction with the tour experience. The correlation coefficients are also calculated to assess the relationship between visitor satisfaction with the tour guide and overall satisfaction with the tour experience. Field (2009) elaborates that Pearson's correlation coefficients (r) measure the strength of the relationship between the two variables. Correlation coefficients are an appropriate measure for the relationship between importance and performance of different variables without predicting the impact of one variable on the other. Finn, Elliott-White and Walton (2000) contend that correlation coefficients help tourism managers to understand how the alteration of one variable is likely to affect the other. Also, statisticians from Victoria University of Wellington's School of Mathematics, Statistics and Operations Research who were consulted at different stages of research recommended the use of Pearson's correlation coefficient.

The research findings are presented in tables and graphs. Means, standard deviation and frequencies are used in reporting the findings. Two IPA grids are also used in two contexts: the first grid presents the importance and performance of different components of package tours. The second IPA grid presents the importance and performance of different attributes of the tour guide in context of visitor satisfaction with guided package tour experience.

\subsection{Limitations and strengths}

Studies of visitor satisfaction with guided package tours have taken different approaches depending on the sample population and area of study. Some researchers have studied satisfaction using qualitative methods while others have used quantitative methods. The study of visitor satisfaction with guided package tours in the northern tourist circuit of Tanzania took a quantitative approach. This study identifies a few limitations associated with questionnaire surveys which are inherent and more systemic in nature. The strengths of this study result from the research design, timing of the data collection process, the sample population surveyed and the analytical tools used to analyse the data. 
This study was conducted during the high tourism season; high season assures the availability of respondents to participate in the study. Also, about $98 \%$ of respondents encountered during the study speak English language which creates the impression that the questionnaire which was prepared in English was clearly understood. The selected study sites, Kilimanjaro International Airport, the Ngorongoro Conservation Area, and Tarangire National Park, receives a large number of tourists in the northern tourist circuit of Tanzania. For instance, the Ngorongoro Conservation Area and Tarangire National Park together were visited by $51 \%$ of all international visitors to the northern tourist circuit of Tanzania in 2011 (MNRT, 2011). The sample derived from the mentioned areas is truly representative of the type and nature of package tourists in the circuit and Tanzania at large. The IPA framework used for data analysis has guided the analysis process and it enables the reader to follow the presentation of findings.

The use of questionnaire surveys during data collection was appropriate for collecting first-hand information about visitor satisfaction with guided package tours. The questionnaire is designed to prompt respondents on what the researcher needs them to answer. Questions were unambiguous and straightforward which made it easier for respondents to complete it without seeking clarification from the researcher.

This study has identified time constraints as a major setback during data collection. Some of the respondents completed half of the questionnaire while others skipped some questions. This drawback was observed from respondents taking tours with Kudu safaris and Nomad Tanzania. As this study was conducted at the end of the tour, some respondents were hurrying to catch the flight back home and to other destinations. In a similar manner, some respondents were tired as a result of a busy schedule of the tour to the extent that completing a questionnaire seemed to be a challenge for them. Moreover, some potential respondents denied participating in the survey as retaliation for flight delays/cancellations at the Kilimanjaro International Airport.

Business confidentiality is another limitation of this study. Twenty six out of twenty nine tour operators requested to participate in this study did not assist because of the 
fear that the information collected would be exposed to their competitors and adversely affect their business. Similarly, some operators withdrew the offer to assist a few days before the commencement of data collection process. This phenomenon resulted in the use of multiple sites that led to an increase in operational costs such as travel.

However, the identified limitations show how challenging it is to study visitor satisfaction with guided package tours. The identified limitations do not disqualify the quality of information collected, but rather prepare other researchers who will conduct similar studies to take the necessary precautions.

\subsection{Summary}

This chapter presents how the study of visitor satisfaction with guided package tours in the northern tourist circuit of Tanzania was conducted. The chapter reviews the literature on the quantitative and qualitative research methods and points out why the quantitative research approach was appropriate. Research design, preparation of the questionnaire and dissemination, sampling procedures and sample size, analytical framework and data analysis are discussed.

Research design, data collection and analysis are significant stages in exploring any tourism phenomena. Collecting data from tourists in a guided package tour setting is an interesting and challenging experience. However, the use of a questionnaire survey has simplified the data collection process because respondents were guided to provide information relevant to the topic.

IPA is an effective tool in organizing the data analysis and presenting the findings. On the one hand, this chapter has identified questionnaire design, high tourism season, English language, IPA and the use of Pearson's correlation coefficients to establish relationships between variable as strengths of this study. On the other hand, time constraints, business confidentiality, the nature of guided package tours in the northern tourism circuit of Tanzania and boredom emanating from cancellation of flights at the Kilimanjaro International Airport are the limitations for data collection and the study more generally. Study findings will be presented in chapters five and six. Quantitative research methods are efficient in collecting information about 
visitor satisfaction with guided package tours because respondents' answers are limited to the topic of inquiry and the information collected is easy to analyse. Also, the quantitative method provides scope for application of IPA to assess visitor satisfaction with package tours. 


\section{CHAPTER FIVE: THE IMPORTANCE AND PERFORMANCE OF DIFFERENT COMPONENTS OF GUIDED PACKAGE TOURS}

\subsection{Introduction}

This chapter presents the research findings from a sample of 250 questionnaires about visitor satisfaction with guided package tours in the northern tourist circuit of Tanzania. This chapter addresses three of the five objectives of this study:

1. To assess the relative importance of different components of guided package tours in terms of visitor satisfaction.

2. To determine visitor satisfaction with the performance of different components of guided package tours in the northern tourist circuit of Tanzania.

3. To assess the relationship between the importance and performance of different components of guided package tours in the context of visitor satisfaction with a guided package tour experience.

The chapter has seven sections. The first section is about the respondents' demographic profile and travel behaviour. It addresses the age, gender, country of origin, duration of stay in Tanzania, purpose of visit and composition of respondents. The second section consists of the nature of guided package tours in the northern tourist circuit of Tanzania. This section examines the length of the guided package tours, visitors' experience with guided package tours in Tanzania, visitor satisfaction with the availability of the Big Five in the protected areas they visited, overall visitor satisfaction with the guided package tour and the most satisfying aspect of the guided package tour experience. The third section assesses the importance of different components of the guided package tour. The fourth section examines the performance of different components of the guided package tours. The fifth section examines the relationship between importance and performance of different components of the guided package tour using a paired $t$-test. It includes the importance-performance grid as a diagnostic tool for visitor satisfaction with the guided package tour. The sixth section presents areas that need some improvement. In the seventh and final section, the key findings will be addressed. 


\subsection{Demographic profile and travel behaviour}

\subsubsection{Respondent demographic profile}

The profile of respondents is an important aspect in quantitative research as this information helps the reader understand the nature of the sample used. The sample size for this study is 250 respondents of which 141 (56.4\%) are female and 109 (43.6\%) are male (Table 5.1). These findings are broadly similar to the 2010 international visitors' exit surveys report in this regard (MNRT, 2012).

This study is dominated by visitors between 25-44 years of age who account for $40.4 \%$ of the total sample followed by the age group of 45-64 year olds accounting for $36.8 \%$. Young travellers (18-24 years) account for $17.2 \%$ while senior visitors (65+ years) account for $5.6 \%$ of the total respondents. These findings show a similar pattern with the international visitors' exit surveys report of 2010. From the 2010 survey report, the dominant age groups are 25-44 years and 45-64 years who account for $51.3 \%$ and $29.3 \%$ of international visitors respectively. There are more young visitors (18-24 years) than senior visitors (65+) (MNRT, 2012).

The respondents who participated in this study are from different parts of the world. About $26.8 \%$ of respondents are from the United States of America, 11.6\% are from the United Kingdom, 6.8\% from Canada, 6.8\% from France and 6.4\% are from Australia. Other countries include China, Brazil, Denmark, Greece, Iran, New Zealand, Norway, Finland, Saud Arabia, Southern Korea, Singapore, Sweden, Russia and Turkey. The findings show that the United States of America, the United Kingdom, Canada, France and Australia are the top five markets in the context of this study (Table 5.1). Compared to the 2010 international visitors' exit surveys report, the United Kingdom was leading with $17.2 \%$ followed by the United States of America (13.3\%), Germany (9.4\%), Italy (8.6\%) and Australia (6.3\%) (MNRT, 2012). Italy is among the top five sources of tourists for Tanzania but it accounts for only $0.4 \%$ of respondents in the current study. The current study shows that North America and Europe are still the leading markets for Tanzanian tourism. This is in line with the 2010 international visitors' exit surveys report which shows that North America and Europe are the dominant markets for Tanzanian tourism. The 
dominance of the North American and European markets is emanating from the intensive promotion of Tanzanian tourism in these regions (MNRT, 2012).

Table 5.1: Respondents' demographic profile

\begin{tabular}{|c|c|c|}
\hline Gender & Frequency (n) & Percent (\%) \\
\hline Male & 109 & 43.6 \\
\hline Female & 141 & 56.4 \\
\hline Total & 250 & 100.0 \\
\hline Age & Frequency (n) & Percent (\%) \\
\hline $18-24$ & 43 & 17.2 \\
\hline $25-44$ & 101 & 40.4 \\
\hline $45-64$ & 92 & 36.8 \\
\hline $65+$ & 14 & 5.6 \\
\hline Total & 250 & 100.0 \\
\hline Country of Origin & Frequency (n) & Percent (\%) \\
\hline USA & 67 & 26.8 \\
\hline United Kingdom & 29 & 11.6 \\
\hline Canada & 17 & 6.8 \\
\hline France & 17 & 6.8 \\
\hline Australia & 16 & 6.4 \\
\hline Germany & 14 & 5.6 \\
\hline Switzerland & 13 & 5.2 \\
\hline Ireland & 8 & 3.2 \\
\hline Belgium & 5 & 2.0 \\
\hline Netherlands & 5 & 2.0 \\
\hline Italy & 4 & 1.6 \\
\hline South Africa & 4 & 1.6 \\
\hline Japan & 2 & 0.8 \\
\hline Spain & 1 & 0.4 \\
\hline Others & 48 & 19.2 \\
\hline Total & 250 & 100.0 \\
\hline
\end{tabular}

\subsubsection{Travel behaviour}

Eighty-eight percent of the respondents are first-time visitors to Tanzania while $12 \%$ are repeat visitors. These findings correspond with Enoch's (1996) argument that many package tourists are first-time travellers. As shown in Table 5.2 the largest 
proportion of visitors $(37.2 \%)$ in the context of this study travel with family and children, $28.4 \%$ travel with friends and $28 \%$ travel with a spouse or partner. Visitors who are travelling alone account for $6.4 \%$ of total respondents $(n=250)$. Visitors who are travelling with family and children, with a spouse or partner or with friends could possibly opt for a guided package tour because it is a convenient way of organising a holiday.

\section{Table 5.2: Travel party}

\begin{tabular}{|l|c|c|}
\hline Travel party & Frequency (n) & Percent (\%) \\
\hline With family and Children & 93 & 37.2 \\
\hline With friends & 71 & 28.4 \\
\hline With a spouse or partner & 70 & 28.0 \\
\hline Alone & 16 & 6.4 \\
\hline Total & $\mathbf{2 5 0}$ & $\mathbf{1 0 0 . 0}$ \\
\hline
\end{tabular}

\subsubsection{The duration of stay and purpose of visiting Tanzania}

As discussed in Chapter Three, the northern tourist circuit of Tanzania leads in attracting international package visitors to the country. Table 5.3 shows that $87.2 \%$ of respondents are travelling to this circuit for holiday and leisure. A few respondents (two percent) are travelling for business, $1.6 \%$ of visitors are visiting friends and relatives and $1.2 \%$ of respondents are conference travellers. Eight percent of respondents are visiting Tanzania for other purposes such as education, exchange programmes, missionary and voluntary work. These findings correspond with the 2010 international visitors' surveys report that indicates that the majority of package visitors to Tanzania come for holiday and leisure purposes (MNRT, 2012). 
Table 5.3: Purpose of visit and duration of stay in Tanzania

\begin{tabular}{|l|c|c|c|c|c|c|}
\hline \multirow{2}{*}{$\begin{array}{c}\text { Duration of } \\
\text { stay in } \\
\text { Tanzania }\end{array}$} & $\begin{array}{c}\text { Holiday } \\
\text { and leisure } \\
(\mathbf{n})\end{array}$ & $\begin{array}{c}\text { VFR } \\
(\mathbf{n})\end{array}$ & $\begin{array}{c}\text { Business } \\
(\mathbf{n})\end{array}$ & $\begin{array}{c}\text { Conference } \\
(\mathbf{n})\end{array}$ & $\begin{array}{c}\text { Other } \\
(\mathbf{n})\end{array}$ & $\begin{array}{c}\text { Total } \\
(\mathbf{n})\end{array}$ \\
\hline 4-7days & 52 & 0 & 1 & 2 & 2 & $57(23 \%)$ \\
\hline 8-11 days & 63 & 1 & 1 & 0 & 2 & $67(27 \%)$ \\
\hline 12-15 days & 75 & 3 & 0 & 1 & 1 & $80(32 \%)$ \\
\hline 16+days & 28 & 0 & 3 & 0 & 15 & $46(18 \%)$ \\
\hline Total & $\mathbf{2 1 8}(\mathbf{8 7 . 2 \%})$ & $\mathbf{4 ( 1 . 6 \% )}$ & $\mathbf{5 ( 2 \% )}$ & $\mathbf{3}(\mathbf{1 . 2 \%})$ & $\mathbf{2 0}(\mathbf{8 \%})$ & $\mathbf{2 5 0}(\mathbf{1 0 0 \% )}$ \\
\hline
\end{tabular}

$\mathrm{VFR}=\mathrm{Visiting}$ friends and relatives

The duration of stay for many visitors in Tanzania is 12-15 days (32\%), 8-11 days (27\%) and 4-7 days (23\%); fewer respondents (18\%) spent 16+ days. Findings show that the majority of package visitors to Tanzania and at the northern tourist circuit in particular stay between eight to fifteen days (categories 8-11 days and 12-15 days combined). The average stay for international visitors to Tanzania derived from the 2010 exit survey report is nine days.

\subsection{The nature of guided package tours in the northern tourist circuit}

\subsubsection{Visitors' previous experience with guided package tours in Tanzania}

As discussed in Chapter Three, the majority of international visitors to Tanzania travel with a package tour. About $87.2 \%$ of international visitors travelling on a guided package tour surveyed in this study were first-time travellers to Tanzania and $12.8 \%$ were repeat package travellers. The findings reflect that many visitors to Tanzania are first-time travellers.

\subsubsection{The length of guided package tours in the northern tourist circuit of Tanzania}

The findings show that the length of package tours experienced by international visitors in the context of this study varies. The shortest package tour is 1-3 days and the longest package tour is 16+ days. The 4-7 day package tour is the most popular with $36 \%$ of respondents followed closely by the $8-11$ day package tour (28.4\% of 
respondents) and the 12-15 day package tour which is preferred by $20.4 \%$ of respondents. Fewer respondents (7.6\%) purchased a 1-3 day package or $16+$ day package tour.

Table 5.4: The length of the guided package tour in the northern tourist circuit

\begin{tabular}{|l|c|c|}
\hline Length of the guided package tour & Frequency $(\mathbf{n})$ & Percent $(\boldsymbol{\%})$ \\
\hline 1-3 days & 19 & 7.6 \\
\hline 4-7days & 90 & 36.0 \\
\hline 8-11 days & 71 & 28.4 \\
\hline 12-15 days & 51 & 20.4 \\
\hline 16+days & 19 & 7.6 \\
\hline Total & $\mathbf{2 5 0}$ & $\mathbf{1 0 0}$ \\
\hline
\end{tabular}

\subsubsection{Overall visitor satisfaction with guided package tours}

Visitor satisfaction with guided package tours is composed of the hard, tangible and soft, intangible elements of the tour operators. As discussed in Chapter Two, visitor satisfaction with guided package tours is composed of, on one hand, the performance of the tour operators and, on the other, visitors' expectations, experience, visitor behaviour during the tour, unforeseen events and perception of equity. Visitor satisfaction with the guided package tour can either be influenced by all components of the package tour or some of the components. In other words, different components of the package tour make different contributions to the overall satisfaction with the guided package tour experience. The findings show that about $73.6 \%$ of international guided package visitors who participated in this study were very satisfied (5=Very satisfied; 1=Very dissatisfied) with the tour experience. Twenty-four percent of visitors surveyed were satisfied while five visitors (two percent) were neither satisfied nor dissatisfied. Only one visitor $(0.4 \%)$ who participated in the study was very dissatisfied with the guided package tour experience in the northern tourist circuit (Table 5.5). None of the respondents were simply dissatisfied with the guided package tour experience. 
Table 5.5: Lengths of package tours and overall visitor satisfaction

\begin{tabular}{|c|c|c|c|c|c|c|}
\hline \multirow{2}{*}{$\begin{array}{l}\text { Overall visitor } \\
\text { satisfaction with the } \\
\text { package tour experience }\end{array}$} & \multicolumn{5}{|c|}{ Length of package tour } & \multirow[b]{2}{*}{$\begin{array}{c}\text { Total } \\
\text { (n) }\end{array}$} \\
\hline & $\begin{array}{c}1-3 \\
\text { days }\end{array}$ & $\begin{array}{c}\text { 4-7 } \\
\text { days }\end{array}$ & $\begin{array}{l}\text { 8-11 } \\
\text { days }\end{array}$ & $\begin{array}{r}12-15 \\
\text { days }\end{array}$ & $\begin{array}{c}\text { 16+ } \\
\text { days }\end{array}$ & \\
\hline Very satisfied & 12 & 66 & 58 & 36 & 12 & $184(73.6 \%)$ \\
\hline Satisfied & 6 & 22 & 12 & 13 & 7 & $60(24.0 \%)$ \\
\hline $\begin{array}{l}\text { Neither satisfied nor } \\
\text { dissatisfied }\end{array}$ & 1 & 2 & 1 & 1 & 0 & $5(2.0 \%)$ \\
\hline Dissatisfied & 0 & 0 & 0 & 0 & 0 & $0(0.0 \%)$ \\
\hline Very dissatisfied & 0 & 0 & 0 & 1 & 0 & $1(0.4 \%)$ \\
\hline Total & 19 & 90 & 71 & 51 & 19 & $250(100 \%)$ \\
\hline
\end{tabular}

The findings show that the northern tourist circuit of Tanzania offers a satisfying guided package tour experience irrespective of the length of tour taken. There is no relationship between the length of the stay and levels of satisfaction as the majority of visitors were satisfied to very satisfied on different types of tours.

Also as noted in section 5.2.1, the majority of the surveyed international visitors in this study were first-time travellers to Tanzania. As discussed in the literature review, previous visitor experiences are likely to affect their impending consumption experience (Yüksel \& Yüksel, 2001). Table 5.6 shows almost similar levels of satisfaction between visitors with prior guided package tour experience in Tanzania and those without such experience. The proportion of very satisfied visitors is high amongst those who have never been to Tanzania with guided package tours (75\%) and those who have been to Tanzania with a package tour (66\%). Thirty-one percent of visitors with previous guided package tour experience rated that they were satisfied compared to $(23 \%)$ of visitors who were inexperienced guided package visitors in the northern tourist circuit of Tanzania. It is not practical to compare satisfaction between experienced and inexperienced guided package visitors in this study because the two sub-samples are very different in terms of size. 
Table 5.6: Satisfaction with guided package tours: First-time and repeat tour takers

\begin{tabular}{|c|c|c|c|}
\hline \multirow{2}{*}{$\begin{array}{l}\text { Overall satisfaction with the } \\
\text { package tour experience }\end{array}$} & \multicolumn{2}{|c|}{$\begin{array}{c}\text { Visited Tanzania previously } \\
\text { with a package tour? }\end{array}$} & \multirow{2}{*}{$\begin{array}{c}\text { Total } \\
(\mathbf{n})\end{array}$} \\
\hline & Yes (n) & No (n) & \\
\hline Very Satisfied & $21(66 \%)$ & $163(75 \%)$ & $184(74 \%)$ \\
\hline Satisfied & $10(31 \%)$ & $50(23 \%)$ & $60(24 \%)$ \\
\hline Neither satisfied nor dissatisfied & $1(3 \%)$ & $4(2 \%)$ & $5(2 \%)$ \\
\hline Dissatisfied & 0 & 0 & $0(0 \%)$ \\
\hline Very dissatisfied & 0 & $1(0 \%)$ & $1(0 \%)$ \\
\hline Total & 32 & 218 & $250(100)$ \\
\hline
\end{tabular}

The findings show that both first-time visitors and repeat tour takers have higher levels of satisfaction with the guided package tour experience possibly because tour operators have performed well on every aspect of the tour.

\subsubsection{Visitor satisfaction with the availability of the Big Five}

In this study, visitors were asked to assess their levels of satisfaction with the availability of the Big Five in the protected areas they visited. A 5-point Likert scale (5=Very satisfied; $1=$ Very dissatisfied) was used for assessment. Table 5.7 shows different levels of satisfaction experienced by international visitors with respect to the Big Five. Visitors are very satisfied with the availability of elephants, buffaloes and lions in the protected areas visited. Leopards and black rhinoceros have lower mean satisfaction scores. Visitors, on average, rated their satisfaction with visibility of black rhinoceros and leopards between "satisfied" and "neither satisfied nor dissatisfied" (Table 5.7). Likewise, the value of standard deviation for leopards (SD 1.158) and black rhinoceros (SD 1.230) are higher than the rest of the group which suggests that visitors had a wider range of responses in terms of their satisfaction scores. 
Table 5.7: Visitor satisfaction with the availability of the Big Five

\begin{tabular}{|l|c|c|}
\hline The Big Five & Mean & SD \\
\hline Elephant & 4.87 & 0.41 \\
\hline Buffalo & 4.78 & 0.50 \\
\hline Lion & 4.66 & 0.71 \\
\hline Leopard & 3.74 & 1.16 \\
\hline Black Rhinoceros & 3.35 & 1.23 \\
\hline
\end{tabular}

$\mathrm{n}=250$ in all cases; $\mathrm{SD}=$ Standard deviation

Different levels of satisfaction with the Big Five could be caused by the fact that black rhinoceros are an endangered species and their population is very small compared to other animals in the Big Five. Visitors therefore may not have seen them. The leopard is a nocturnal animal; it spends time hiding in trees during the day and hunts at night. Guided tours in the protected areas are mostly conducted during the day time which creates fewer chances of seeing them. Elephants, buffaloes and lions have higher population densities in protected areas in the northern tourist circuit which increases the chances of seeing them.

\subsection{5: The most satisfying aspect of the guided package tour experience}

This study incorporates an open-ended question in order to gain views from respondents about the most satisfying aspect of their tour. Respondents who participated in the study were asked "what was the most satisfying aspect of the tour". Thirty-one respondents $(12 \%)$ who participated in this study chose not to answer this question. It is not clear whether they were more satisfied to the extent that they failed to figure out what aspect of the tour was the most satisfying or they were possibly failed to answer this part of the questionnaire. Two hundred and nineteen respondents (88\%) who participated attempted this question and gave their views. Key phrases from the open ended question were coded and put into the SPSS data sheets. One hundred and ninety-eight statements were produced from 219 
respondents. These statements were studied, evaluated and grouped together based on the frequency of response. Fourteen themes emerged out of one hundred and ninety-eight statements. The themes that emerged were further grouped into the six main components of the guided package tour. Some respondents were satisfied with the tour more generally a phenomenon that led to the creation of a new category “overall package tour" (Table 5.8).

Table 5.8: The most satisfying aspect of the guided package tour

\begin{tabular}{|c|c|c|c|c|}
\hline $\begin{array}{l}\text { Tour } \\
\text { components }\end{array}$ & $\begin{array}{l}\text { The most satisfying aspect of the } \\
\text { guided package tour }\end{array}$ & $\mathbf{F}(\mathbf{n})$ & $\mathbf{V P}(\%)$ & $\mathbf{R O}$ \\
\hline \multirow[t]{7}{*}{ Attractions } & $\begin{array}{l}\text { Abundance of wildlife in their } \\
\text { natural habitat }\end{array}$ & 91 & 41 & 1 \\
\hline & $\begin{array}{l}\text { Being at the summit of Mount } \\
\text { Kilimanjaro }\end{array}$ & 16 & 7 & 3 \\
\hline & $\begin{array}{l}\text { Culture and hospitality of } \\
\text { Tanzanians in general }\end{array}$ & 13 & 6 & 4 \\
\hline & Beautiful landscapes & 10 & 5 & 6 \\
\hline & The wildlife and Maasai culture & 12 & 5 & 5 \\
\hline & To get to see the Big Five & 10 & 5 & 7 \\
\hline & Sub total & 151 & 69 & \\
\hline \multirow[t]{3}{*}{ Tour guide } & $\begin{array}{l}\text { Friendly and knowledgeable tour } \\
\text { guides }\end{array}$ & 36 & 16 & 2 \\
\hline & Tour guides' communication skills & 4 & 2 & 12 \\
\hline & Sub total & 40 & 18 & \\
\hline Transportation & Outstanding tour driver & 5 & 2 & 10 \\
\hline \multirow[t]{3}{*}{ Accommodation } & The quality of hotel facilities & 9 & 4 & 8 \\
\hline & Good customer care & 5 & 2 & 11 \\
\hline & Sub total & 14 & 6 & \\
\hline Food & $\begin{array}{l}\text { The professional service and food } \\
\text { quality }\end{array}$ & 2 & 1 & 13 \\
\hline \multirow{3}{*}{$\begin{array}{l}\text { Overall tour } \\
\text { experience }\end{array}$} & A well-organised tour & 7 & 3 & 9 \\
\hline & Price of the package tour & 1 & 0 & 14 \\
\hline & Sub total & 8 & 3 & \\
\hline \multicolumn{2}{|l|}{ Total } & 219 & 100 & \\
\hline
\end{tabular}

$\mathrm{F}=$ Frequency; $\mathrm{VP}=$ Valid percentage $\mathrm{RO}=\mathrm{Rank}$ order 
The most satisfying aspect of the guided package tour in the northern tourist circuit of Tanzania is the abundance of wildlife in their natural habitat followed, in order, by friendly and knowledgeable tour guides; being at the top of Mount Kilimanjaro; and the culture and hospitality of Tanzanians (Table 5.8). The findings further show that visitors are more satisfied with wildlife and Maasai culture, beautiful landscapes, the ability to see the Big Five, the quality of hotel facilities, a well-organised tour and an outstanding tour driver. A few respondents mentioned that they were more satisfied with the price of the package tour, the professional service and quality of the food.

The findings show that the majority of guided package visitors are more satisfied with aspects of attractions and the tour guide. Wildlife in their natural environment is the major tourism product in the northern tourist circuit of Tanzania which forms the objective of travel for many visitors to Tanzania. One contributing factor for higher satisfaction with the abundance of wildlife could be the desire of visitors to see special groups of animals - for example, the carnivores (lions, leopards, cheetahs and hyenas) or the larger herbivores (elephants, hippopotamus, buffaloes, black rhinoceros and giraffes). The ability of visitors to see these animals in close proximity helps them to meet their desire which consequently results in high satisfaction. Climbing Mount Kilimanjaro is a satisfying aspect for mountaineering visitors. Mount Kilimanjaro is the highest mountain in Africa and it is the only mountain located in a tropical area that maintains snow the whole year. High visitor satisfaction with the tour guides could result from their friendliness, knowledge about wildlife and interpretation of attractions during the tour.

\subsection{The importance of different components of a guided package tour}

As discussed in Chapter Two, visitors tend to assess the importance of different components of the guided package tour based on a number of factors ranging from their objective of travel to their travel experiences. The assessment of the importance of different components of the package tour differs between visitors. This study assesses six components of guided package tours. Respondents were asked to rate the importance of these components on a 5-point Likert scale (5=Very important; 
$1=$ Not important at all). Table 5.9 shows the mean importance scores of the six components of the guided package tour in descending order.

Table 5.9: The importance of different components of the guided package tour

\begin{tabular}{|l|c|c|}
\hline Components of the guided package tour & Mean & SD \\
\hline Attractions & 4.80 & 0.45 \\
\hline Tour guide & 4.66 & 0.61 \\
\hline Transportation & 4.47 & 0.72 \\
\hline Accommodation & 4.46 & 0.65 \\
\hline Pre-arrival services & 4.37 & 0.83 \\
\hline Food & 4.30 & 0.75 \\
\hline Average & $\mathbf{4 . 5 1}$ & $\mathbf{0 . 6 7}$ \\
\hline
\end{tabular}

$\mathrm{N}=250$ in all cases; $\mathrm{SD}=\mathrm{Standard}$ deviation

All components have a mean score above four; this means that all components are rated as important by visitors (Table 5.9). Attractions have the highest mean importance scores followed by the tour guide. Transportation and accommodation have more or less the same importance score. In relation to other components of the guided package tours, food has the lowest mean importance score followed by prearrival services (Table 5.9). The low standard deviation (SD less than one) shows that visitors were consistent in their assessment of these components. Lower values of standard deviation show that the majority of respondents scored the components between four and five on a 5-point Likert scale. There is a possibility that visitors rated attractions as a very important component of the guided package tour because of certain specific features located at the northern tourist circuit of Tanzania, for example wildlife and natural features.

The components of the guided package tour were further examined. Table 5.10 shows a list of the service attributes of the six components of the guided package tour in the context of this study. Respondents were asked to rate on a 5-point Likert scale the importance of the service attributes of the six components of the guided package tours (5=Very important; $1=$ Not important at all). Professional and experienced driver has the highest mean importance score and Maasai culture has the lowest mean importance score. 
Table 5.10: The importance of different service attributes of the guided package tour to visitor satisfaction

\begin{tabular}{|l|l|c|c|c|}
\hline \multirow{2}{*}{$\begin{array}{l}\text { Tour } \\
\text { components }\end{array}$} & $\begin{array}{l}\text { Service attributes of the guided package } \\
\text { tours }\end{array}$ & Mean & SD & RO \\
\hline \multirow{4}{*}{ Attraction } & Abundance of wildlife in the parks & 4.67 & .50 & 2 \\
\cline { 2 - 5 } & Natural features & 4.52 & .58 & 6 \\
\cline { 2 - 5 } & The availability of the Big Five & 4.28 & .84 & 10 \\
\cline { 2 - 5 } & The Maasai culture & 3.82 & 1.02 & 19 \\
\hline \multirow{5}{*}{ Tour guide } & Tour guide has good communication skills & 4.61 & .53 & 4 \\
\cline { 2 - 5 } & Tour guide has a sense of humour & 4.27 & .81 & 12 \\
\cline { 2 - 5 } & Tour guide speaks my language & 4.26 & 1.15 & 13 \\
\hline \multirow{5}{*}{ Transportation } & Professional and experienced driver & 4.77 & .45 & 1 \\
\cline { 2 - 5 } & Open roof car for ease of game viewing & 4.65 & .61 & 3 \\
\cline { 2 - 5 } & Condition of sightseeing vehicles & 4.37 & .70 & 7 \\
\hline \multirow{4}{*}{ Accommodation } & Quality of hotel facilities & 4.28 & .74 & 11 \\
\cline { 2 - 5 } & Location of the hotel & 4.20 & .79 & 14 \\
\cline { 2 - 5 } & Reasonable price & 4.15 & .78 & 15 \\
\hline \multirow{3}{*}{$\begin{array}{l}\text { Pre-arrival } \\
\text { service }\end{array}$} & Availability of airport pickup service & 4.37 & .86 & 8 \\
\cline { 2 - 5 } & $\begin{array}{l}\text { Provision of information about the package } \\
\text { tour }\end{array}$ & 4.32 & .75 & 9 \\
\cline { 2 - 5 } & Provision of information about the country & 3.94 & .95 & 18 \\
\hline \multirow{5}{*}{ Food } & Clean restaurant environment & 4.59 & .60 & 5 \\
\cline { 2 - 5 } & Attitude of restaurant staff & 4.13 & .79 & 16 \\
\cline { 2 - 5 } & Variety of food & 4.04 & .79 & 17 \\
\hline \multirow{2}{*}{ Average } & & 4.34 & .74 & \\
\hline
\end{tabular}

$\mathrm{SD}=$ Standard deviation; $\mathrm{n}=250$ in all cases $; \mathrm{RO}=\mathrm{Rank}$ order

In the context of attractions, the results show that the abundance of wildlife in the park has the highest mean importance score followed by natural features and the availability of the Big Five. Maasai culture has the lowest mean importance score in the context of attractions. One possible reason for higher importance scores for the abundance of wildlife in the parks and lower scores for the Maasai culture could be that many tour operators market guided package tours as wildlife tours. Therefore, those taking wildlife tours do not necessarily see cultural attraction as important. 
Tour guides' communication skills have higher mean scores than any other attributes of the tour guides. Tour guides' sense of humour and their ability to speak the visitors' own language have similar mean importance scores. As noted in Chapter Two, one of the major roles of tour guides is the interpretation of the tourist attractions for visitors. It is likely that visitors prefer a tour guide with good communication skills in order to perform this role. Also, it is impractical for tour guides to speak the language of every visitor because international visitors who are taking package tours in the northern tourist circuit of Tanzania are coming from different countries. The questionnaire was written in English and it was distributed to tour guides who speak English. In the same way, a professional and experienced tour driver is rated as a very important aspect of transportation followed by the open roof vehicle for ease of game viewing. The condition of the sightseeing vehicles has a lower mean importance score in this context. A professional and experienced tour driver has a high mean importance score probably because visitors believe that the driver knows where the wildlife is. The open roof vehicles are important for safaris because they give more opportunity to see animals and take photos.

The quality of hotel facilities has a higher mean importance score than the location of the hotel and the price. Hotel facilities like the size of the bed and room are important for determining visitor satisfaction with accommodation (Bowie \& Chang, 2005). In the context of pre-arrival services, the majority of international visitors pay more attention to the availability of airport pickup services and the provision of information about the package tour than the provision of information about the country. It is possible that the availability of the airport pickup service has a higher mean importance score because the majority of guided package visitors (88\%) participated in this study were first-time travellers to Tanzania. They are unfamiliar with the language (Swahili), transportation and location of the hotel. Therefore being picked up from the airport provides them with a valuable service. Furthermore, a clean restaurant environment has a higher mean importance score in the context of food followed by the attitude of the restaurant staff, while variety of food scores the lowest. One contributing factor for the higher mean importance score for clean restaurant environment could be that visitors are highly concerned about their health during the tour and a hygienic restaurant would reduce the likelihood of contracting 
illness. There is the possibility that visitors pay less attention to the variety of food because the main focus of the tour is seeing wildlife, not enjoying a variety of food.

\subsection{The performance of different components of the guided package tour}

Visitor satisfaction with guided package tours can be examined by comparing the importance and performance of every component of the package tour. The previous section shows that all components of the guided package tour are important to visitors in this regard. The section assesses the performance of the same components of the guided package tour. On a 5-point Likert scale (5=Very satisfied; 1=Very dissatisfied) visitors were asked to rank the performance of the six main components of the package tours.

Findings show that visitors were satisfied with the performance of the tour operators (Mean greater than four) in delivering the six components of the guided package tour. The values of the standard deviation are low (SD less than one) which shows that visitors were consistent in the assessment of the performance of the different components of the guided package tour. Table 5.11 shows that attractions have a higher mean performance score followed by tour guide. Transportation has a higher mean performance score than pre-arrival services and accommodation. Food has a lower performance score than other components (Table 5.11).

Table 5.11: Visitor satisfaction with the performance of different components of the package tour

\begin{tabular}{|l|c|c|}
\hline Components of a guided package tour & Mean & SD \\
\hline Attractions & 4.76 & 0.56 \\
\hline Tour guide & 4.64 & 0.64 \\
\hline Transportation & 4.58 & 0.62 \\
\hline Pre-arrival services & 4.52 & 0.67 \\
\hline Accommodation & 4.46 & 0.67 \\
\hline Food & 4.33 & 0.73 \\
\hline Average & $\mathbf{4 . 5 5}$ & $\mathbf{0 . 6 5}$ \\
\hline
\end{tabular}

$\mathrm{n}=250$ in all cases; $\mathrm{SD}=$ Standard deviation 
One contributing factor for higher visitor satisfaction with the performance of attractions could be the fact that international visitors travel to Tanzania to see the wildlife in their natural environment and other natural features. The northern tourist circuit of Tanzania has a diversity and high abundance of wildlife. Thus visitors have been able to meet their objectives of visiting this circuit. The top three components of the package tour show the typical safari product in the northern tourist circuit that is composed of attractions, the tour guide and transportation.

The components of the guided package tour were further examined by using selected service attributes. On a 5-point Likert scale ( $5=$ Very satisfied; $1=$ Very dissatisfied) visitors were asked to rank their levels of satisfaction with the performance of the tour operators according to different attributes of the guided package tours. The mean performance ratings for the different attributes of the guided package tour are presented in Table 5.12. Open roof car for ease of game viewing and abundance of wildlife in the parks have higher mean performance scores than the other attributes. Reasonable price for the hotel and Maasai culture have the lower mean performance scores than the other attributes. 
Table 5.12: Visitor satisfaction with the performance of different service attributes of the guided package tour

\begin{tabular}{|c|c|c|c|c|}
\hline $\begin{array}{c}\text { Tour } \\
\text { Components }\end{array}$ & $\begin{array}{c}\text { Service attributes of the guided package } \\
\text { tours }\end{array}$ & Mean & SD & $\mathbf{R O}$ \\
\hline \multirow[t]{4}{*}{ Attraction } & Abundance of wildlife in the parks & 4.76 & .50 & 2 \\
\hline & Natural features & 4.65 & .75 & 4 \\
\hline & The availability of the Big Five & 4.46 & .89 & 11 \\
\hline & The Maasai culture & 4.03 & .61 & 18 \\
\hline \multirow[t]{3}{*}{ Tour guide } & Tour guide has good communication skills & 4.60 & .78 & 5 \\
\hline & Tour guide speaks my language & 4.56 & .77 & 7 \\
\hline & Tour guide has a sense of humour & 4.55 & .72 & 8 \\
\hline \multirow[t]{3}{*}{ Transportation } & Open roof car for ease of game viewing & 4.77 & .66 & 1 \\
\hline & Professional and experience driver & 4.74 & .54 & 3 \\
\hline & Condition of sightseeing vehicles & 4.49 & .49 & 9 \\
\hline \multirow{3}{*}{$\begin{array}{l}\text { Pre-arrival } \\
\text { service }\end{array}$} & Availability of airport pickup service & 4.47 & .73 & 10 \\
\hline & $\begin{array}{l}\text { Provision of information about the package } \\
\text { tour }\end{array}$ & 4.14 & .79 & 16 \\
\hline & Provision of information about the country & 4.04 & .75 & 17 \\
\hline \multirow[t]{3}{*}{ Accommodation } & Quality of hotel facilities & 4.42 & .67 & 13 \\
\hline & Location of the hotel & 4.38 & .69 & 14 \\
\hline & Reasonable price & 4.02 & .81 & 19 \\
\hline \multirow[t]{3}{*}{ Food } & Clean restaurant environment & 4.57 & .79 & 6 \\
\hline & Attitude of restaurant staff & 4.46 & .70 & 12 \\
\hline & Variety of food & 4.25 & .62 & 15 \\
\hline \multicolumn{2}{|l|}{ Average } & 4.44 & .70 & \\
\hline
\end{tabular}

$\mathrm{SD}=$ Standard deviation; $\mathrm{n}=250$ in all cases $; \mathrm{RO}=\mathrm{Rank}$ order

In the context of attractions, the availability of wildlife in the parks has the highest mean performance score followed by natural features and the availability of the Big Five at the protected areas visited. Maasai culture has a lower mean performance score than other attributes of the attractions (Table 5.12). Visitors were more satisfied with the abundance of wildlife in the park and natural features as these attributes have high mean performance scores. High performance scores are probably the case because of the world-renowned protected areas (the Ngorongoro Conservation Area which includes Ngorongoro Crater and Olduvai Gorge, Lake Manyara, Mt Kilimanjaro, Serengeti and Tarangire National Parks) which are 
located in this area. For the tour guide, Table 5.12 shows that tour guides' communication skills have a higher performance score than the ability of the tour guide to speak the visitors' language and tour guides' sense of humour. However, these differences in mean scores are very small, which implies that visitors are satisfied with the performance of the tour guide.

With regard to transportation, visitors are highly satisfied with the performance of the tour operator on the availability of the open roof car for ease of game viewing and the professional and experienced tour driver. The condition of the sightseeing vehicle has a lower mean performance score than the rest of the attributes in the context of transportation. Visitors appreciate the availability of open roof vehicles; these cars are widely used in the northern tourist circuit as they facilitate wildlife viewing. Most of these cars are modified Land Rovers or Land Cruisers that can withstand the terrain and rough roads in the protected areas. Meanwhile, for prearrival services, visitors were more satisfied with tour operators' performance in the context of the availability of the airport pickup services than the provision of information about the package tour and the provision of the information about the country (Table 5.12). One possible reason for higher satisfaction scores for the availability of airport pickup services could be the punctuality of tour operators during airport pickups.

The findings show that visitors approve of the quality of hotel facilities and the location of the hotel. The price of accommodation has a lower mean performance score. Visitors were more satisfied with the quality of the hotel facilities and location because many hotels in the northern tourist circuit are located close or within the protected areas - for example, Ngorongoro Sopa Lodge located within the Ngorongoro Conservation Area. Meanwhile, visitors were more satisfied with clean restaurant environments and the attitude of restaurant staff than with the variety of food. However, visitors could not be described as dissatisfied with the variety of the food. It is simply a matter of them not rating it as highly as many of the other service attributes. 


\subsection{Importance and performance of different components of the guided package tour}

The importance and performance scores presented in the previous sections of this chapter show that the six components of the package tour were important to visitors and tour operators performed highly during the delivery. The means of six components of the guided package tour were tested in pairs (paired $t$-test) to examine whether there was a significant difference between the mean importance and mean performance scores. The difference between the mean importance and performance scores is statistically significant when the p-value is less than or equal to 0.05 (twotailed) and not statistically significant when the p-value is greater than 0.05 (twotailed) (Field, 2009). The p-values (two-tailed) and $t$-values of the six components of the guided package tours are presented in Table 5.13.

Table 5.13: Paired $t$-test for the importance and performance of different components of the guided package tour

\begin{tabular}{|l|c|c|c|}
\hline Components of the package tour & Mean & $\mathbf{t}$ & Sig. (2-tailed) \\
\hline Attractions & .152 & -1.226 & .221 \\
\hline Tour guide & .004 & -.233 & .816 \\
\hline Transportation & .028 & 2.138 & .034 \\
\hline Pre-arrival services & .112 & 2.764 & .006 \\
\hline Accommodation & -.048 & .074 & .941 \\
\hline Food & -.012 & .460 & .646 \\
\hline
\end{tabular}

$\mathrm{t}=(t$-values $) ; \operatorname{Sig}(2$-tailed $)=\mathrm{p}$-value; degree of freedom is 249 in all cases.

The paired $t$-test shows that the mean importance scores of transportation $t(249)=-$ 1.226, $\mathrm{p}=0.034)$ and pre-arrival services $t(249)=2.138, \mathrm{p}=0.006)$ are statistically different $(\mathrm{p}<0.05)$ from their corresponding mean performance scores. Visitors scored the performance of transportation and pre-arrival services higher than the importance of these components. On the contrary, the difference between the mean 
importance and performance scores of attractions, tour guide, accommodation and food are not statistically significant ( $\mathrm{p}>0.05)$ : attractions $t(249)=-1.226, \mathrm{p}=0.221)$, tour guides $t(249)=-0.233, \mathrm{p}=0.816)$, accommodation $t(249)=0.074, \mathrm{p}=0.941)$ and food $t(249)=0.460, \mathrm{p}=0.646)$. The findings suggest that visitors gave similar scores to the importance and performance of attractions, tour guide, accommodation and food. Arguably, the importance of accommodation, attractions, food and tour guide is directly proportional to the levels of satisfaction.

In the same way, the mean importance and mean performance of service attributes of the package tours were further examined by using paired $t$-test (Table 5.14). The calculated means of each attribute were tested in pairs in order to determine whether there is a significant difference between mean importance and performance scores. The findings show that the mean performance scores for the different attributes of the attractions are higher than the importance scores $(\mathrm{p}<0.05)$ for abundance of wildlife in the parks $t(249)=-2.654, \mathrm{p}=0.008)$, natural features $t(249)=-2.824$, $\mathrm{p}=0.005)$, availability of the Big Five $t(249)=-2.663, \mathrm{p}=0.008)$ and Maasai culture $t(249)=-3.652, \mathrm{p}=000)$. This implies that visitors were satisfied with tour operators' performance with regard to attractions. Similarly, the performance scores of tour guides in the context of their ability to speak visitors' language $t(249)=-4.438$, $\mathrm{p}=0.000$ ) and their sense of humour $t(249)=-5.482, \mathrm{p}=0.000)$ were higher than the importance scores. On the contrary, there is no significant difference $t(249)=0.226$, $\mathrm{p}=0.821$ ) between the mean importance and mean performance scores of tour guides in terms of their communication skills. 
Table 5.14: Paired $t$-test for the mean importance and mean performance of different service attributes of the package tour

\begin{tabular}{|c|c|c|c|c|}
\hline \multicolumn{2}{|c|}{ Components of the package tour } & \multirow{2}{*}{$\begin{array}{c}\text { Mean } \\
-.112\end{array}$} & \multirow{2}{*}{$\frac{\mathbf{T}}{-2.654}$} & \multirow{2}{*}{$\begin{array}{c}\begin{array}{c}\text { Sig. } \\
\text { (2-tailed) }\end{array} \\
.008\end{array}$} \\
\hline Attraction & Abundance of wildlife in the parks & & & \\
\hline & Natural features & -.128 & -2.824 & .005 \\
\hline & The availability of the Big Five & -.172 & -2.663 & .008 \\
\hline & The Maasai culture & -.212 & -3.652 & .000 \\
\hline \multirow[t]{3}{*}{ Tour guide } & $\begin{array}{l}\text { Tour guide has good } \\
\text { communication skills }\end{array}$ & .012 & .226 & .821 \\
\hline & Tour guide speaks my language & -.300 & -4.438 & .000 \\
\hline & Tour guide has a sense of humour & -.280 & -5.482 & .000 \\
\hline \multirow[t]{3}{*}{ Transportation } & $\begin{array}{l}\text { Open roof car for ease of game } \\
\text { viewing }\end{array}$ & -.096 & -2.266 & .024 \\
\hline & Professional and experienced driver & .036 & .870 & .385 \\
\hline & Condition of sightseeing vehicles & -.124 & -2.286 & .023 \\
\hline \multirow[t]{3}{*}{$\begin{array}{l}\text { Pre-arrival } \\
\text { service }\end{array}$} & $\begin{array}{l}\text { Availability of airport pickup } \\
\text { service }\end{array}$ & -.104 & -1.829 & .069 \\
\hline & $\begin{array}{l}\text { Provision of information about the } \\
\text { package tour }\end{array}$ & .176 & 2.894 & .004 \\
\hline & $\begin{array}{l}\text { Provision of information about the } \\
\text { country }\end{array}$ & -.096 & -1.560 & .120 \\
\hline \multirow[t]{3}{*}{ Accommodation } & Quality of hotel facilities & -.140 & -2.494 & .013 \\
\hline & Location of the hotel & -.180 & -3.122 & .002 \\
\hline & Reasonable price & .128 & 1.951 & .052 \\
\hline \multirow[t]{3}{*}{ Food } & Clean restaurant environment & .016 & .316 & .753 \\
\hline & Attitude of restaurant staff & -.328 & -5.687 & .000 \\
\hline & Variety of food & -.212 & -3.307 & .001 \\
\hline
\end{tabular}

$\mathrm{t}=(t$-values $) ; \operatorname{Sig}(2$-tailed $)=\mathrm{p}$-value; degree of freedom is 249 in all cases

On the one hand, the findings show that the availability of an open roof car for ease of game viewing $t(249)=-2.266, \mathrm{p}=0.024)$ and the good condition of sightseeing vehicles $t(249)=-2.286, \mathrm{p}=0.023$ ) have significantly higher mean performance scores than mean importance ratings. On the other, the results show no significant difference $t(249)=0.870, \mathrm{p}=0.385)$ between the importance and performance scores for a professional and experienced tour driver. Visitors rated the tour driver as a very 
important aspect of the tour and they are very satisfied with the tour drivers. With regard to pre-arrival service, there is no significant difference between the mean importance and performance scores for the provision of information about the country $t(249)=-1.829, \mathrm{p}=069)$ and the availability of airport pickup $t(249)=-1.560$, $\mathrm{p}=0.120$ ). This finding suggests that these attributes do not have a direct contribution to visitor satisfaction with the guided package tour experience. Therefore visitors are likely to have put similar scores for both importance and performance. The mean performance scores of the tour operators in the context of the provision of information about the package tour are lower than the mean importance scores. This difference is statistically significant $t(249)=2.894, \mathrm{p}=0.004)$. The lower mean performance score for the provision of information about the guided package tour could be caused perhaps by the lack of clear practical information about the tour, for example what to bring during the tour and shopping stops.

The findings show higher mean performance scores for the quality of hotel and location of the hotel than the mean importance scores. The mean difference is statistically significant: quality of hotel facilities $t(249)=-2.494, \mathrm{p}=0.013$ ) and location of the hotel $t(249)=-3.122, \mathrm{p}=0.002)$. Visitors were satisfied with the tour operators' performance with respect to the location of the hotel within which they were placed and the facilities therein. There is no significant difference between the mean importance and mean performance scores for the price of the hotel $t(249)=1.951, \mathrm{p}=0.052)$. Visitors had similar importance and performance scores for the price of accommodation service which suggests that they were satisfied with the price paid. Furthermore, the attitudes of hotel staff and variety of food have higher mean performance ratings than the mean importance ratings. The difference in mean scores is statistically significant: attitude of hotel staff $t(249)=-5.687, \mathrm{p}=0.000)$ and variety of food $t(249)=-3.307, \mathrm{p}=0.001)$. Despite higher mean importance and performance scores for a clean restaurant environment, the difference in means are not statistically significant: $t(249)=0.316, \mathrm{p}=0.753)$. This implies that visitors were pleased with the performance of the hotel in the context of the hygiene of the hotel environment and the way in which hotel staff approached them during the delivery of services. 


\subsubsection{The importance-performance grid}

The importance-performance grid examines how well tour operators performed in offering different services in the guided package tours to visitors. The mean importance and mean performance scores of different attributes of the guided package tour were plotted on the scatter chart: importance on the y-axis and performance on the x-axis (Figure 5.1). All attributes of the guided package tour are concentrated on the upper right corner of the scatter plot. This shows that the majority of respondents scored between important to very important on the importance scale, and satisfied to very satisfied on the satisfaction or performance scale. The grand means for importance and performance were calculated (4.34, grand mean for importance and 4.44, grand mean for performance). The intersection line was placed based on the grand means of the attribute scores to produce the four quadrants of the importance-performance grid.

Figure 5.1: Scatter plot for the mean importance-performance scores for different service attributes of the guided package tour

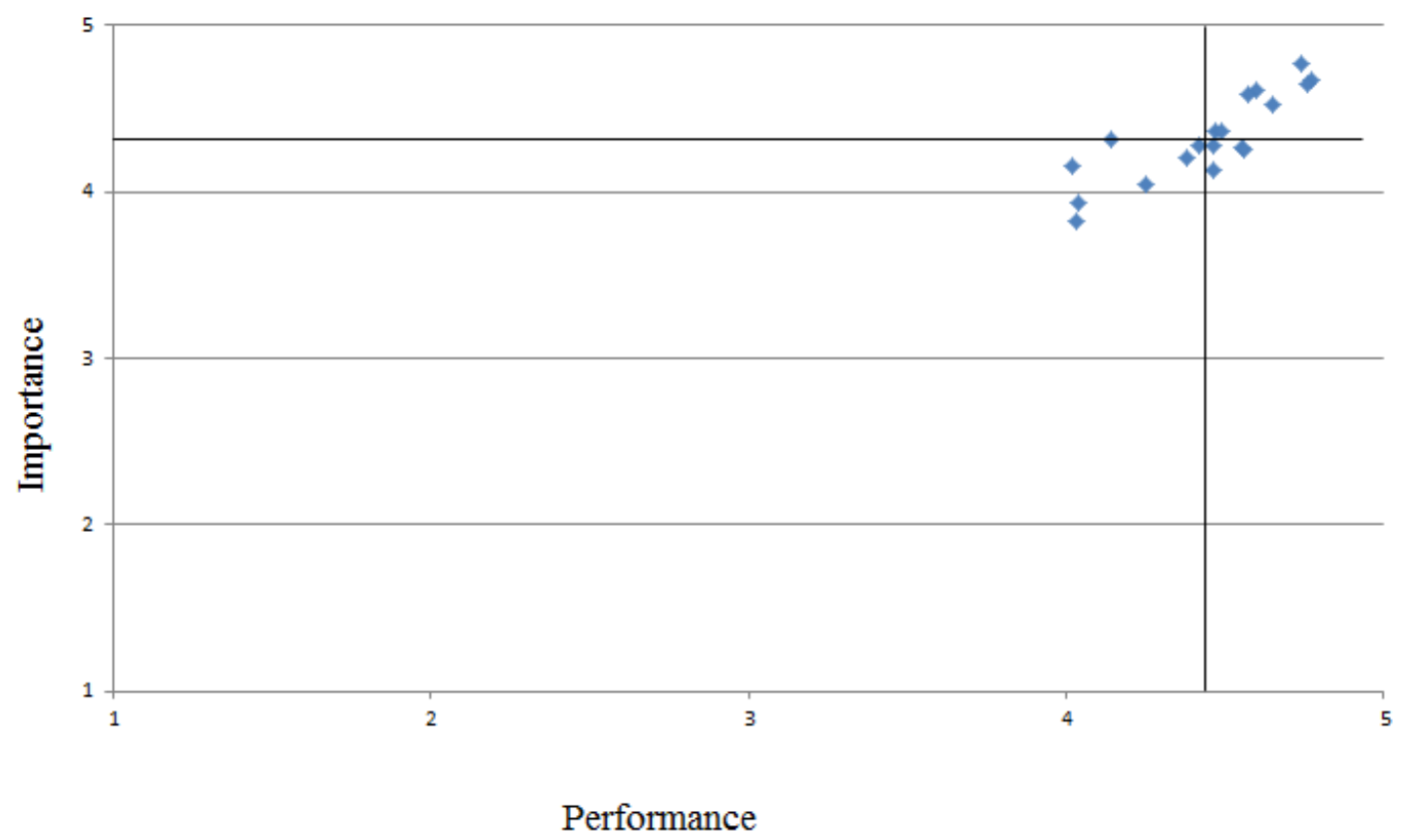

Figure 5.2 presents the findings in an importance-performance grid. Many of the service attributes of the package tour are positioned in the Keep Up Good Work and 
Low Priority quadrants. Four are in the Possible Overkill quadrant and one attribute is in the Concentrate Here quadrant. The findings suggest that tour operators should concentrate on the provision of information about the package tour. This service attribute is located at Concentrate Here which implies that this attribute is very important to visitors but its importance mean is higher than its performance mean. The Keep Up The Good Work quadrant represents attributes that are very important to visitors and being performed satisfactorily during the tour. These attributes include the availability of animals in the parks and the natural features for the attractions component, tour guides' good communication skills, the professional and experienced tour driver, open roof car for ease of game viewing and condition of sightseeing vehicles for transportation, the availability of the airport pickup service and the clean hotel environment. The tour operators have to work hard in order to maintain high levels of performance for attributes with regard to hotel, pre-arrival service, tour guide and transportation. The Ministry of Natural Resources and Tourism should keep up with conservation wildlife and natural features because these attributes are very important and very satisfying.

Figure 5.2: Importance-performance grid for different service attributes of the guided package tour

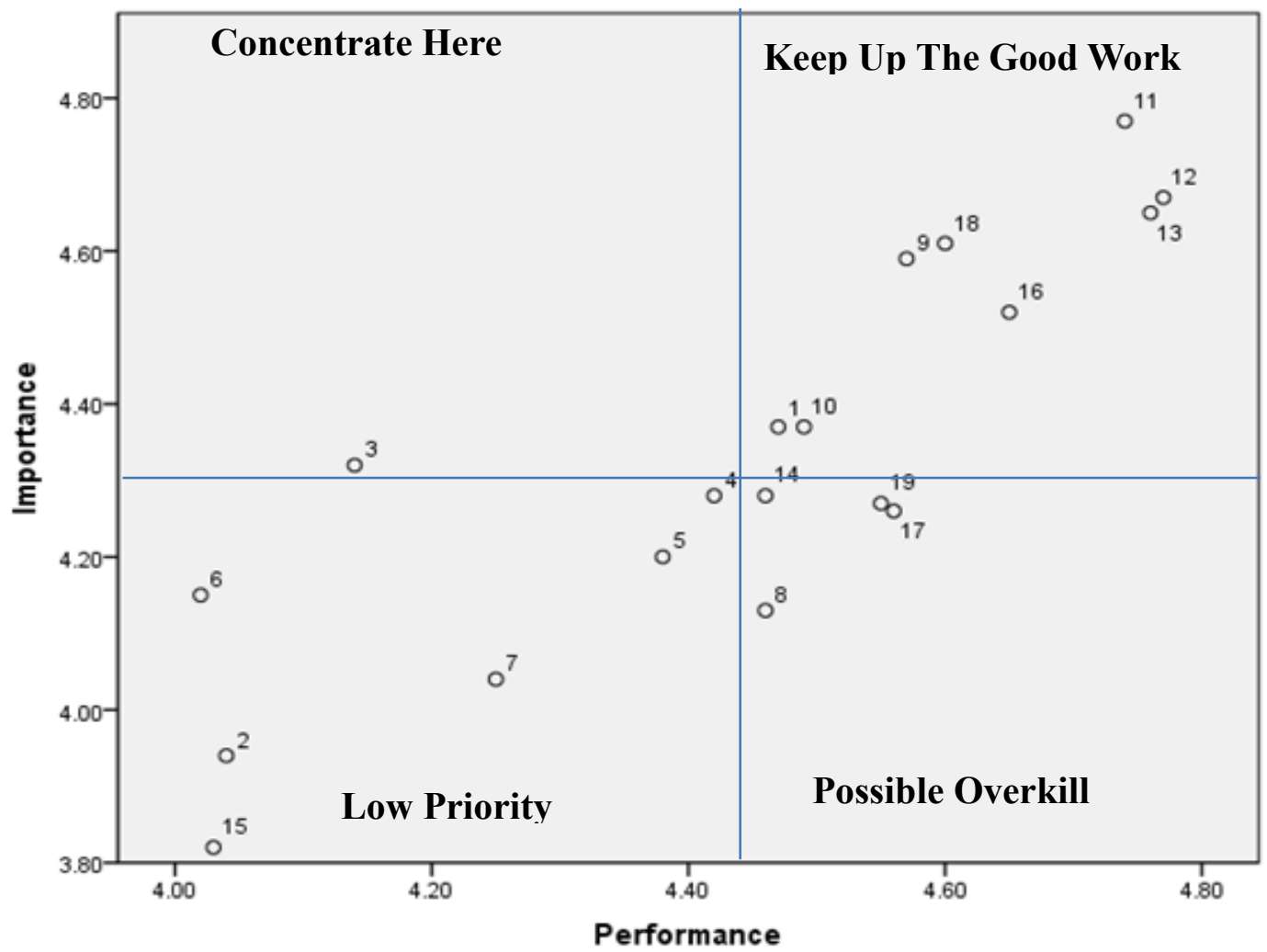


5= Very important/Very satisfied: $1=$ Not important at all/Very dissatisfied

\section{Key}

\begin{tabular}{|c|c|c|c|}
\hline & Keep Up The Good Work & & Possible Overkill \\
\hline 1 & $\begin{array}{l}\text { Availability of airport pickup } \\
\text { service }\end{array}$ & 8 & Attitude of restaurant staff \\
\hline 9 & Clean restaurant environment & 14 & Availability of the Big Five \\
\hline 10 & Condition of sightseeing vehicles & 17 & Tour guide speaks my language \\
\hline 11 & Professional and experienced driver & 19 & $\begin{array}{l}\text { Tour guide has a sense of } \\
\text { humour }\end{array}$ \\
\hline 12 & $\begin{array}{l}\text { Open roof car for ease of game } \\
\text { viewing }\end{array}$ & & Low Priority \\
\hline 13 & Abundance of wildlife in the parks & 2 & $\begin{array}{l}\text { Provision of information about } \\
\text { the country }\end{array}$ \\
\hline 16 & Natural features & 4 & Quality of hotel facilities \\
\hline \multirow[t]{2}{*}{18} & $\begin{array}{l}\text { Tour guide has good } \\
\text { communication skills }\end{array}$ & 5 & Location of the hotel \\
\hline & Concentrate Here & 6 & Reasonable price \\
\hline \multirow[t]{2}{*}{3} & \multirow{2}{*}{$\begin{array}{l}\text { Provision of information about the } \\
\text { package tour }\end{array}$} & 7 & Variety of food \\
\hline & & 15 & Maasai culture \\
\hline
\end{tabular}

The availability of the Big Five (attractions), tour guide speaks visitors' language and tour guides' sense of humour and attitudes of restaurant staff fall in the Possible Overkill category. These attributes are performed well during the tour but they are not as important to visitors. Despite being located in this quadrant, these attributes have importance scores of four and above, therefore they should not be neglected. Furthermore, the location of the hotel, quality of hotel facilities and reasonable price (accommodation), the Maasai culture (attractions), the provision of information about the country (pre-arrival service) and variety of food (food) are located in the Low priority quadrant. This quadrant represents attributes that are not as important to visitors and are not as satisfactorily performed during the tour. As discussed in Chapter Four, IPA measures the relative but not absolute importance and performance of different attributes of the package tour. For example, all three attributes of guided package tours in the context of accommodation are located in this quadrant. These attributes have mean importance and mean performance scores above 4 which show that they are important to visitors and satisfactorily performed during the tour. However, relative to other attributes of the package tours, these 
attributes are less important to visitors and are fairly performed during the tour. The Maasai culture and provision of the information about the country should not be neglected completely because these service attributes have importance scores between 3.8 and four and performance scores greater than four.

\subsection{Areas for improvement}

One of the main objectives of understanding visitor satisfaction with guided package tours is to improve service provision. As discussed in Chapter Two, visitors in the guided package tour setting receive services from different providers. Understanding areas of strength and weakness in service provision provides some insight into service providers on where to focus their attention. In order to understand areas for improvement, an open-ended question "what should be improved in order to offer a more satisfying guided package tour experience?" was asked. Seventy-six respondents (30\%) who participated in this study skipped this question. Twenty-nine respondents $(12 \%)$ responded that they are very satisfied with the guided package tour experience and nothing had to be improved. One hundred and forty-five respondents identified areas that need some improvement in order to offer a very satisfying guided package tour experience. Open-ended answers were evaluated and entered in the SPSS data sheet. Descriptive statistics (valid percentages) were calculated. One hundred and five statements were produced that identify areas that need some improvement.

These statements were further studied and grouped based on the frequency of response. Twenty five areas that need some improvement were identified. The identified areas were then clustered into seven categories in Table 5.15. 
Table 5.15: Areas to be improved

\begin{tabular}{|c|c|c|c|c|}
\hline Tour components & Areas to be improved & $\mathbf{F}(\mathbf{n})$ & $\mathbf{P}(\%)$ & RO \\
\hline \multirow[t]{4}{*}{ Attractions } & Road in the protected areas & 11 & 8 & 3 \\
\hline & $\begin{array}{l}\text { Controlling number of safari cars going to } \\
\text { Ngorongoro Crater }\end{array}$ & 4 & 3 & 14 \\
\hline & Protection of black rhinoceros & 3 & 2 & 17 \\
\hline & Sub total & 18 & 13 & \\
\hline \multirow[t]{4}{*}{ Tour guide } & Language skills & 4 & 3 & 13 \\
\hline & Tour guide should stick to the programme & 2 & 1 & 23 \\
\hline & More information about tipping & 2 & 1 & 24 \\
\hline & Sub total & 8 & 5 & \\
\hline \multirow[t]{3}{*}{ Transportation } & Better seat belts in the safari car & 4 & 3 & 16 \\
\hline & Maintenance of sightseeing vehicles & 3 & 2 & 20 \\
\hline & Sub total & 7 & 5 & \\
\hline \multirow[t]{4}{*}{ Pre-arrival service } & $\begin{array}{l}\text { More information about guided package } \\
\text { tour }\end{array}$ & 24 & 17 & 1 \\
\hline & Punctuality during airport pickups & 5 & 3 & 11 \\
\hline & Better service at the airport & 5 & 3 & 12 \\
\hline & Sub total & 34 & 23 & \\
\hline \multirow[t]{5}{*}{ Accommodation } & Warm water and insects in campsites & 7 & 5 & 6 \\
\hline & Flexibility in hotel bookings & 5 & 3 & 9 \\
\hline & Hygiene at the campsites & 4 & 3 & 15 \\
\hline & Free WI-FI internet services in hotels & 3 & 2 & 18 \\
\hline & Sub total & 19 & 13 & \\
\hline \multirow[t]{4}{*}{ Food } & The quality of food & 14 & 10 & 2 \\
\hline & Availability of local food in restaurants & 10 & 7 & 4 \\
\hline & Better lunch boxes & 5 & 3 & 10 \\
\hline & Sub total & 29 & 20 & \\
\hline \multirow{8}{*}{$\begin{array}{l}\text { Overall tour } \\
\text { experience }\end{array}$} & Reasonable price for safari & 7 & 5 & 7 \\
\hline & More time to enjoy the hotel after safari & 8 & 5 & 5 \\
\hline & More time at the parks & 5 & 3 & 8 \\
\hline & Separating tourist into age classes & 3 & 2 & 21 \\
\hline & More time to interact with Maasai in Bomas & 3 & 2 & 19 \\
\hline & $\begin{array}{l}\text { Field gear for porters and guides climbing } \\
\text { Mt Kilimanjaro }\end{array}$ & 2 & 1 & 22 \\
\hline & Availability of more adventure experiences & 2 & 1 & 25 \\
\hline & Sub total & 30 & 19 & \\
\hline \multicolumn{2}{|l|}{ Total } & 145 & 100 & \\
\hline
\end{tabular}

$\mathrm{F}=$ Frequency $; \mathrm{P}=$ Valid percentage $; \mathrm{RO}=\mathrm{Rank}$ order 
Many of the international visitors who participated in this study suggested that more information about the guided package tour should be provided prior to the tour - for example, information about airport charges, sites to be visited and entry fees to the protected areas. Provision of clear information about the tour would help package tourists plan and budget before the tour. The quality of the food and availability of local food in the restaurant needs some improvement. Availability of local food in the restaurant would provide visitors with more opportunity to experience Tanzanian culture. As noted in section 5.4, that food has the lowest satisfaction scores to other components of the guided package tour. Improvement of the quality of food would increase levels of visitor satisfaction with food.

Visitors identify roads in the protected areas as among the major areas in need of improvement. Roads in the protected areas are weather roads, some of which tend to be damaged during the rainy season. Poor road conditions sometimes limit tourists from exploring the attractions located in the protected areas they are visiting. Regular maintenance will make the roads passable the whole year round and increase comfort during game viewing. Some other areas of improvement include more time to enjoy the accommodation facilities, availability of warm water in the campsite and the price of the guided package tour are some of the major areas that need improvement.

Some areas of improvement suggested by international visitors cannot be addressed by tour operators themselves. These areas need coordination between different stakeholders such as the government, the hotels, the airport authority and immigration. For example, maintenance of roads in protected areas can be done by the governing authority, either Tanzania National Parks Authority or the Ngorongoro Conservation Areas Authority. But the price of the guided package tour, information about the tour, provision of good field gear for tour guides and porters climbing Mount Kilimanjaro is the tour operators' responsibility. The quality of the food, the provision of local food in restaurants and lunch boxes can be done by the hotel. However, tour operators as the primary host of international visitors have a huge role to perform. They are the ones who know exactly what international visitors want when they book a package tour. At the end of the tour, if something went wrong they are the ones that tend to be blamed. 
Overall, cooperation amongst tour operators, policy-makers and other service providers is very crucial in addressing the identified areas of improvement in order to offer a more satisfying guided package tour experience.

\subsection{Summary}

This chapter addresses various dimensions of guided package tours more broadly and the first three research objectives. The chapter assesses the relative importance of different components of package tours in terms of visitor satisfaction, and the relationship between the importance and performance of different components of package tours in the context of visitor satisfaction with a package tour experience. It points out the relative importance of different components of the guided package tour (Table 5.9 and 5.10). Visitor satisfaction with different components of guided package tours is addressed (Table 5.11 and 5.12). The relationship between the importance and performance of different components of the package tours is elaborated on in this chapter by using the importance-performance grid (Figure 5.3). This chapter has also identified the most satisfying aspects of the guided package tour (Table 5.8) as well as areas for improvement (Table 5.15). Overall, visitor satisfaction with the guided package tour experience is analysed together with the satisfaction of the availability of the Big Five.

The majority of international visitors who are visiting Tanzania are first-time travellers to Tanzania. The sample of guided package visitors is dominated by holiday and leisure travellers. The findings show that all components of the guided package tour are very important and they are very satisfied with the performance of the tour provider. Attractions, the tour guide and transportation are very important and very satisfying components of the guided package tour in the northern tourist circuit. Food is the component of the guided package tour that has lowest importance and performance. Chapter Six will examine tour guides more specifically and address the fourth research objective. This chapter will assess the relationship between visitor satisfaction with tour guides and overall satisfaction with the guided package tour experience, as well as addressing the management implications of different levels of visitor satisfaction with the tour guide. 
Chapter six: The importance and performance of different attributes of the tour guide

\section{CHAPTER SIX: THE IMPORTANCE AND PERFORMANCE OF DIFFERENT ATTRIBUTES OF THE TOUR GUIDE}

\subsection{Introduction}

Tour guides play a significant role in visitor experiences in guided package tours (Huang, Hsu \& Chan, 2010). There are several guided package tour studies that specifically address the role of the tour guide (Bowie \& Chang, 2005; Chang, 2006; Geva \& Goldman, 1991; Holloway, 1981; Huang, Hsu \& Chang, 2010; Wong, 2001). This study pays special attention to the role of tour guides. As highlighted in the previous chapter, this chapter addresses the fourth objective of this study:

4. The relationship between visitor satisfaction with the tour guide and overall visitor satisfaction with the guided package tour experience.

This chapter has five sections. The first section examines the relationship between visitor satisfaction with tour guides and overall satisfaction with the guided package tour experience. Pearson's correlation coefficient ( $r$ ) is used to assess this relationship. The second section assesses the importance of the tour guide to visitors. The third section examines visitor satisfaction with the performance of the tour guide. The fourth section analyses the relationship between the importance and performance of tour guides by using paired $t$-tests and the importance-performance analysis (IPA). The fifth and last section addresses the management implications of the research findings.

\subsection{Visitor satisfaction with tour guides and overall satisfaction with the guided package tour experience}

As noted in Chapter Five, visitors have different levels of satisfaction with different components of the guided package tour. Also, the majority of international guided package visitors surveyed were satisfied with their guided package tour experience. But it was not clear how different components of the guided package tour contributed to the overall visitor satisfaction with the tour experience. Pearson's correlation coefficients were used to explore this phenomenon. Pearson's correlation 
coefficients were calculated to examine the relationship between visitor satisfaction with different components of the guided package tour and overall visitor satisfaction with the tour experience. As discussed in Chapter Four, Pearson's correlation coefficients assess the strength of the relationship between two variables (Field, 2009). Visitor satisfaction with different components of the guided package tour was correlated with overall satisfaction with the package tour experience. Pearson's correlation coefficients calculated were significant (two-tailed), $\mathrm{p}<0.01$ (Table 6.1). The findings show that each component of the guided package tour has an impact on overall satisfaction with the guided package tour experience.

Table 6.1: Correlations between visitor satisfaction with different components of the guided package tour and overall satisfaction with the tour experience

\begin{tabular}{|c|c|c|}
\hline \multirow{2}{*}{$\begin{array}{l}\text { Visitor satisfaction with } \\
\text { tour components }\end{array}$} & \multicolumn{2}{|c|}{ Overall visitor satisfaction } \\
\hline & $\begin{array}{c}\text { Pearson's correlation } \\
\text { coefficients }(\mathbf{r})\end{array}$ & Sig. (2-tailed) \\
\hline Tour guide & $.613^{* *}$ & .000 \\
\hline Attractions & $.499^{* * *}$ & .000 \\
\hline Transportation & $.480^{* * *}$ & .000 \\
\hline Food & $.469^{* * *}$ & .000 \\
\hline Accommodation & $.464^{* * *}$ & .000 \\
\hline Pre-arrival services & $.348^{* * *}$ & .000 \\
\hline
\end{tabular}

** Correlation is significant at the 0.01 level (2-tailed), $\mathrm{n}=250$ in all cases

The findings show that visitor satisfaction with the tour guide has the highest correlation with overall satisfaction with the guided package tour experience $(\mathrm{r}=0.613, \mathrm{p}=0.000)$. Pearson's correlation coefficients show that visitor satisfaction with other components of the guided package tour is significantly correlated with the overall satisfaction with the guided package tour experience: attractions $(r=0.499$, $\mathrm{p}=0.000)$, transportation $(\mathrm{r}=0.480, \mathrm{p}=0.000)$, food $(\mathrm{r}=0.469, \mathrm{p}=0.000)$, accommodation $(\mathrm{r}=0.464, \mathrm{p}=0.000)$ and pre-arrival services $(\mathrm{r}=0.348, \mathrm{p}=0.000)$. Correlation coefficients also illustrate that visitors placed high satisfaction scores with regard to their satisfaction with the performance of different components of the guided package tour. 
As seen in Chapter Five, visitors were more satisfied with the performance of attractions followed by, in order, tour guides, transportation, pre-arrival services, accommodation, and finally food. However, correlation analysis shows different results with regard to the component of the guided package tour. Correlation analysis shows that visitor satisfaction with the performance of the tour guide makes the greatest contribution to overall satisfaction with the guided package tour experience (Table 6.1). Visitor satisfaction with the performance of pre-arrival services makes the smallest contribution to the overall visitor satisfaction with the guided package tour experience.

\subsection{The importance of the tour guide}

As discussed in Chapter Two, the major responsibilities of the tour guide during the tour include leading the tour, interpretation of tourist attractions, solving issues that occur during the tour and linking tourists with service providers during the tour. Tour guides play a significant role in making sure that visitors are having a satisfying guided package tour experience. This study assesses twelve attributes of the tour guide (Ap \& Wong, 2001; Huang, Hsu \& Chan, 2010; Wong, 2001). On a 5point Likert scale ( $5=$ Very important; $1=$ Not important at all), visitors were asked to rate the importance of the attributes of tour guides. Overall, the findings show that attributes of the tour guide have mean importance scores greater than four and standard deviations that are less than one. The majority of respondents scored each attribute as either four or five on the 5-point Likert scale. This implies that all attributes assessed are important to visitors, and visitors were consistently ranking the attributes high during the survey. Table 6.2 shows that tour guides' knowledge about wildlife is a very important attribute of tour guides. This attribute has the highest mean importance score of all the attributes of the tour guides. Tour guide's sense of humour has the lowest mean importance score. Tour guide knowledge about wildlife has a higher mean importance score than tour guide's knowledge about local culture. This phenomenon is likely to be caused by the fact that the majority of package visitors visit the northern tourist circuit to see wildlife in their natural habitat. Thus, being accompanied by a tour guide who is knowledgeable about wildlife becomes important. 
Table 6.2: The importance of different attributes of the tour guide

\begin{tabular}{|l|c|c|}
\hline Attributes of the tour guide & Mean & SD \\
\hline Knowledge about wildlife & 4.79 & .44 \\
\hline Focusses on the safety of the tour members & 4.69 & .52 \\
\hline Communication skills & 4.68 & .50 \\
\hline Professional ethic & 4.65 & .57 \\
\hline Care of customers' needs & 4.60 & .57 \\
\hline Good language skills & 4.60 & .59 \\
\hline Knowledge about local culture & 4.50 & .66 \\
\hline Time management skills & 4.40 & .68 \\
\hline $\begin{array}{l}\text { Able to manage interaction between tourists and local } \\
\text { communities }\end{array}$ & 4.37 & .77 \\
\hline Good presentation and interpretation skills & 4.35 & .71 \\
\hline Capable of handling customers' complaints properly & 4.33 & .76 \\
\hline Sense of humour & 4.31 & .79 \\
\hline Average & $\mathbf{4 . 5 2}$ & $\mathbf{. 6 3}$ \\
\hline
\end{tabular}

$\mathrm{n}=250$ in all cases; $\mathrm{SD}=$ Standard deviation

Table 6.2 illustrates that visitors scored tour guides higher on the ability to focus on the safety of the tour members than on the communication skills and their professional work ethic. Safety issues seem to be more important to visitors who are travelling with a guided package tour in a remote wildlife area. As noted previously, the majority of the guided package tourists who participated in this study were firsttime tour takers in the northern tourism circuit. The northern tourist circuit has a high density of animals that are categorised as "dangerous" (buffaloes, lions, leopards and elephants) which raises concern for safety during the tour.

The tour guides' care of customers' needs has a similar mean importance score to the tour guide's good language skills. These two attributes have a higher mean importance score than the tour guide's knowledge about local culture. As discussed in Chapter Two, a tour guide is a professional who is involved in providing services to visitors. For tour guides to excel in this career, they need to have good communication, customer care skills and time management skills. 
Visitors rated tour guides higher on their ability to manage interaction between tourists and local communities than on their presentation and interpretation skills. Tour guides act like a link between local communities and tourist. Tour guides determine who meets with tourists, the duration and level of contact. For example, in the northern tourist circuit of Tanzania, tour guides stop at en-route curio shops in order for tourists to purchase souvenirs. They have the power to decide which area to stop at and time to be spent at each shopping point. Visitors were impressed with the way in which tour guides assume this responsibility during the tour. As discussed in Chapter Two, tour guide's presentation and interpretation skills play a significant role in enhancing the visitor experience and understanding the destination's attractions, culture and the environment they experience-for example, the history of Tanzania, the meaning of different signs in the protected areas and the information provided by local artists. Overall, the findings show that the majority of package visitors who are visiting the northern tourist circuit prefer tour guides who are knowledgeable about wildlife, who have excellent customer service and communication skills as well as adhere to the professional tour guides' work ethic.

\subsection{Visitor satisfaction with the performance of the tour guide}

The performance of tour guides is an interesting phenomenon to assess in the guided package tour setting because tour guides play a significant role in managing the visitor experience by managing interactions between tourists and locals and the environment. Respondents were asked to assess their levels of satisfaction with the performance of tour guides by using 12 service attributes on a 5-point Likert scale (5=Very satisfied; 1=Very dissatisfied). Table 6.3 shows a rank order of the attributes in accordance with their mean performance scores. Tour guides' knowledge about wildlife has the highest mean performance score. The ability of tour guides to handle customers' complaints properly has the lowest mean performance score. However, all attributes assessed have mean performance scores greater than four and standard deviations less than one. The grand mean score of attributes' mean performance scores is 4.51. The findings show that visitors surveyed are satisfied with the performance of tour guides and the majority of them scored either satisfied or very satisfied on a 5-point Likert scale. 
Visitors are more satisfied with the tour guide's knowledge about wildlife than the capacity of the tour guide to handle customers' complaints properly. As noted in Chapter Five, the majority of international guided package visitors who participated in this study came to see wildlife in its natural habitat. It is possible that tour guides who accompanied them were knowledgeable about wildlife, a phenomenon that enabled visitors to learn more about wildlife while seeing it during the tour.

As displayed in Table 6.3, respondents are a little more satisfied with the performance of tour guides with regard to their ability to focus on the safety of the tour members, and a little less satisfied with tour guides' language skills and their knowledge about local culture. One possible reason could be the ability of tour guides to remind visitors about safety measures abroad - for example, to put seat belts on, to avoid feeding animals during the tour and to stay in the car due to the high density of wildlife in the northern tourist circuit.

Table 6.3: Visitor satisfaction with the performance of different attributes of tour guides

\begin{tabular}{|l|c|c|}
\hline Attributes of tour guide & Mean & SD \\
\hline Knowledge about wildlife & 4.72 & 0.57 \\
\hline Focusses on the safety of the tour members & 4.61 & 0.65 \\
\hline Has good language skills & 4.56 & 0.73 \\
\hline Knowledge about local culture & 4.56 & 0.69 \\
\hline Care of customers' needs & 4.54 & 0.68 \\
\hline Professional ethics & 4.54 & 0.71 \\
\hline Communication skills & 4.53 & 0.78 \\
\hline Sense of humour & 4.47 & 0.71 \\
\hline Good presentation and interpretation skills & 4.47 & 0.75 \\
\hline Time management skills & 4.46 & 0.77 \\
\hline $\begin{array}{l}\text { Able to manage interactions between tourists and local } \\
\text { communities }\end{array}$ & 4.38 & 0.81 \\
\hline Capable of handling customers' complaints properly & 4.32 & 0.82 \\
\hline Average & $\mathbf{4 . 5 1}$ & $\mathbf{0 . 7 2}$ \\
\hline
\end{tabular}

$\mathrm{n}=250$ in all cases, $\mathrm{SD}=$ Standard deviation 
Visitors scored tour guides slightly higher with regard to the ability of handling customers' needs and professional ethics compared to the tour guides' communication skills. One contributing factor could be that tour guides in the northern tourist circuit have positive attitudes toward their job, they are friendly and they respect all members of the tour. Also, it is possible that visitors surveyed are impressed with tour guides' communication skills (proficiency in language) which enabled them to interact and engage in different activities during the tour in spite of the fact that they came from different countries with different cultures and languages.

Visitors rated tour guides a little higher regarding their sense of humour, the good presentation and interpretation skills than time management skills. One possible reason could be that good presentation and interpretation skills enabled visitors to understand the significance of the area they visited and raise their awareness about conservation of wildlife. Similarly, it is possible that a good sense of humour has enabled tour guides to appear interesting, friendly and sincere during the tour. Moreover, Table 6.3 demonstrates that visitors rated tour guides slightly higher in the context of the capacity to manage interactions between tourists and local communities than the ability to handle customers' complaints properly. As discussed in Chapter Two, tour guides play a huge role as a cultural interface between visitors and local communities. They disseminate information about the destination and its resources as directed by the governing authority while keeping the established boundaries between tourists and local communities. In general, international visitors surveyed in this study are more satisfied with tour guides with respect to their knowledge about wildlife, their ability to focus on the safety of the tour members, customer service skills and communication skills and professional work ethic.

\subsection{The importance and performance of the tour guide}

As discussed in Chapter Four, respondents answered similarly phrased statements about the importance and performance of tour guides. Visitors were asked to evaluate the importance and performance of various attributes related to the knowledge and actions of tour guides. Having similarly phrased responses for the 
importance and performance of tour guides provided scope for performing paired $t$ tests to assess the differences between the mean scores. The paired $t$-tests suggest that the difference between the mean importance and mean performance scores is statistically significant only if the probability is less than or equal to 0.05 (twotailed), but the difference is considered not statistically significant when the probability is greater than 0.05 (two-tailed) (Field, 2009) (Table 6.4).

Table 6.4: Paired $t$-tests for the importance and performance of different attributes of tour guides

\begin{tabular}{|l|c|c|c|}
\hline Attributes of the tour guide & Mean & T & Sig. (2-ailed) \\
\hline Knowledge about wildlife & -.072 & -1.929 & .055 \\
\hline Care of customers' needs & -.056 & -1.152 & .251 \\
\hline $\begin{array}{l}\text { Capable of handling customers' complaints } \\
\text { properly }\end{array}$ & -.008 & -.150 & .881 \\
\hline Good language skills & -.040 & -.762 & .447 \\
\hline Knowledge about local culture & .056 & 1.107 & .269 \\
\hline Time management skills & .068 & 1.231 & .219 \\
\hline $\begin{array}{l}\text { Able to manage interactions between } \\
\text { tourists and local communities }\end{array}$ & .012 & .221 & .825 \\
\hline Focusses on the safety of the tour members & -.080 & -2.012 & .045 \\
\hline Professional ethic & -.108 & -2.293 & .023 \\
\hline Communication skills & -.152 & -2.941 & .004 \\
\hline Sense of humour & .160 & 3.121 & .002 \\
\hline Good presentation and interpretation skills & .116 & 2.504 & .013 \\
\hline
\end{tabular}

$\mathrm{t}=(t$-value $)$; Sig. $(2$-tailed $)=\mathrm{p}$-value; the degree of freedom is 249 in all cases

Table 6.4 demonstrates that the value for the mean importance score for the following attributes of tour guides is not significantly higher $(p>0.05)$ than the mean performance score. These attributes include tour guides' knowledge about wildlife $t(249)=-1.929, \mathrm{p}=0.055)$, the tour guides' customer care attitude $t(249)=-1.152$, $\mathrm{p}=0.251$ ), the capacity of tour guides to handle customers' complaints properly $t(249)=-0.150, \mathrm{p}=0.881)$ and language skills $t(249)=-0.76, \mathrm{p}=0.447)$. Visitors scored tour guides almost the same with regard to the importance and performance of the 
mentioned attributes. This phenomenon could result from specific knowledge or skills that visitors preferred from tour guides. For example, tour guides' knowledge about wildlife is likely to be assessed based on tour guides' knowledge about animals and their habitat, the history of national parks, their conservation status, different management strategies and laws that govern these areas.

The paired $t$-tests show that the values for the mean performance scores for tour guides with regard to knowledge about local culture $t(249)=1.107, \mathrm{p}=0.269)$, time management skills $t(249)=1.231, \mathrm{p}=0.219)$ and the ability to manage interactions between tourists and local communities $t(249)=0.221, \mathrm{p}=0.825)$ are not significantly higher than the values for the mean importance scores. The paired $t$-tests suggest that visitors gave similar scores with regard to the importance and performance of tour guides in that regard. For example, some aspects of culture like language, food, religion, arts, and dress are important indicators for determining visitor satisfaction with the tour guide.

Furthermore, the difference between the values for mean importance and mean performance scores are significant $(\mathrm{p}<0.05)$ : tour guides' good communication skills $t(249)=-2.941, \mathrm{p}=0.004)$, the tour guides' professional ethic $t(249)=-2.293, \mathrm{p}=0.023)$ and the ability of the tour guide to focus on the safety of the tour members $t(249)=-$ 2.012, $\mathrm{p}=0.045)$. The findings suggest that visitors rated tour guides higher on the importance than performance of these attributes. Even though the values for the mean performance scores are above the grand mean, the performance scores failed to reach the importance that visitors gave to these attributes.

The difference between the mean performance and the mean importance scores are significant: tour guides' good presentation and interpretation skills $t(249)=2.504$, $\mathrm{p}=0.013$ ) and the tour guides' sense of humour $t(249)=3.121, \mathrm{p}=0.002)$. Although these two attributes have the mean performance score below the grand mean score, visitors are more impressed with the performance of tour guides in that regard. Overall, the paired $t$-tests have demonstrated a clear cut difference between the values for the mean importance and mean performance of different service attributes of tour guides. 


\subsubsection{The importance-performance grid for the tour guide}

Visitor satisfaction with the tour guide is a function of both the importance placed on the attributes of the tour guide and judgement of the performance of the attributes in question. The assessment of the importance and performance of the tour guide was conducted after the guided package tour experience. The mean importance and performance scores of the twelve attributes of the tour guide were computed in the previous section (Table 6.2 and 6.3) are graphically presented (Figure 6.1), importance on the $y$-axis and performance on the x-axis. As illustrated on the scatter plot, all attributes are skewed to the upper right corner of the graph. This scatter plot shows that all attributes have high mean importance and mean performance scores.

\section{Figure 6.1: Scatter plot for the mean importance-performance scores for} different attributes of the tour guide

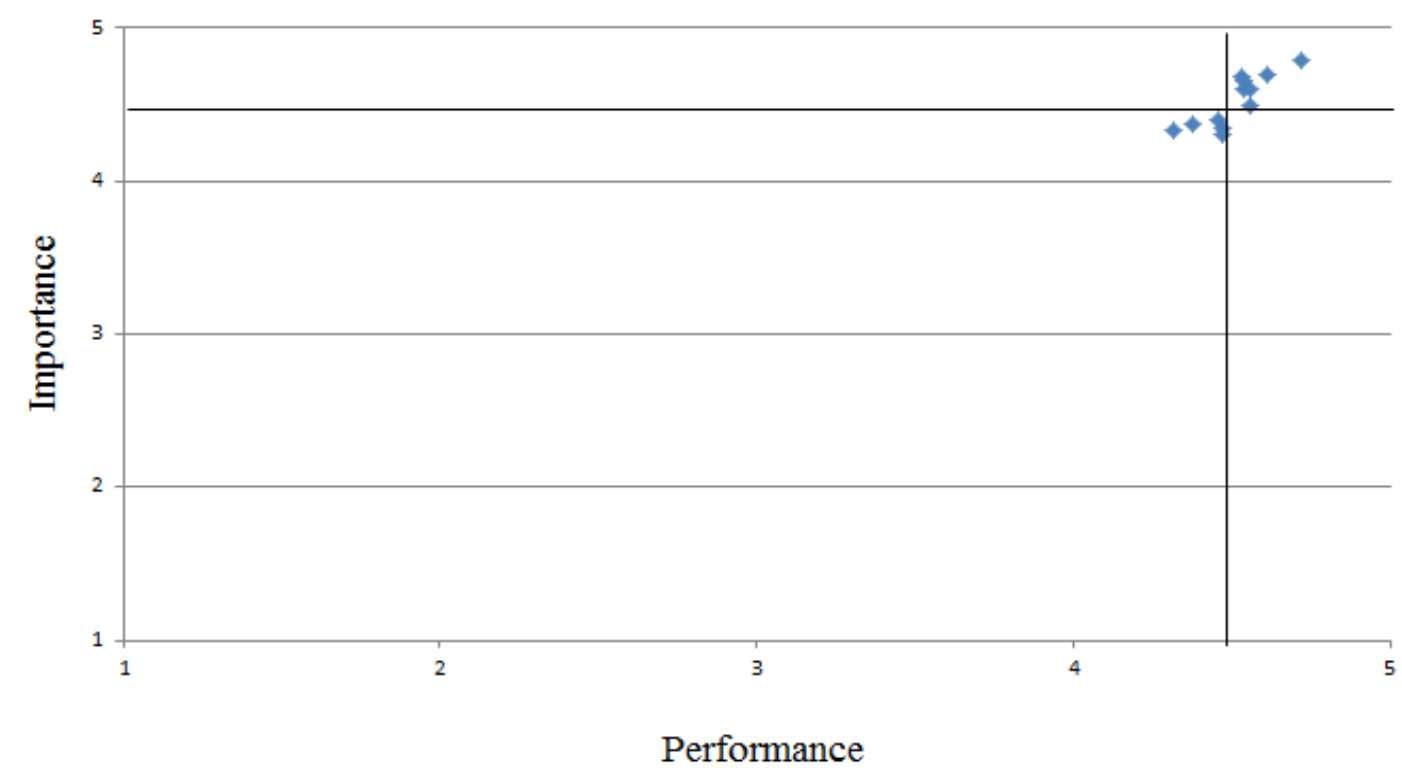

The grand mean importance and mean performance scores (Table 6.2 and 6.3) are rounded to the nearest decimal (4.5) in order to facilitate the placement of crosshairs. The grand means are used to partition the importance-performance grid into four quadrants; Concentrate Here, Keep Up the Good Work, Possible Overkill and Low Priority (Figure 6.2). Twelve attributes of tour guides fall into two quadrants Keep Up the Good Work and Low Priority. Based on the assessed attributes of the tour guide, there is no attribute that is important to visitors and performing 
unsatisfactorily (Concentrate Here). Similarly, no attribute that falls into the Possible Overkill quadrant.

Figure 6.2: Importance-performance grid for different attributes of the tour guide

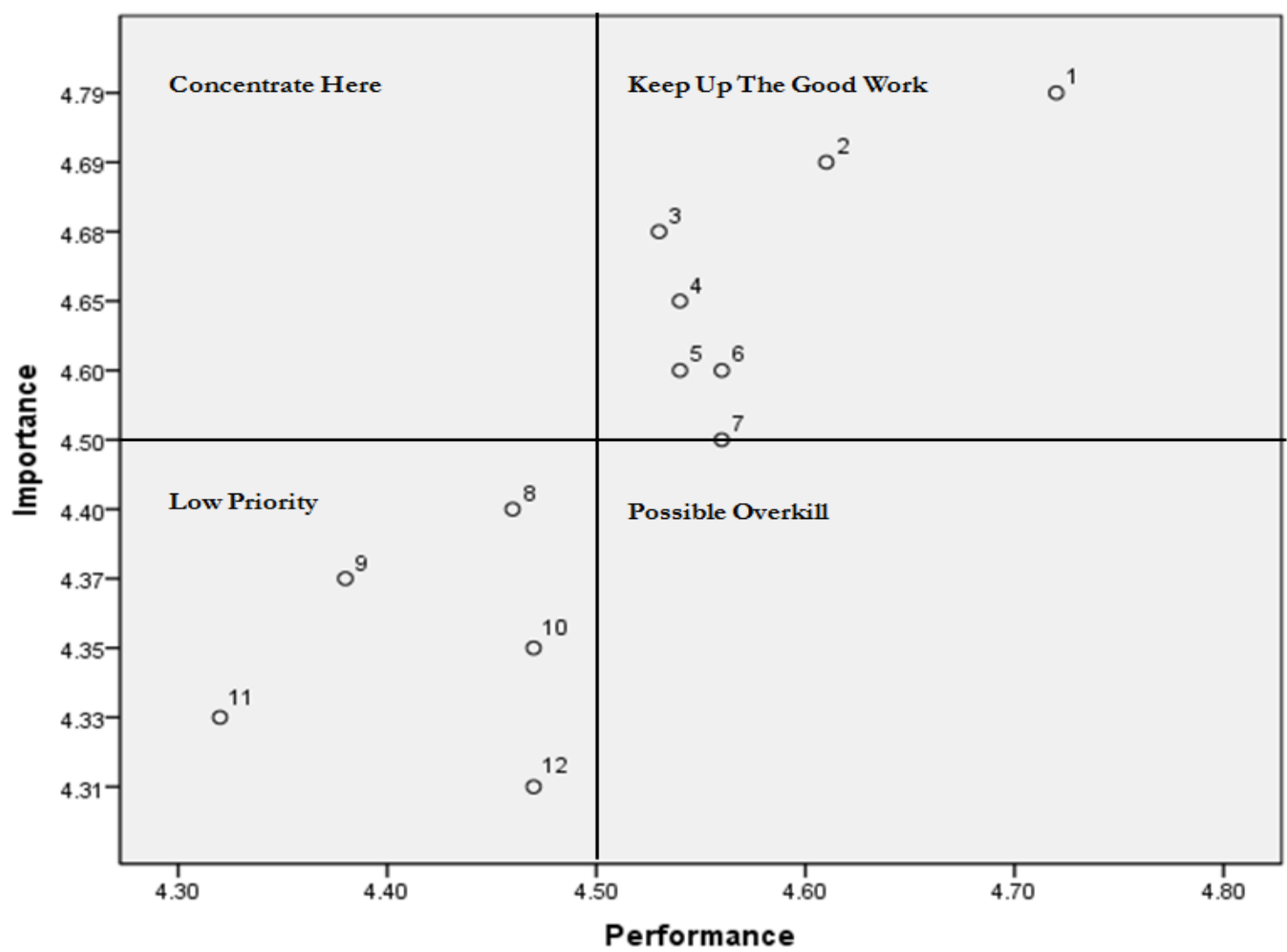

(5=Very important/Very satisfied: $1=$ Not important at all/Very dissatisfied)

\section{Key}

\begin{tabular}{|l|l|c|l|}
\hline & $\begin{array}{l}\text { Keep Up The Good Work } \\
\text { attributes }\end{array}$ & & Low Priority attributes \\
\hline 1 & Knowledge about wildlife & 8 & Time management skills \\
\hline 2 & $\begin{array}{l}\text { Focusses on the safety of the tour } \\
\text { members }\end{array}$ & 9 & $\begin{array}{l}\text { Able to manage interactions } \\
\text { between tourists and local } \\
\text { communities }\end{array}$ \\
\hline 3 & Communication skills & 10 & $\begin{array}{l}\text { Good presentation and interpretation } \\
\text { skills }\end{array}$ \\
\hline 4 & Professional ethic & 11 & $\begin{array}{l}\text { Capable of handling customers' } \\
\text { complaints properly }\end{array}$ \\
\hline 5 & Care of customers' needs & 12 & Sense of humour \\
\hline 6 & Good language skills & \multicolumn{2}{|l|}{} \\
\hline 7 & Knowledge about local culture &
\end{tabular}


Chapter six: The importance and performance of different attributes of the tour guide

The Keep Up The Good Work quadrant contains attributes that are high in both importance and performance scores. Figure 6.1 shows that seven out of twelve attributes of the tour guide are located in this quadrant. The findings suggest that visitors prefer tour guides who are knowledgeable about wildlife and local culture, highly customer focussed, working in accordance with tour guides' professional ethics and have good communication and language skills. A successful tour guide should be able to provide detailed information about visitor attractions and the tour and maintain customer relationships. In order to perform this critical role, knowledge about attractions, good communication skills (language) and positive attitudes about the job are salient factors. The findings suggest that tour operators should employ tour guides who have these characteristics in order to maintain visitor satisfaction with tour guiding.

Figure 6.1 illustrates that five attributes of the tour guide fall into the Low Priority quadrant. These attributes have relatively lower mean importance and mean performance scores. These attributes include the tour guide's time management skills, presentation and interpretation skills, the ability of the tour guide to manage interactions between tourists and local communities, the capacity of the tour guide to handle customers' complaints properly and tour guide's sense of humour. The findings demonstrate that visitors attach a little lower importance to these attributes and they are a little less satisfied with the performance of tour guides with respect to these attributes. A contributing factor for lower importance and performance scores could be the fact that these attributes are difficult to assess because they work well with other attributes. For example, tour guides' presentation and interpretation skills depend much on the knowledge of the tour guide about the topic that he/she presents to visitors. Also, the capacity of tour guides to handle customers' complaints properly can easily be assessed based on the situations that occur during the tour for example loss of visitors' property. Although these attributes are located in the Low Priority quadrant, they have mean importance and mean performance scores between 4.30 and 4.47 on a 5-point Likert scale. Also, Martilla and James (1977) emphasise that IPA technique measures the relative but not absolute importance and performance of the attribute. Relative to other attributes of the tour guide, these 
attributes located in the Low Priority quadrant are a little less important and a little less well performed by tour guides.

\subsection{Summary}

This chapter assesses the relationship between visitor satisfaction with tour guides and the overall satisfaction with the guided package tour experience. The findings show tour guides' knowledge about wildlife and their ability to focus on the safety of the tour members are very important attributes of tour guides. The tour guides' sense of humour and their capability of handling customers' complaints properly are less important attributes relative to other attributes. Visitors were very satisfied with the tour guides' knowledge about wildlife and their ability to focus on the safety of the tour members, and a little less satisfied with the capability of the tour guide to handle customers' complaints properly and their ability to manage interaction between tourists and local communities. The relationship between the importance and performance of the tour guide is examined by using an importance-performance grid. The grid shows that tour guides' knowledge about wildlife, their ability to focus on the safety of the tour members, their communication skills, their professional ethic, their ability to care for customers' needs, tour guides' language skills and tour guides' knowledge about local culture are very important attributes of the tour guides and they are performing very well. These are areas of strength for tour guides, and tour operators should consider these attributes during the hiring of a tour guide.

Moreover, tour guides' time management skills, tour guides' ability to manage interaction between tourists and local communities, tour guides' presentation and interpretation skills, the capacity of tour guides to handle customers' complaints properly and tour guides' sense of humour are attributes of low priority to visitor satisfaction with tour guides. These attributes have slightly lower importance scores and slightly lower performance scores relative to other attributes. Tour guides should not ignore these attributes because they play a significant role in enhancing visitor satisfaction with tour guides. 
Visitor satisfaction with the tour guide has the highest correlation with overall satisfaction with the guided package tour experience of all the components studied. In general, the findings suggest that tour operators should employ tour guides who are knowledgeable about wildlife, have good communication skills, and are customer-care focused as these attributes enhance visitor satisfaction with the tour guide in the guided package tour setting. The management implications identified in this chapter will be further discussed in Chapter Seven. 


\section{CHAPTER SEVEN: DISCUSSION, IMPLICATIONS AND CONCLUSION}

\subsection{Introduction}

Visitor satisfaction with guided package tours is a worthwhile topic to explore because it helps tourism service providers to evaluate their performance and prepare relevant strategies to maintain or improve service provision. Assessing visitor satisfaction with tourism products and services is a challenge because satisfaction is a psychological phenomenon that can be affected by many factors. Also, in the guided package tour setting, visitors receive services from different providers; this phenomenon makes the assessment of visitor satisfaction a bit complicated because visitors are likely to be more satisfied with one provider and less satisfied with the other. This study investigates visitor satisfaction with the guided package tour in the northern tourist circuit of Tanzania. Using importance-performance analysis (IPA) as an analytical tool, five research objectives are addressed.

1. To assess the relative importance of different components of guided package tours in terms of visitor satisfaction.

2. To determine visitor satisfaction with the performance of different components of guided package tours in the northern tourist circuit of Tanzania.

3. To assess the relationship between the importance and performance of different components of guided package tours in the context of visitor satisfaction with a guided package tour experience.

4. To assess the relationship between visitor satisfaction with the tour guide and overall satisfaction with a guided package tour experience.

5. To determine the management implications of visitor satisfaction with guided package tours in the northern tourist circuit of Tanzania.

This chapter discusses the key research findings presented in chapters five and six in relation to the literature. The chapter also reviews the study's five research objectives. The findings of this study provide a broad understanding of the guided package tour conducted in rural wildlife area. IPA has structured the data analysis process, presentation of the research findings and identification of management 
implications of visitor satisfaction with guided package tours in the northern tourist circuit. This chapter is structured based on the objectives of this study. The headings for sections 7.1 to 7.5 are the study's research objectives. The chapter has seven sections. The first section discusses the relative importance of different components of guided package tours in terms of visitor satisfaction. The second section focuses on visitor satisfaction with different components of guided package tours in the northern tourist circuit of Tanzania. The third section presents the relationship between the importance and performance of different components of guided package tours in the context of visitor satisfaction with a guided package tour experience. The fourth section discusses the relationship between visitor satisfaction with the tour guide and overall visitor satisfaction with the guided package tour experience. The fifth section presents the management implications of visitor satisfaction with guided package tours in the northern tourist circuit of Tanzania. This section presents management implication for tour operators, tour guides, protected areas, food providers and accommodation providers. The sixth section deals with areas for future research. The seventh and final section concludes the thesis.

\subsection{The relative importance of different components of guided package tours in terms of visitor satisfaction}

The findings of this study show that the six components of the guided package tour assessed are very important to visitor satisfaction with the tour experience. The attractions, tour guide and transportation are slightly more important components relative to the other components of the guided package tour (Table 5.9). This thesis argues that attractions, tour guides and transportation are the salient features of the guided package tour to international guided package visitors in the northern tourist circuit. In the rural wildlife areas, these components of the guided package tour are relatively more important than accommodation, pre-arrival services and food.

The findings show that the abundance of wildlife in the parks and natural features are very important attributes of the guided package tour in the context of attractions (Table 5.10). As discussed in Chapter Three, wildlife and natural features are the major attractions in the northern tourist circuit that attract about $80 \%$ of international visitors to Tanzania (Okello \& Yerian, 2009). Tanzania is largely promoted as the 
land of Kilimanjaro, Zanzibar and the Serengeti. This promotional slogan emphasises the importance of wildlife and natural features as principle attractions in Tanzania. The higher importance scores for wildlife and natural features (Table 5.10) reflect the needs for the majority of international visitors to see wildlife in its habitat and natural features more so than to the availability of the Big Five and Maasai culture. The findings support the previous studies by Okello and Yerian (2009) that wildlife and natural features are the major attraction for safari package visitors. It is not clear whether visitors who participated in the study are aware of the term Big Five and what constitutes the Big Five. This may have affected their importance score.

The tour guide is a salient component of the guided package tour in the northern tourist circuit of Tanzania. The communication skills of the tour guide are a very important attribute of the tour guide to visitor satisfaction. The communication skills of the tour guide are relatively more important than tour guides' sense of humour and their ability to speak the visitors' language (Table 5.10). The northern tourist circuit receives visitors from different parts of the world. Many of the guided package tours are composed of a mixture of visitors who speak different languages. In that context, communication skills become a salient attribute of tour guides who lead a safari guided package tour. The findings support Bowie and Chang's (2005) argument that the poor communication skills of tour guides can cause misunderstandings between tour guides and tour members. The communication skills of the tour guide are very important in a safari tour because the tour guide is the only person involved in the presentation and interpretation of attractions (wildlife and nature) unlike coach tours in cities where other attractions have site specific person to present and interpret - for example, museums that have collections of art and events.

Moreover, transportation is a very important component of the guided package tour because it facilitates game viewing. The professional and experienced tour driver and open roof car for ease of game viewing are very important attributes under transportation that influence visitor satisfaction with the guided package tour (Table 5.10). The majority of international guided package visitors are first-time safari tour takers in the northern tourist circuit (Table 5.6). Some of them are likely to visit once 
in the lifetime. They expect to have a tour driver who will enable them to fulfil their dreams of seeing as much wildlife as possible without bending laws that govern protected areas. The findings support Okello, D’Amour and Manka's (2008) study that the tour driver is a very important person in the guided tour as he/she has a stake in what to see and what not to see and they can easily influence the duration of game viewing during the tour. The tour driver can drive slowly at areas with a high density of animals for viewing, or take visitors to specific areas in the park that have a high density of animals - for example water points. Likewise, many tour operators use images of open roof cars on their websites when they promote and market their tour. This phenomenon creates a positive image about the importance of safari cars for the performance of the guided package tour in rural wildlife areas. Safari cars carry few passengers which makes it a lot easier for the tour guide to manage visitor behaviour during the tour.

Visitors' perception of the importance of different components of the guided package tour in the northern tourist circuit is largely determined by their travel objectives, needs and travel experience.

\subsection{Visitor satisfaction with different components of guided package tours in the northern tourist circuit of Tanzania}

Visitor satisfaction is one measure of performance; a high visitor satisfaction score reflects a high performance of the attribute measured. In this study satisfaction is used to discuss the performance of different components of the guided package tour. The findings reveal that visitors are very satisfied with all components of the guided package tour. Visitors are very satisfied with attractions followed, in order, by tour guides and transportation (Table 5.11). This confirm McDonnell's (2001, p.7) warning that visitor satisfaction surveys are likely to produce high satisfaction scores simply because "respondents are loathe to state that they have not enjoyed a service that they have freely chosen". The order of satisfaction follows the same order as importance for the three most important components of the guided package tour. This finding shows a close relationship between the importance and performance of different components of the guided package tour with respect to visitor satisfaction. 
The findings support Bowie and Chang's (2005) contention that visitor satisfaction with the guided package tour is determined by soft elements and hard tangible elements of the tour. Attractions and transportation represent the hard part of the guided package tour while the services of the tour guide are the soft element of the guided package tour. These three most satisfying components of the guided package tour are the salient features of a typical safari in the northern tourist circuit (attractions, tour guides and transportation).

The findings show that international guided package visitors who are visiting the northern tourist circuit are very satisfied with the abundance of wildlife in the parks and natural features in the context of attractions (Table 5.12). For example, the plains of the Serengeti and Ngorongoro Crater provide more opportunities for visitors to see wildlife ranging from small to large mammals. The majority of international guided package visitors who visit the northern tourist circuit have high expectations of seeing lots of wildlife in their natural habitat. The ability of these protected areas to meet visitors' expectations yield a high visitor satisfaction. Similar findings were reported by Okello and Yerian (2009) that wildlife is the most satisfying aspect of the tour in the northern tourist circuit of Tanzania. Some of the international guided package visitors expect to observe specific animal behaviour such as mating, hunting, foraging and migration during the tour. For example, watching lions hunting a zebra or cheetah chasing impala, or wildebeest migration in Serengeti National Park are some of the interesting and memorable animal behaviours. Arabatzis and Grigoroudis (2010) contend that high levels of visitor satisfaction reflect the extent to which their expectations have been met.

Likewise, international guided package visitors are more satisfied with the abundance of wildlife in a protected area than the availability of the Big Five as a single group (Table 5.12). The findings show that visitors are more satisfied with the availability of elephants, buffaloes and lions. Visitors are a little less satisfied with the availability of leopards and black rhinoceros in the protected areas visited (Table 5.7). The results affirm Torres-Sovero et al.'s (2012) comment that the ability to see a specific species of animal is a very satisfying aspect of a tour in the protected area. Leopards are active at night and rest during the day time by hiding in the forest or 
bushes. Most of the guided tours in the northern tourist circuit are conducted during the daytime which reduces the chance of seeing them. The black rhinoceros is a critical endangered species and few are left in the wild. This phenomenon results in less chances of seeing them which could result in less satisfaction. Also, the density of wildlife, the behaviour of wildlife and the vegetation structure of protected areas determines game viewing. It is in this regard that the animal species that make the Big Five are not equally available in the protected area. Therefore, Tanzania should focus more of its attention on the protection of black rhinoceros, as an increase in their numbers could yield a high satisfaction among the international visitors in the northern tourist circuit if there are more black rhinoceros they will be more commonly sighted. This study argues that tour operators should not necessarily use the term Big Five in their promotional literature, and it is advisable for them to name the specific animals that will be seen individually.

Beautiful landscapes such as Ngorongoro Crater, Mount Kilimanjaro, Mount Meru and the East African Rift Valley are some of the unique natural features in this circuit. As discussed in Chapter Three these features attract many of the international visitors in the region. The findings indicate that natural features are very important aspects of the guided package tour, and visitors are very satisfied in that regard (Table 5.12). The findings support Okello and Grasty's (2009) study that visitors who are visiting the northern tourist circuit are highly satisfied with beautiful landscapes. The physical features contribute significantly in shaping visitor expectations especially when they are included in the marketing and promotion materials or destination branding. For example, "Tanzania, the land of Kilimanjaro, Zanzibar and the Serengeti" is one of the destination brands used by the Tanzania Tourist Board to promote Tanzania tourism internationally. This destination brand emphasises wildlife and natural features as major tourism attractions in Tanzania. Many of the visitors expect to see those physical features and the ability of the destination to meet visitor expectations enhances their satisfaction. Also, some of the protected areas in the northern tourist circuit offer both wildlife and natural features for example, Mount Kilimanjaro National Park (Mount Kilimanjaro and wildlife), the Ngorongoro Conservation Area (Ngorongoro Crater and wildlife) and Lake Manyara National Park (Lake Manyara, Rift Valley and wildlife). 
The tour guide is the crucial component of the guided package tour that influences the success of the guided package tour experience. The findings show that the communication skills of the tour guide are a very important and very satisfying aspect of the guided package tour. Excellent tour guide communication skills enable visitors to understand commentaries and interpretation of the attractions during the tour. This study affirms Ap and Wong's (2001), Chang's (2006), and Wong's (2001) findings that good communication skills and language proficiency are salient features of visitor satisfaction with tour guides. IPA reveals that international guided visitors are more satisfied with the communication skills of tour guides than to their sense of humour and the ability to speak visitor's own language. Communication skills involve the ability of tour guides to provide clear information so that there is a lack of ambiguity.

Reliable transportation is another salient feature of the guided package tour in the northern tourist circuit of Tanzania. The findings show that visitors are very satisfied with the availability of open roof cars for ease of game viewing and professional and experienced tour drivers (Table 5.12). Visitors are more satisfied with the fact that safari cars are open roofed than to the condition of these cars. Open roof cars are mostly used in the northern tourist circuit; they facilitate game viewing and reduce seat rotation. It is not necessary for tourists to sit in the front in order to have a better view. This increases the perception of equity among the visitors which yields high satisfaction. Bowie and Chang (2005) add that seat rotation during the tour if is not done properly could potentially result in confusion and even conflicts among the tour members. Seat rotation does not appear to be an issue for the safari tours examined in this study.

Moreover, the findings show that a professional and experienced tour driver is a very important attribute of the guided package tour, and visitors are very satisfied with tour drivers' performance. The ability of the tour driver to ensure a safe trip in the parks, locating animals to see in the protected areas influences visitor satisfaction with their performances. Despite the fact that wild animals are mobile in the park, tour drivers can communicate with other drivers and take visitors to places that have 
more animals to view (Okello, D'Amour \& Manka, 2008). The active communication between tour drivers and visitors aboard enhance visitor satisfaction with the tour because visitors can ask the driver to stop or drive slowly during game viewing in the park. However, it is easy for visitors to confuse the role of tour driver and tour guide during the tour if the tour company uses a professional tour guide to assume both roles.

IPA shows that visitors are less satisfied with the performance of food relative to other components of the guided package tour (Table 5.11). Low levels of visitor satisfaction with food are the result of the attitude of the restaurant staff and lack of variety of food in hotels. The safari package tours are conducted in protected areas with few restaurants and hotels unlike coach tour in cities. Visitors on a safari tour have a more limited chance of experiencing a variety of food offered in the destination that they are visiting.

7.3 The relationship between the importance and performance of different components of guided package tours in the context of visitor satisfaction with a guided package tour experience

There is a close relationship between the importance and performance of different components of the guided package tour in determining visitor satisfaction with the tour experience. This relationship is well illustrated using an IPA grid. The IPA grid shows that the abundance of wildlife in the parks, professional and experienced tour driver, open roof car for ease of game viewing, natural features, tour guides' communication skills, clean restaurant environment, the condition of sightseeing vehicles and the availability of an airport pickup service are attributes of the guided package tour that are very important to visitors and performing very well (Figure 5.3). These attributes contribute to visitor satisfaction with the guided package tour in the northern tourist circuit and in the rural wildlife area at large. Visitors are very satisfied with the performance of attributes that are very important to them. The tour operators in the northern tourist circuit should make sure that they maintain the performance of these attributes in order to ensure high visitor satisfaction with guided package tour in the northern tourist circuit of Tanzania. 
The findings show that the availability of the Big Five, tour guides' sense of humour, the ability of the guides to speak the visitor's language and the attitude of restaurant staff are attributes of the guided package tour that are performing very well but they are less important to visitors. These attributes are referred to as possible overkills in the IPA grid. The paired $t$-tests show that the difference between the mean importance and mean performance scores for these attributes is significant (Table 5.14). This study argues that guided tour providers in the northern tourist circuit should not necessarily focus as much of their attention on these attributes because they are slightly less important to visitors relative to other attributes of the guided package tour. They should focus their attention on the provision of information about the guided package tour to visitors taking their tour. This attribute of the guided package tour is very important to visitors but tour operators are not performing this task as well relative to other attributes of the guided package tour.

Moreover, this study argues that the provision of information about the country, the Maasai culture, variety of food, reasonable price of the hotel, the quality of hotel facilities and location of hotel are attributes of low priority in determining visitor satisfaction with guided package tours in the northern tourist circuit. These attributes are a little less important to visitors and they are a little less well performed during the tour. The low importance and performance scores with regard to Maasai culture reflects the overdependence and dominance of wildlife and natural features as the main tourist attractions in the northern tourist circuit. In spite of being a low priority attribute, the $t$-test shows that visitors have scored higher with regard to performance than importance of the Maasai culture during the tour (Table 5.14). This finding supports Okello, D'Amour and Manka's (2009) argument that cultural attractions are poorly promoted in spite of their impact in enhancing visitor satisfaction. This finding shows that there is a potential in cultural tourism if it is well promoted like wildlife.

This study uses IPA for the first time in measuring visitor satisfaction with safari guided package tours. The tool presents four relationships between the importance and performance of different attributes of the safari guided package tour in the northern tourist circuit (Figure 5.3). The high importance and well-performed 
attributes Keep Up The Good Work indicates the major strengths of the guided package tour in the northern tourist circuit of Tanzania. Tour providers should keep up with the current strategies in provision of services to visitors. The little less important attributes but highly performed ones are Possible Overkills while the slightly less important and slightly less well performed attributes represents a Low Priority area. Tour operators should focus their attention on the Concentrate Here quadrant as it demonstrates attributes of the guided package tour that are very important but performed less well by the providers. The Concentrate Here shows that tour providers failed to provide satisfying information about the guided package tour.

\subsection{The relationship between visitor satisfaction with the tour guide and overall visitor satisfaction with the guided package tour experience}

The findings show that visitors are very satisfied with the guided package tour experience in the northern tourist circuit. Visitor satisfaction with the different components of the guided package tour correlates with overall satisfaction with the tour experience (Table 6.1). The overall visitor satisfaction with the guided package tour in the northern tourist circuit is influenced by attractions, tour guides, transportation, accommodation, pre-arrival services and food (Table 6.1). This study supports Geva and Goldman's (1991) findings that overall visitor satisfaction in the guided package tour is determined by all activities and services that visitors accessed during the tour. However, relative to other components of the guided package tour, visitor satisfaction with tour guides has a higher contribution to overall visitor satisfaction with the guided package tour (Table 6.1). This finding supports the argument that the performance of the tour guide contributes significantly to overall visitor satisfaction with the guided package tour experience (Bowie \& Chang, 2005; Chang, 2006; Geva \& Goldman, 1991; Huang, Hsu \& Chan, 2010). The use of Pearson's correlation coefficient (r) provides scope to compare visitor satisfaction with all components of the safari guided package tour with overall visitor satisfaction with the tour experience. This study unlike previous studies (Bowie \& Chang, 2005; Chang, 2006; Geva \& Goldman, 1991; Huang, Hsu \& Chan, 2010) shows the order of contribution of different components of the guided package tour to overall satisfaction with the tour experience. Visitor satisfaction with the tour guide leads 
and is then followed, in order, by visitor satisfaction with attractions, transportation, food, accommodation and pre-arrival services.

To some of the tour companies in the northern tourist circuit, the role of the tour guide in shaping the visitor experience starts immediately after a visitor arrives at the airport. Tour guides are responsible for picking up visitors from the airport, taking them to see animals and bringing them back to the airport after a number of days on the tour. Tour guides provide a comprehensive interpretation of attractions, manage interactions between local communities and tourists and impart knowledge about wildlife to visitors. Tour guides play a significant role in leading the tour and they are key service providers during the tour (Fomiatti, 2008; Geva \& Goldman, 1991). Tour guides link visitors with different service providers and in many cases visitors tend to build trust with the tour guides. The findings are consistent with Huang, Hsu and Chan's (2010, p.29) argument that "in package tour service delivery, tour guide performance is the most salient determinant of tourist satisfaction because most of the service encounters happen between tour guides and tourists". Tour guides play a significant role in influencing visitor satisfaction with the safari guided package tour in the northern tourist circuit. A good relationship between tour guides and members of the tour has a lot of influence on the repeat visitation. Bowie and Chang (2005) found that many of guided package tourists select a specific tour company to travel with based on their previous positive experiences with tour guides/tour leaders. This study found that the safari tours did not have many repeat visitors. However, satisfied customers can spread positive word of mouth recommendations to the potential first-time visitors.

This study argues that pre-arrival services influence visitor satisfaction with the tour experience. However, visitor satisfaction with pre-arrival services makes less of a contribution to overall satisfaction with the guided package tour experience (Table 6.1). With regard to pre-arrival services, this study investigates visitor satisfaction with the availability of an airport pickup service, provision of information about the guided package tour and provision of information about the country (Table 5.12). The findings show that visitors are more satisfied with the availability of airport pickup service than the provision of information about the package tour and the 
country before arrival (Table 5.12). The information about the nature of the tour, areas to be visited, duration of the tour, optional tours, airport taxes and shopping spots is very important to visitors but not sufficiently provided. The findings support Bowie and Chang's (2005) view that the provision of practical information at the beginning of the tour helps to shape visitor expectations, a phenomenon that is crucial for the success of the tour. Tour providers in the northern tourist circuit should make sure that visitors are very satisfied with all components of the guided package tour because satisfaction with every component shapes the overall satisfaction with the tour experience.

\subsubsection{The role of the tour guide in the guided package tour experience}

Visitor satisfaction with tour guides contributes significantly to overall satisfaction with the guided package tour experience in the northern tourist circuit. High visitor satisfaction with tour guides is shaped by tour guides' knowledge, customer care attitudes, skills and their friendliness during the tour (Tables $5.8 \& 6.3$ ). Knowledge about wildlife is a very important attribute of tour guides who are leading guided package tours in the northern tourist circuit because wildlife is the major attraction that forms the objective of travel for the majority of international visitors. Tour guides' knowledge about species of wildlife located in the circuit is a very important attribute of visitor satisfaction with the tour guide. Some attractions in the northern tourist circuit are not well-documented; therefore tour guides are needed as resourceful personnel during the tour. This finding support Okello and Yerian's (2009) result that tour guides' competence in terms of the knowledge about wildlife helps to enhance the quality of the visitor experience. In a rural wildlife area with few information centres, libraries and internet services, tour guides remain as the sole sources of information and knowledge during the tour. This study is consistent with Ap and Wong's (2001), Enoch's (1996), McDonnell's (2001) and Wong's (2001) findings that tour guides who have detailed knowledge about tourist attractions have a high chance of satisfying visitors. Also, many of the visitors who are travelling with the guided package tour have higher expectations of learning from the tour that is guided by a professional guide (Enoch, 1996). Knowledgeable tour 
guides provide an opportunity for visitors to learn more about attractions and the destination that they are visiting.

Another very important and very satisfying aspect of the tour guide is the ability to focus on the safety of tour members (Tables $6.2 \& 6.3$ ). Visitors are highly concerned about their safety during the tour and they are highly satisfied with tour guides' performance in that regard. This study supports Wang et al.'s (2012) findings which show that international visitors are highly concerned about their safety during the tour. Concern about safety for many of the international visitors is exacerbated by a number of factors such as high densities of wildlife in this circuit that are perceived as potentially dangerous and documentaries about how wildlife can be potentially dangerous to humans. For example, some documentaries show a pride of lions attacking humans in the southern part of Tanzania (one such video can be watched on YouTube, and has been viewed 259,096 times). It is in this regard that the Tanzania National Parks Authority and the Ngorongoro Conservation Area Authority encourage game viewing from the safari car. Another factor is the attack on British tourists at one of the wildlife resorts in Kenya by Somali gunmen in 2011 (Gettleman, 2011). Therefore, when this information reaches the potential visitors who have never been to Africa, it is obvious that safety would be a first priority.

Tour guides' professional work ethic is a very important and a very satisfying attribute of tour guiding in the northern tourist circuit of Tanzania. The ability of tour guides to follow rules and regulations that govern protected areas, show loyalty to the company, honesty to the tour members, enthusiasm during presentation and interpretation of attractions, and respect to tour members throughout the tour is significant. The results support Ap and Wong's (2001) finding that the tour guide's work ethic is the key to success in their guiding work. Tour guides' work ethic is a more important attribute of the tour guide than their customer cares skills, language skills and knowledge about local culture. However, the work ethic of the tour guide is a difficult attribute to assess from visitors' perspective because some visitors might not be aware of the term and what is actually meant from a tour guide's point of view. Visitors do not see the tasks performed by tour guides behind the scenes. Similarly, the language skills of tour guides are a crucial attribute to visitor 
satisfaction with the tour guide in the northern tourist circuit. Tour guides' language proficiency enables them to share their knowledge about wildlife and local culture with visitors.

The customer care and empathy of the tour guides is another very important attribute of tour guides that determine visitor satisfaction with the tour guide. The tour guides' positive attitudes toward customers, their willingness to help and their good sense of responsibility are crucial factors that determine visitor satisfaction with the tour guide. Also, the friendliness of the tour guides influences the customer relationship during the tour. The results are consistent with Wong's (2001) and Wang et al.'s (2007) findings that customer relations influence visitor satisfaction with the tour guide. According to the literature, visitor travel experiences with guided package tours have an effect on their satisfaction with tour guides' customer care skills. As discussed in Chapter Two, visitors use their previous experiences as a baseline in assessing the current experience with tour guides. But previous experience is not the case in this study as the majority of visitors are first-time tour takers in the northern tourist circuit (Table 5.6); therefore their assessment is based on current experience and perhaps expectations.

Visitors scored tour guides' knowledge about local culture as a very important attribute of tour guides and visitors were very satisfied with tour guides' performance in that regard (Table 6.2 and 6.3). The competency of tour guides in terms of interpretation of local arts, languages and way of living enhance visitor satisfaction with local culture. Tour guides play a significant role as cultural brokers between visitors and local communities. This finding supports previous studies by Bowie and Chang (2005) and Chang (2006) that tour guides' ability to narrate stories about local history, customs and culture enhance visitor satisfaction with tour guides. Tour guides in this circuit have proved their inter-cultural understanding through their ability to take care of customers' needs during the tour. Also, in an open-ended questionnaire, 12 respondents out of 219 reported that they were satisfied with the wildlife and Maasai culture (Table 5.8). This study encourages tour providers to discuss connections between wildlife and the Maasai people more explicitly. If 
visitors are there to view the wildlife, maybe they would be interested in, say, Maasai perspectives on the wildlife.

Furthermore, the findings of this study reveal attributes of tour guides that are of low priority in determining visitor satisfaction with the tour guide in the northern tourist circuit (Figure 6.2). The attributes of low priority include the capacity of tour guides to handle customers' complaints properly, the ability of tour guides to manage interactions between tourists and local communities, tour guides' sense of humour, tour guides' presentation and interpretation skills and tour guides' time management skills. These attributes are a little less important to visitors and visitors are slightly less satisfied with tour guides' performance. The low priority attributes of tour guides are based on their interpersonal skills and are largely affected by visitors' experiences during the tour. For example, the capacity of tour guides to handle customers' complaints properly is possibly deemed to be of lower priority by visitors because the visitors did not have many complaints.

The performance of tour guides with regard to the presentation and interpretation skills depend on their knowledge in the industry. Pond (1993) argues that the primary function of the tour guide is to educate visitors, and this role is largely determined by their knowledge of the area. It is in this regard that visitors are more satisfied with tour guide knowledge about wildlife and culture than their skills in presentation and interpretation. The findings show that visitor satisfaction with the tour guide cannot be explained by a single attribute, rather a combination of attributes ranging from interpersonal skills, professional skills, knowledge, and customer empathy.

\subsection{The management implications of visitor satisfaction with the guided package tour in the northern tourist circuit of Tanzania}

IPA helps to identify areas of strength and weakness and provides useful information for strategic decision-making. It guides managers on areas that need more attention, areas of strength, possible overkill and low priority areas in a straight forward matrix. Many of the studies about visitor satisfaction with the guided package tour have focused on the role of the tour guide in enhancing visitor satisfaction (Bowie \& 
Chang, 2005; Chang, 2006; Geva \& Goldman, 1991; Holloway, 1981; Huang, Hsu \& Chang, 2010; Wong, 2001). These studies derived the management implications in the context of the tour guide/tour leader. The current study has identified management implications based on the importance and performance of different components of the guided package tour and the literature. The ability to apply this knowledge is a critical point of success in delivering a satisfying guided package tour experience.

\subsubsection{Management implications for the tour operators}

The literature review shows that tour operators place a huge commitment on retaining customers. This study shows that the majority of respondents are first-time tour takers in Tanzania. Thus there is not much customer retention and repeat visitation in the northern tourist circuit of Tanzania. Tour operators are the primary host of international visitors who are taking safari package tours in this circuit. They also play a significant role in linking international visitors who are taking their tour with other tourism providers during the tour. It is in that regard that the guided package tour operators become the first target for blame when guided package visitors are not satisfied with service delivery. Geva and Goldman (1991) argue that tour companies are at a disadvantaged position in most cases as they are not present at every stage of the service delivery in the guided package tour setting. Therefore tour operators should work closely with other stakeholders who are involved in the guided package tour in making sure that visitors receive satisfying services during the tour.

As discussed in Chapter Two, international visitors travel with guided package tours because it is a less expensive way of organizing a holiday that provides more opportunities to visit more attractions at an affordable price. However, in an open ended question, seven out of 145 respondents responded to this question and raised a concern about the price of the tour package (Table 5.15). In order to attain the primary objective of satisfying and retaining visitors, the tour operator should review the price of safari tour packages. Visitors in the guided package tour tend to compare the price they paid and the level of service they received during the tour. Tour 
operators should adjust the price of tour package to reflect value for money. Perhaps tour operators need to more effectively explain to visitors how their prices are derived. This phenomenon will increase the perception of equity.

The tour guide often spends a lot of time with visitors during the tour. International visitors perceive tour guides as a very important component of the guided package tour and they are very satisfied with the tour guides' performance. The findings show that visitor satisfaction with the tour guide has a higher contribution to overall satisfaction with the guided package tour experience. Therefore, in order to maintain a high level of visitor satisfaction with the guided package tour in the northern tourist circuit of Tanzania, this study recommends that tour operators should make sure that they improve tour guides' working environment. This includes attractive remuneration packages, provision of decent field gear and on-the-job training during off-seasons.

The findings show that, on one hand, visitors are less satisfied with the provision of information about the guided package tour and the country in general (Table 5.12). On the other, they are more satisfied with the availability of the airport pickup. Since the airport pickup is mostly conducted by tour guides, tour operators should use the airport pickup as an avenue for informing international visitors about the impending guided package tour. Provision of information about the guided package tour such as the itinerary, shopping spots, services available for visitors with special needs, optional tours and safety and security during the tour before the start of the tour helps visitors to control their expectations about the tour experience. Provision of information prior to the commencement of the guided tour reduces potential conflicts between tourists and tour guides during the tour (Wang et al., 2000). Also, a briefing during the airport pickup would help tour operators to understand various needs from the members of the tour, for example dietary needs (vegetarians/vegans) and maybe a desire to try local food and drink. This phenomenon will create a positive impression about customer care. The ability of tour operators to meet the immediate needs of the guided package tour's clientele results in high satisfaction. 
The findings show that visitors are very satisfied with the availability of wildlife and less satisfied with Maasai culture. High visitor satisfaction with the availability of wildlife reflects the nature of the tourism industry in the northern tourist circuit that is wildlife based. The study reveals that visitors scored Maasai culture as a little less important attribute of the guided package tour, but they are satisfied with the performance (Table 5.14). Therefore, there is a need to link Maasai culture with wildlife or natural feature as a way of promoting and making Maasai culture more interesting to visitors who are on a wildlife tour.

\subsubsection{Management implications for tour guides}

Tour guides play a key role in shaping the visitor experience with the guided package tour. The communication skills of tour guides, especially language proficiency, is vital for their success in leading tours composed of a mixture of international visitors from different parts of the world (Ap \& Wong, 2001, McDonnell, 2001). The results show that the northern tourist circuit of receives visitors from different parts of the world (Table 5.1). North America and Europe are major markets for Tanzanian tourism. In spite of the English language being widely spoken in North America and Europe, visitors from these regions also speak other languages. This phenomenon creates a need for tour guides to have a broad understanding of other languages. The ability of tour guides to speak at least one or more major language (French, German, Spanish or Russian) in addition to English would help to enhance intercultural communication. Wong (2001, p.64) contends that "a successful tour guide needs good communication skills to deliver a highquality service to customers". Therefore, tour guides should make a deliberate effort to learn new languages depending on market demand.

Visitors are very satisfied with tour guides, knowledge of wildlife but they are a little less satisfied with tour guides' presentation and interpretation skills. The presentation and interpretation skills of tour guides help visitors to gain more understanding about the area that they are visiting. Therefore, tour guides should attend courses especially those related to effective communication skills and customer care. Attending courses will provide tour guides with an opportunity to 
learn different presentation and interpretation skills that would help to strengthen their guiding career.

\subsubsection{Management implications for protected areas}

Safari guided package tours in the northern tourist circuit are conducted in protected areas. The finding shows that roads in protected areas are in poor condition according to some visitors (Table 5.15). The roads in protected areas are weather roads and they are vulnerable to heavy rains. Regular road repair would increase the quality of roads in the protected areas and make them passable the whole year which would consequently enhance visitor experience. Fletcher and Fletcher (2003) argue that maintenance of the park increases visitor satisfaction and repeat visitation. Therefore, the Tanzania National Parks Authority and the Ngorongoro Conservation Area Authority should make sure that roads within the areas that they are managing are in good condition all year round.

Similarly, the findings of this study show that international guided package visitors are very satisfied with the availability of wildlife in the protected areas but they are slightly less satisfied with the availability of black rhinoceros (Table 5.7). The black rhinoceros is one of the CITES critically endangered species. There are a few that remain in the northern tourist circuit of Tanzania. Being an endangered mega fauna, black rhinoceros bring the attention of many international visitors to the northern tourist circuit. Better conservation measures would increase the number of black rhinoceros in the northern tourist circuit of Tanzania. Therefore, the increase in number of black rhinoceros in the protected areas would result in a high chance of seeing them during game viewing, a phenomenon that would result in high visitor satisfaction.

\subsubsection{Management implications for food providers}

The findings of this study show that visitor satisfaction with food contributes significantly to overall satisfaction with the guided package tour experience (Table 
6.1). The results further show that visitors are a little more satisfied with clean restaurant environments than the variety of food (Table 5.12). Food preparation and way of eating provides visitors with some insight into the local culture. Quan and Wang (2004, p.299) argue that food provides visitors with a "memorable and enjoyable holiday atmosphere". However, the study shows that visitors are less satisfied with the quality of the food in the northern tourist circuit (Table 5.15). The quality of the food enhances visitor satisfaction with food. Poor quality of food has a high chance of dissatisfying visitors. Visitor satisfaction with the quality of the food is largely affected by visitors' gastronomic experience. This study argues that visitors who are taking guided tours in cities have more opportunities to experience a variety of food due to the availability of a range of restaurants in cities than in the rural wildlife areas.

Therefore, food providers in the northern tourist circuit should make sure that they provide a variety of food in restaurants including local food (based on the demand of tourists) during the tour. The quality of food is largely determined by the preparation, storage and presentation of the food. Food providers should make sure that they use qualified employees to prepare and serve food to visitors. Improving the quality of the food would yield a high visitor satisfaction with their guided package tour experience.

\subsubsection{Management implications for accommodation providers}

The findings show that visitors are more satisfied with the quality of the hotel facilities and the location of the hotel but they are less satisfied with the price (Table 5.12). In the rural wildlife areas there are a few hotels unlike urban areas, and many of these hotels are located close or within the protected areas. This phenomenon puts guided package visitors in a disadvantage position in terms of the selection of accommodation services compared to those who are on city tours. Studies by Bowie and Chang (2005) and Wang et al. (2000) show that in the guided package tour visitor satisfaction with accommodation services is largely determined by visitor travel experience and the perception of equity. Therefore, accommodation providers in the northern tourist circuit should offer their service at a reasonable price. A 
reasonable price for accommodation services would increase visitor satisfaction with accommodation service and overall satisfaction with the tour experience.

\subsection{Areas for future research}

IPA has been widely used to measure satisfaction in the tourism and leisure industry. This study applies this framework for the first time to assess visitor satisfaction with the safari guided package tours in the northern tourist circuit. This tool proves its effectiveness in assessing visitor satisfaction. The findings of this study can be applied by guided package tour operators and policy makers in rural African wildlife areas. As a result of a lack of resources (time and money) the scope of this study was limited to international visitors, a phenomenon that limits the generalisability of these findings. Also, only a single research instrument, a questionnaire, was used to measure satisfaction. This study identifies the following areas that need more attention in the near future:

- There is a need to conduct further study using qualitative research methods (indepth interviews and/or participant observation). Qualitative research enables a researcher to explore why certain phenomenon occurred during the study. This technique would provide more understanding about why visitors were very satisfied with some attributes of the guided package tour and less satisfied with other attributes during the tour. These techniques will bring more information about visitor expectations with the guided package tours conducted in the rural wildlife areas and how these expectations affect visitors' perceptions of the importance and the performance of different components of the guided package tour. Participant observation will provide researchers with an opportunity to assess the performance of tour guides during the tour and how it affects visitor satisfaction.

- There is a need to conduct a focus group discussion with guided package visitors before the tour to develop the important service features of the guided package tour from a visitor perspective. Then one could assess the performance of every feature produced to determine visitor satisfaction with the guided package tour 
experience. The use of focus group discussion will produce service attributes that are area specific and product oriented as well as attributes that affect visitors' needs and decision-making. Also, the focus group discussion would help to identify new attributes of the guided package tour that would be measured in the rural area setting because much of the attributes of the guided package tour discussed in the literature are derived from coach tours conducted in urban areas.

- This study assessed the importance and performance of different components of the guided package tour to visitor satisfaction at the end of the tour. Visitor satisfaction with the guided package tour experience is largely affected by visitors' expectations and experience. There is a need to conduct a study to assess the importance of different components of the package tour before the tour and the performance after the tour. This study will provide more information about visitor expectations and how their expectations affect their satisfaction

- IPA is a very effective measure of visitor satisfaction with the guided package tour. However, the placement of crosshairs creates a challenge as some researchers use the grand mean of the attributes while others use the mean of the scale. This phenomenon affects the placement of the attributes in the grid, analysis of findings, interpretation and the management implications of the research findings (Pearce, 2012). The current study uses the grand means to place the crosshairs. Thus, one could conduct another study using the means of the scale (the midpoints of the $\mathrm{x}$ and $\mathrm{y}$ axis) in positioning of the crosshairs.

- There is a potential bias with regard to the use of the 5-point Likert scale in measuring visitor satisfaction with the guided package tour experience. Visitors have a tendency of scoring four out of five because the majority of them do not want to admit that they made a wrong choice to purchase certain tourism products or they had a bad experience (Pearce, 2005). Therefore a comparative study should be conducted in the northern tourist circuit using the same attributes but a different scale (zero to ten rating scales). The use of an expanded scale would provide more options for visitors to assess satisfaction with guided package tours. 
- Tipping is a pertinent issue in the guided package tour setting. Visitors tend to tip as gratitude based on the quality of the service provision. The amount to tip and who to give a tip to remains a challenge in the guided package tour setting. Tipping behaviour varies from one part of the world to the other. Tipping is perceived to increase the performance of the tour leader or tour guide in the guided package tour but it can also adversely affect satisfaction with the tour (Chang, 2006). Poor methods of collecting tips during the tour are likely to create conflict between tour guides and members of the tour. Tourists do not want tour guides who demand tips. There is a need to assess visitors' perception of tipping in the safari guided package tour setting. Tipping was raised by visitors on an open-ended question as an area for improvement. Two out of eight respondents who gave their views on areas for improvement in the context of tour guides requested more information about tipping (Table 5.15). 


\subsection{Overall conclusion}

The study of visitor satisfaction with the guided package tour in the northern tourist circuit uses IPA for the first time in assessing visitor satisfaction with the safari guided package tour. This study has identified the relative importance of different components of the guided package tour in terms of visitor satisfaction; visitor satisfaction with different components of the guided package tour; the relationship between importance and performance of different components of the guided package tour; and the relationship between visitor satisfaction with the tour guide and overall satisfaction with the guided package tour experience. It also identifies management implications based on the importance and performance of different components of the guided package tour.

The findings show that all components of the guided package tour are very important to visitor satisfaction, but attractions, tour guide and transportation are relatively more important components of the safari guided package tour in the northern tourist circuit. Interestingly, the findings show that visitors are very satisfied with the performance of all components of the guided package tour; attractions, tour guide and transportation rate more highly relative to other components.

The findings suggest that there is a close relationship between the importance and performance of different components of the guided package tour in the context of visitor satisfaction. The study shows that the abundance of wildlife in the parks, professional and experienced tour drivers, open roof cars for ease game viewing, natural features, tour guides' communication skills, clean restaurant environment, condition of the sightseeing vehicles and the availability of the airport pickup service are very important and very satisfying attributes of the guided package tour experience in the northern tourist circuit. In general, international visitors are very satisfied with the performance of tour providers on very important attributes of the guided package tour.

The findings show that overall visitor satisfaction with the guided package tour experience is determined by visitor satisfaction with all components of the guided package tour. The level of contribution to overall visitor satisfaction with the tour 
experience varies among the components of the guided package tour. The study argues that visitor satisfaction with the tour guide makes the highest contribution to overall satisfaction with the tour experience. High visitor satisfaction with tour guides is attributable to their knowledge about wildlife, their ability to focus on the safety of the tour members, their good language skills, their knowledge about local culture, their ability to care about the customers' needs, their communication skills and the ability to adhere to a professional guiding ethic. These attributes of the tour guide are very important to visitor satisfaction with tour guiding and visitors are very satisfied in that regard.

Moreover, the provision of information about the guided package tour needs attention from the tour operators. The information about the guided package tour is a very important aspect of the guided package tour but it is slightly less well performed by the operators. Also, road maintenance in protected areas, the availability of the variety of food in restaurants, protection of wildlife (black rhinoceros) and price of accommodation services are areas of improvement that call for a great cooperation amongst different service providers who are directly or indirectly involved in the provision of various services in the guided package tour.

The study suggests that tour providers in collaboration with the Ministry of Natural Resources and Tourism and the Tanzania Tourist Board should focus their attention on developing and promoting tourism products that feature wildlife and natural features. They are the most important and most satisfying attributes of the guided package tour in the northern tourist circuit for visitors. Maasai culture could be promoted alongside with wildlife/natural features. By doing so many international visitors would become aware of Maasai culture and develop more of an interest to experience this culture during their tour. Assessing visitor satisfaction with the guided package tour experience in the northern tourist circuit brings a new perspective on what makes a satisfying guided package tour experience in a developing country where the primary attraction is the wildlife in their natural habitat. 


\section{REFERENCES}

Ap, J., \& Wong, K. K. F. (2001). Case study on tour guiding: professionalism, issues and problems. Tourism Management, 22(5), 551-563.

Arabatzis, G., \& Grigoroudis, E. (2010). Visitors' satisfaction, perceptions and gap analysis: The case of Dadia-Lefkimi-Souflion National Park. Forest Policy and Economics, 12(3), 163-172.

Azzopardi, E., \& Nash, R. (2013). A critical evaluation of importance-performance analysis. Tourism Management, 35, 222-233.

Bank of Tanzania, (2011). Financial stability report. Available: http://www.bottz.org/Publications/Finstability/FinancialStabilityReportSept_ 2011.pdf (12.12.2012).

Bowen, D., \& Clarke, J. (2002). Reflections of tourist satisfaction research: Past, present and future. Journal of Vacation Marketing, 8(4), 297-308.

Bowie, D., \& Chang, C. J. (2005). Tourist satisfaction: A view from a mixed international guided package tour. Journal of Vacation Marketing, 11(4),303322.

Chang, J. C. (2006). Customer satisfaction with tour leaders' performance: A study of Taiwan's package tours. Asia Pacific Journal of tourism Research, 11(1), 97-116.

Chang, J. C., \& Chiu, C.-P. (2008). Perceptions of package tour providers about tipping in Taiwan. Original Scientific Paper, 56(4), 355-370.

Charnley, S. (2005). From Nature Tourism to Ecotourism? The case of the Ngorongoro Conservation Area, Tanzania. Human Organization, 64(1), 75-88.

Chen, H., Hwang, S., \& Lee, C. (2006). Visitors' characteristics of guided interpretation tours. Journal of Tourism Research, 59(10-11), 1167-1181.

Cohen, E. (1985). The tourist guide the origins, structure and dynamics of a role. Annals of Tourism Research, 12(1), 5-29.

Eagles, P.F.J. (2007). Global trends affecting tourism in protected areas. In R. Bushell \& P.F.J, Eagles (Eds.), Tourism and protected areas: Benefits 
beyond boundaries The Vth IUCN world parks congress (pp. 27-43). CABI, Oxford.

Enoch, Y. (1996). Contents of tour packages: A cross-cultural comparison. Annals of Tourism Research, 23(3), 599-616.

Field, A. P. (2009). Discovering statistics using SPSS: And sex and drugs and rock ' $n$ ' roll.London: SAGE Publications.

Finn, M., Elliot-White, M., \& Walton, M. (2000). Tourism and leisure research methods: Data collection, analysis, and interpretation. Harlow: Longman.

Fletcher, D., \& Fletcher, H. (2003). Manageable predictors of Park visitor satisfaction: Maintenance and personnel. Journal of Park and Recreation Administration, 21(1), 21-37.

Formiatti, D. (2008). Cultural behaviour of European tour groups in Scotland. Scottish Languages Review, 18, 11-30.

Gettleman, J. (2011). Somali Gunmen Attack British Tourists in Kenya. Available: http://www.nytimes.com/2011/09/12/world/africa/12kenya.html?_r=0 (03.01.2013).

Geva, A., \& Goldman, A. (1991). Satisfaction measurement in guided tours. Annals of Tourism Research, 18(2), 177-185.

Global Finance, (2012). Tanzania. Available: http://www.gfmag.com/gdp-data-country-reports/164-tanzania-gdp-countryreport.html\#axzz2FMuctj83.

Holloway, J. C. (1981). The guided tour: A sociological approach. Annals of Tourism Research, 8(3), 377-402.

Huang, S., Hsu. C. H. C., \& Chan, A. (2010). Tour guide performance and tourist satisfaction: A study of the package tours in Shanghai. Journal of Hospitality and Tourism Research, 34(1), 3-33.

Kao, M. C., Patterson, I., Scott, N., \& Li, C. K. (2008). Motivation and satisfaction of Taiwanese tourists who visit Australia: An explanatory study. Journal of Travel \& Tourism Marketing, 24(1), 17-32.

Kweka, J. (2004). Tourism and economy of Tanzania: A CGE analysis. Paper presented at the CSAE conference on Growth, poverty reduction and human development in Africa. Oxford, UK: March. 
Leclerc, D., \& Martin, J. N. (2004). Cultural behaviour of European tour groups in Scotland. International Journal of Intercultural Relations, 28(3-4), 181-200.

Liu,W-Y., Liu,Y-H., Huang, S-Y., \& Wen, H-Z. (2010). Measuring the relationship between customers' satisfaction and cognition: A case of Janfusun Fancyworld in Taiwan. World Academy of Science, Engineering and Technology, 71, 859- 865 .

Lück, M. (2011). An importance-performance analysis of Backpackers at Robinson Crusoe Island Resort, Fiji. Ara (Caribbean) Journal of Tourism Research,43(3), 43-53.

Martilla, J. A., \& James, J. C. (1977). Importance-performance analysis. The Journal of Marketing, 41(1), 77-79.

McDonnell, I. (2001). The role of the tour guide in transferring cultural understanding: working paper no.3, School of leisure, sport and tourism, university of technology, Sydney. Available:

http://www.business.uts.edu.au/lst/downloads/WP03_McDonnell.pdf (13.03.2012).

McMullan, R., \& O’Neill, M. (2010). Towards a valid and reliable measure of visitor satisfaction. Journal of Vacation Marketing, 16(1), 29-44.

Mitchell, J., Keane, J., \& Laidlaw, J. (2009). Making success work for the poor: Package tourism in northern Tanzania. Final report. Available: http://www.odi.org.uk/sites/odi.org.uk/files/odi-assets/publications-opinionfiles/4203.pdf (12.05.2012).

Mkumbo, P. J. (2010). Tourism distribution channels in the northern tourist circuit of Tanzania. Master of Tourism Management Thesis, School of Management, Victoria University of Wellington.

Ministry of Natural Resources and Tourism, (1999). The National Tourism Policy. Dar es Salaam. Author

Ministry of Natural Resources and Tourism, (2002). Tourism master plan strategy and action. Available:

http://www.tzonline.org/pdf/tourismmasterplan.pdf (4/3/2012).

Ministry of Natural Resources and Tourism, (2007). The wildlife policy of Tanzania.Dar es Salaam. Author. 
Ministry of Natural Resources and Tourism, (2011). The 2011 Tourism Statistical Bulletin. Dar es Salaam. Tourism Division.

Ministry of Natural Resources and Tourism, (2012). The 2010 international visitors' survey report. Available:

http://www.bot-tz.org/Publications/TTSS/TTSS-2010.pdf (11/09/2012).

National Bureau Statistics, (2013). Preliminary results for 2012 national census. Available:

http://www.nbs.go.tz/sensa2012/index.php (28.01.2013).

Nelson, F. (2012). Blessing or curse? The political economy of Tourism development in Tanzania. Journal of Sustainable Tourism, 20(3), 359-375.

Oh, H. (2001). Revisiting importance-performance analysis. Tourism Management, 22(6), 617-627.

Okello, M. M., D’Amour, D., \& Manka, G. S. (2008). Tourism attractions and satisfaction of Amboseli National Park, Kenya. Tourism Analysis, 13(4), 373-386.

Okello, M. M., \& Grasty, K. (2009). The role of large mammals and protected areas to tourist satisfaction in the northern circuit, Tanzania. Tourism Analysis, 14(5), 691-697.

Okello, M. M., \& Yerian, S. (2009). Tourist satisfaction in relation to attractions and implication for conservation in the protected areas of the northern circuit, Tanzania. Journal of Sustainable Tourism, 17(5), 605-625.

Pearce, D. G. (2012). Frameworks for tourism research. Cambridge, MA: CAB International.

Pearce, P. L. (2005). Tourist behaviour: Themes and conceptual schemes. Clevedon: Channel View Publications.

Philemon, B. (2009). Local tourism doubles despite global economic crunch. Available:

http://www.safarilands.org/index.php/tourism/more/local_tourism_doubles_d espite_global_crunch/(12.08.2012).

Pizam, A., \& Ellis, T. (1999). Customer satisfaction and its measurement in hospitality enterprises. International Journal of Contemporary Hospitality Management, 11(7), 326-339. 
Pizam, A., \& Mansfeld, Y. (1999). Consumer behavior in travel and tourism. New York: Haworth Press.

Pond, L. K. (1993). The professional guide: dynamics of tour guiding. New York, USA: Van Nostrand Reinhold.

Quan, S., \& Wang, N. (2004). Towards a structural model of the tourist experience: An illustration from food experiences in tourism. Tourism Management, 25(3), 297-305.

Reisinger, Y., \& Steiner, C. (2006). Reconceptualising interpretation: The role of tour guides in authentic tourism. Current Issues in Tourism, 9(6), 481-498.

Reynolds, P., \& Braithwaite, D. (2001). Towards a conceptual framework for wildlife tourism. Tourism Management, 22(1), 31-42.

Ritchie, B, W., Burns, P., \& Palmer, C. (2005). Tourism research methods: Integrating theory with practice. Cambridge, MA: CABI Pub.

Ross, E. D., \& Iso-Ahola, S. (1991). Sightseeing tourists' motivation and satisfaction. Annals of Tourism Research, 18(2), 226-237.

Runyoro, V. A., \& Kidegesho, J. R. (2010). Coping with the effect of global economic recession on tourism industry in Tanzania: Are we prepared? Journal of Tourism Challenge and Trends, 3(1), 95-110.

Salazar, N. B. (2006). Touristifying Tanzania local guides, global discourse. Annals of Tourism Research, 33(3), 833-852.

Sirgy, M. J., Cole, D., Kosenko, R., Meadow, H. L., Rahtz, D., Cicic, M., Jin, G. S., Yarsuvat, D., Blenkhorn, D. L., \& Nagpal, N. (1995). A life satisfaction measure: Additional validational data for congruity life satisfaction measure. Social Indicator Research, 34(2), 237-259.

Swarbrooke, J., \& Horner, S. (1999). Consumer behaviour in tourism. Oxford: Butterworth-Heinemann.

Tanzania Invest, (2011). Tanzania Tourism Sector Report 2011. Available: http://www.tanzaniainvest.com/tanzania-tourism-sector (18.11.2012).

Tanzania Invest, (2012). Tanzania to attract 1.6 million tourists by 2015. Available: http://www.tanzaniainvest.com/tourism/news/475-tanzania-to-attract-16million-tourists-by-2015 (10/12/2012). 
Tanzania review, (2011). Celebrating 50 years of independence. Available: http://www.scribd.com/doc/56698796/Tanzania-Review-2011-2012 (3/12/2012).

Tonge, J., Moore, S. A., \& Taplin, R. (2011). Visitor satisfaction analysis as a tool for park managers: A review and case study. Annals of Leisure Research, 14(4), 289-303.

Torres-Sovero, C., González, J. A., Martín-López, B., \& Kirkby, C. A. (2012). Social- ecological factors influencing tourist satisfaction in three ecotourism lodges in the southern Peruvian Amazon. Tourism Management, 33(3), 545552.

UNWTO (2011). Annual report 2011. Available:

http://www2.unwto.org/en/publication/unwto-annual-report-2011

$(6 / 01 / 2013)$

UNWTO, (2012). International tourism hits one billion: Available:

http://media.unwto.org/en/press-release/2012-12-12/international-tourismhits- one-billion (12/01/2013).

United Republic of Tanzania, (2012). The Tanzania five years development plan 2011/2012-2015/2016.Unleashing Tanzania's latent growth potential. Available:

http://www.tanzania.go.tz/pdf/FYDP-2012-07-26.pdf (10/01/2013).

Veal, A. J. (2006). Research methods for leisure and tourism: A practical guide. Harlow, England: FT Prentice Hall.

Wade, D. J., \& Eagles, P. F. J. (2003). The use of importance-performance analysis and market segmentation for tourism management in parks and protected areas: An application to Tanzania's National Parks. Journal of Ecotourism, 2(3), 196-212.

Walle, A. H. (1997). Quantitative versus qualitative tourism research. Annals of Tourism Research, 24(3), 524-536.

Wang, K-C., Hsieh, A.-T., \& Huan, T.-C. (2000). Critical service features in group package tour: An exploratory research. Tourism Management, 21(2), 177-189.

Wang, K.-K., Hsieh, A.-T., Chuo, S.-H., \& Lin, Y.-S. (2007). GPTCCC: An instrument for measuring group package tour service. Tourism Management, 28(2), 361-376. 
Wang, C.-K., Ma, A.-P., Hsu,T.-M., Jao.C.-P. A., \& Lin,W.-C. (2012). Seniors' perceptions of service features on outbound group package tours. Journal of Business Research (In Press, Corrected Proof).

World Economic Forum, (2011). Travel \& Tourism Competitiveness Report 2011. Available: http://www.weforum.org/reports/travel-tourism-competitivenessreport-2011 (09/10/2012).

World Heritage Convention, (2012). The United Republic of Tanzanian's World Heritage Sites. Available:

http://whc.unesco.org/en/statesparties/tz (06/12/2012).

Wong, A. (2001). Satisfaction with local tour guides in Hong Kong. Pacific Tourism Review, 5(1), 59-67.

World Federation of Tour Guide Association, (2003). What is a tour guide? Available:

http://wftga.org/tourist-guiding/what-tourist-guide (06/01/2012).

Xu, J. B., \& Chan, A. (2010). Service experience and package tours. Asia Pacific Journal of Tourism Research, 15(2), 177-194.

Yüksel, A., \& Yüksel, F. (2001). Measurement and management issues in customer satisfaction research: Review, critique and research agenda: Part one. Journal of Travel and Tourism Marketing, 10(4), 47-80. 


\section{APPENDIX: QUESTIONNAIRE}

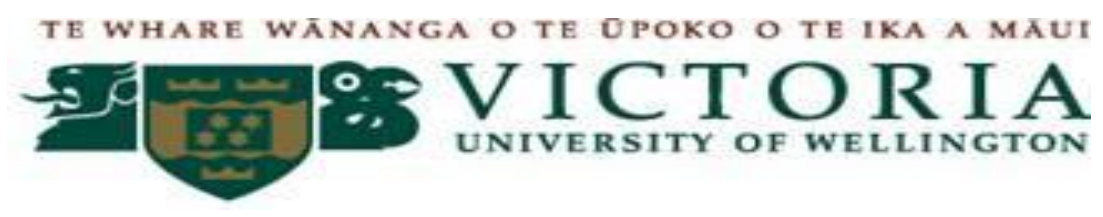

QUESTIONNARE INFORMATION SHEET

\section{VISITOR SATISFACTION WITH GUIDED PACKAGE TOURS IN THE NORTHERN TOURIST CIRCUIT OF TANZANIA}

My name is Elisante Ombeni Leguma and I am a Master's student at Victoria University of Wellington in New Zealand. My Master's thesis examines package tours in the northern tourist circuit of Tanzania. In particular, I am interested in visitors' satisfaction.

I would like to invite you to participate in this research project by completing the attached questionnaire. This questionnaire will take approximately 10 to 12 minutes to complete. You will not be asked to provide your name or contact details. Data will be coded and remain in my custody, it will be destroyed one year after the completion of the research. The results will be available at the Victoria University of Wellington library only after my Master's thesis has been completed. The results of this research will be shared with the package tour company you are travelling with.

Ethical approval for this research has been obtained from the university. The data I collect will only be reported in aggregate form. By completing this questionnaire you agree to the terms outlined above. You can choose to discontinue the questionnaire at anytime during its completion. Incomplete questionnaires will be destroyed. After completing the questionnaire, please put it in the box provided in the sightseeing vehicle.

Your participation in the research is very much appreciated. You are welcome to take this information sheet with you by removing it from the questionnaire. If you need any further clarification please do not hesitate to contact me or my supervisors

$\begin{array}{lll}\text { Mr. Elisante.O. Leguma } & \text { Dr. Adam Weaver } & \text { Dr. Julia Albrecht } \\ \text { Student Researcher } & \text { Supervisor } & \text { Supervisor } \\ \text { School of Management } & \text { School of Management } & \text { School of Management } \\ \text { Victoria University of } & \text { Victoria University of } & \text { Victoria University of } \\ \text { Wellington } & \text { Wellington } & \text { Wellington } \\ \text { elisante.leguma@vuw.ac.nz } & \text { adam.weaver@vuw.ac.nz } & \text { julia.albrecht@vuw.ac.nz }\end{array}$

\section{QUESTIONS}




\subsection{Length of stay and travel behaviour}

1.1. Have you visited Tanzania before? Yes $\bigcirc$ No $\mathrm{O}$

1.2. What is your reason for visiting Tanzania? (Please tick one option from the table below)

\begin{tabular}{lccccc}
\hline Purpose of visit & $\begin{array}{c}\text { Holiday } \\
\text { and } \\
\text { Leisure }\end{array}$ & $\begin{array}{c}\text { Visiting } \\
\text { friends and } \\
\text { relatives }\end{array}$ & Business & Conference & $\begin{array}{c}\text { Other (please } \\
\text { specify) }\end{array}$ \\
\hline Please select & $\mathrm{O}$ & $\mathrm{O}$ & $\mathrm{O}$ & $\mathrm{O}$ & \\
\hline
\end{tabular}

1.3 How long are you planning to stay in Tanzania? (Please select one option from the table below)

\begin{tabular}{lccccc}
\hline Length of Stay in Days & 1-3 Days & 4-7 Days & 8-11 Days & 12-15 Days & 16+Days \\
& & & & & 0 \\
\hline Please select & 0 & 0 & 0 & 0 & 0 \\
\hline
\end{tabular}

\subsection{Your current package tour}

A package tour is a type of tour where all important services are organized or provided by a tour operating company. For example, booking the flight, pre arrival services, accommodation, food, tour guide, ground transport and attractions are all included.

2.1. Have you visited Tanzania with a package tour before? Yes $\bigcirc$ No $\bigcirc$

2.2. What is the length of your package tour in the northern tourist circuit of Tanzania?

(Please tick one option from the table below)

\begin{tabular}{llllll}
\hline Length of the Tour in Days & 1-3 Days & 4-7 Days & 8-11 Days & $\begin{array}{c}12-15 \\
\text { Days }\end{array}$ & $16+$ Days \\
\hline Please select & 0 & 0 & 0 & 0 & 0 \\
\hline
\end{tabular}


2.3. How important are the following components of a package tour to your satisfaction with a tour experience? (Please tick one option for every statement)

\begin{tabular}{|c|c|c|c|c|c|c|}
\hline & $\begin{array}{l}\text { Component of the } \\
\text { package tour }\end{array}$ & $\begin{array}{l}\text { Very } \\
\text { important }\end{array}$ & Important & $\begin{array}{l}\text { Not } \\
\text { sure }\end{array}$ & $\begin{array}{l}\text { Not } \\
\text { important }\end{array}$ & $\begin{array}{l}\text { Not } \\
\text { important at } \\
\text { all }\end{array}$ \\
\hline 1 & $\begin{array}{l}\text { Pre-arrival services (e.g. } \\
\text { airport pickup) }\end{array}$ & $\mathrm{O}$ & $\mathrm{O}$ & 0 & $\mathrm{O}$ & 0 \\
\hline 2 & Accommodation & $\mathrm{O}$ & $\mathrm{O}$ & O & O & O \\
\hline 3 & Food & 0 & 0 & 0 & 0 & 0 \\
\hline 4 & $\begin{array}{l}\text { Transportation } \\
\text { (sightseeing vehicles) }\end{array}$ & 0 & O & O & 0 & 0 \\
\hline 5 & $\begin{array}{l}\text { Attractions (e.g. } \\
\text { wildlife, culture) }\end{array}$ & O & O & 0 & O & O \\
\hline 6 & $\begin{array}{l}\text { Tour guide (e.g. } \\
\text { language skills, } \\
\text { communications skills ) }\end{array}$ & O & O & O & O & O \\
\hline
\end{tabular}


2.4. How important are the following components of a package tour to your satisfaction with a tour experience? (Please tick one option for every statement)

\begin{tabular}{|c|c|c|c|c|c|c|}
\hline & $\begin{array}{l}\text { Component of the } \\
\text { package tour }\end{array}$ & $\begin{array}{l}\text { Very } \\
\text { important }\end{array}$ & Important & $\begin{array}{l}\text { Not } \\
\text { sure }\end{array}$ & $\begin{array}{l}\text { Not } \\
\text { important }\end{array}$ & $\begin{array}{l}\text { Not } \\
\text { important } \\
\text { at all }\end{array}$ \\
\hline \multirow[t]{4}{*}{1} & Pre-arrival services & & & & & \\
\hline & $\begin{array}{l}\text { Availability of airport } \\
\text { pickup service }\end{array}$ & $\mathrm{O}$ & $\mathrm{O}$ & O & $\mathrm{O}$ & O \\
\hline & $\begin{array}{l}\text { Provision of information } \\
\text { about the country }\end{array}$ & 0 & 0 & 0 & 0 & 0 \\
\hline & $\begin{array}{l}\text { Provision of information } \\
\text { about the package tour }\end{array}$ & 0 & 0 & 0 & 0 & 0 \\
\hline \multirow[t]{4}{*}{2} & Accommodation & & & & & \\
\hline & Quality of hotel facilities & $\mathrm{O}$ & $\mathrm{O}$ & $\mathrm{O}$ & $\mathrm{O}$ & $\mathrm{O}$ \\
\hline & Location of the hotel & O & 0 & 0 & 0 & 0 \\
\hline & Reasonable price & $\mathrm{O}$ & O & $\mathrm{O}$ & $\mathrm{O}$ & $\mathrm{O}$ \\
\hline \multirow[t]{4}{*}{3} & Food & & & & & \\
\hline & Variety of food & $\mathrm{O}$ & $\mathrm{O}$ & $\mathrm{O}$ & $\mathrm{O}$ & O \\
\hline & Attitude of restaurant staff & 0 & 0 & 0 & 0 & 0 \\
\hline & $\begin{array}{l}\text { Clean restaurant } \\
\text { environment }\end{array}$ & $\mathrm{O}$ & $\mathrm{O}$ & $\mathrm{O}$ & $\mathrm{O}$ & $\mathrm{O}$ \\
\hline \multirow[t]{4}{*}{4} & Transportation & & & & & \\
\hline & $\begin{array}{l}\text { Condition of the } \\
\text { sightseeing vehicles }\end{array}$ & $\mathrm{O}$ & 0 & 0 & 0 & 0 \\
\hline & $\begin{array}{l}\text { Professional and } \\
\text { experienced driver }\end{array}$ & O & $\mathrm{O}$ & $\mathrm{O}$ & $\mathrm{O}$ & $\mathrm{O}$ \\
\hline & $\begin{array}{l}\text { Open roof car for ease of } \\
\text { game viewing }\end{array}$ & O & $\mathrm{O}$ & $\mathrm{O}$ & $\mathrm{O}$ & $\mathrm{O}$ \\
\hline \multirow[t]{5}{*}{5} & Attractions & & & & & \\
\hline & $\begin{array}{l}\text { Abundance of wildlife in } \\
\text { the parks }\end{array}$ & $\mathrm{O}$ & $\mathrm{O}$ & $\mathrm{O}$ & $\mathrm{O}$ & $\mathrm{O}$ \\
\hline & $\begin{array}{l}\text { The availability of the Big } \\
\text { Five(Buffalo, Elephant, } \\
\text { Leopard, Lion and } \\
\text { Rhinoceros) }\end{array}$ & & & & & \\
\hline & The Maasai culture & O & O & O & O & O \\
\hline & $\begin{array}{l}\text { Natural features (e.g. } \\
\text { Ngorongoro crater, } \\
\text { Mt Kilimanjaro) }\end{array}$ & O & O & O & 0 & 0 \\
\hline \multirow[t]{4}{*}{6} & Tour guide & & & & & \\
\hline & $\begin{array}{l}\text { Tour guide speaks my } \\
\text { language }\end{array}$ & 0 & 0 & O & 0 & 0 \\
\hline & $\begin{array}{l}\text { Tour guide has good } \\
\text { communication skills }\end{array}$ & 0 & 0 & 0 & 0 & 0 \\
\hline & $\begin{array}{l}\text { Tour guide has a sense of } \\
\text { humour }\end{array}$ & 0 & 0 & 0 & 0 & 0 \\
\hline
\end{tabular}


2.5. How satisfied are you with these different attributes of the package tour? (Please tick one option for every statement)

\begin{tabular}{llccccc}
\hline \multicolumn{1}{c}{$\begin{array}{l}\text { Component of the } \\
\text { package tour }\end{array}$} & $\begin{array}{l}\text { Very } \\
\text { satisfied }\end{array}$ & Satisfied & $\begin{array}{l}\text { Neither } \\
\text { satisfied } \\
\text { nor } \\
\text { dissatisfied }\end{array}$ & Dissatisfied & $\begin{array}{l}\text { Very } \\
\text { dissatisfied }\end{array}$ \\
\hline 1 & $\begin{array}{l}\text { Pre-arrival services } \\
\text { (e.g. airport pickup) }\end{array}$ & O & O & O & 0 & 0 \\
2 & Accommodation & 0 & 0 & 0 & 0 & 0 \\
3 & Food & 0 & 0 & 0 & 0 & 0 \\
4 & $\begin{array}{l}\text { Transportation } \\
\text { (sightseeing vehicles) }\end{array}$ & 0 & 0 & 0 & 0 & 0 \\
5 & $\begin{array}{l}\text { Attraction (e.g. } \\
\text { wildlife, culture) }\end{array}$ & 0 & 0 & 0 & 0 & 0 \\
6 & $\begin{array}{l}\text { Tour guide (e.g. } \\
\text { language skills) }\end{array}$ & 0 & 0 & 0 & 0 & 0 \\
\hline
\end{tabular}


2.6. How satisfied are you with these different attributes of the package tour? (Please tick one option for every statement)

\begin{tabular}{|c|c|c|c|c|c|c|}
\hline & $\begin{array}{l}\text { Component of the package } \\
\text { tour }\end{array}$ & $\begin{array}{l}\text { Very } \\
\text { satisfied }\end{array}$ & Satisfied & $\begin{array}{l}\text { Neither } \\
\text { satisfied } \\
\text { nor } \\
\text { dissatisfied }\end{array}$ & Dissatisfied & $\begin{array}{l}\text { Very } \\
\text { dissatisfied }\end{array}$ \\
\hline \multirow[t]{4}{*}{1} & Pre-arrival services & & & & & \\
\hline & $\begin{array}{l}\text { Availability of airport } \\
\text { pickup service }\end{array}$ & $\mathrm{O}$ & $\mathrm{O}$ & $\mathrm{O}$ & $\mathrm{O}$ & $\mathrm{O}$ \\
\hline & $\begin{array}{l}\text { Provision of information } \\
\text { about the country }\end{array}$ & 0 & 0 & 0 & 0 & 0 \\
\hline & $\begin{array}{l}\text { Provision of information } \\
\text { about the package tour }\end{array}$ & 0 & 0 & 0 & 0 & 0 \\
\hline \multirow[t]{3}{*}{ in } & Accommodation & & & & & \\
\hline & Quality of hotel facilities & 0 & 0 & 0 & 0 & 0 \\
\hline & Location of the hotel & 0 & 0 & 0 & 0 & $\mathrm{O}$ \\
\hline & Reasonable price & 0 & 0 & $\mathrm{O}$ & $\mathrm{O}$ & 0 \\
\hline \multirow[t]{4}{*}{3} & Food & & & & & \\
\hline & Variety of food & $\mathrm{O}$ & $\mathrm{O}$ & $\mathrm{O}$ & $\mathrm{O}$ & $\mathrm{O}$ \\
\hline & Attitude of restaurant staff & 0 & 0 & 0 & 0 & 0 \\
\hline & $\begin{array}{l}\text { Clean restaurant } \\
\text { environment }\end{array}$ & O & O & O & 0 & 0 \\
\hline \multirow[t]{4}{*}{4} & Transportation & & & & & \\
\hline & $\begin{array}{l}\text { Condition of the } \\
\text { sightseeing vehicles }\end{array}$ & $\mathrm{O}$ & $\mathrm{O}$ & O & $\mathrm{O}$ & $\mathrm{O}$ \\
\hline & $\begin{array}{l}\text { Professional and } \\
\text { experienced driver }\end{array}$ & $\mathrm{O}$ & $\mathrm{O}$ & $\mathrm{O}$ & 0 & $\mathrm{O}$ \\
\hline & $\begin{array}{l}\text { Open roof car for ease of } \\
\text { game viewing }\end{array}$ & $\mathrm{O}$ & $\mathrm{O}$ & $\mathrm{O}$ & $\mathrm{O}$ & $\mathrm{O}$ \\
\hline \multirow[t]{5}{*}{5} & Attractions & & & & & \\
\hline & $\begin{array}{l}\text { Abundance of wildlife in } \\
\text { the parks }\end{array}$ & $\mathrm{O}$ & $\mathrm{O}$ & $\mathrm{O}$ & $\mathrm{O}$ & $\mathrm{O}$ \\
\hline & $\begin{array}{l}\text { The availability of the Big } \\
\text { Five(Buffalo, Elephant, } \\
\text { Leopard, Lion and } \\
\text { Rhinoceros) }\end{array}$ & & & & & \\
\hline & The Maasai culture & $\mathrm{O}$ & $\mathrm{O}$ & $\mathrm{O}$ & $\mathrm{O}$ & $\mathrm{O}$ \\
\hline & $\begin{array}{l}\text { Natural features (e.g. } \\
\text { Ngorongoro crater, } \\
\text { Mt Kilimanjaro) }\end{array}$ & $\mathrm{O}$ & $\mathrm{O}$ & $\mathrm{O}$ & $\mathrm{O}$ & $\mathrm{O}$ \\
\hline \multirow[t]{4}{*}{6} & Tour guide & & & & & \\
\hline & $\begin{array}{l}\text { Tour guide speaks my } \\
\text { language }\end{array}$ & $\mathrm{O}$ & 0 & 0 & 0 & 0 \\
\hline & $\begin{array}{l}\text { Tour guide has good } \\
\text { communication skills }\end{array}$ & 0 & 0 & 0 & 0 & 0 \\
\hline & $\begin{array}{l}\text { Tour guide has a sense of } \\
\text { humour }\end{array}$ & 0 & 0 & 0 & 0 & 0 \\
\hline
\end{tabular}


2.7. Overall, how satisfied were you with the package tour experience?

\begin{tabular}{ccccc}
\hline $\begin{array}{c}\text { Very } \\
\text { satisfied }\end{array}$ & Satisfied & $\begin{array}{c}\text { Neither satisfied nor } \\
\text { dissatisfied }\end{array}$ & Dissatisfied & $\begin{array}{c}\text { Very } \\
\text { dissatisfied }\end{array}$ \\
\hline 0 & 0 & 0 & 0 & 0 \\
\hline
\end{tabular}

2.8. What was the most satisfying aspect of this tour?

2.9. What should be improved in order to offer a more satisfying package tour experience?

The "Big Five" is the term used by hunters to describe the most dangerous animals to hunt in spite of their size. The terminology has been widely used in marketing photography safaris in Africa.

2.10. How satisfied were you with the availability of the members of the Big Five in the protected areas visited?

\begin{tabular}{|c|c|c|c|c|c|c|}
\hline & The Big Five & $\begin{array}{c}\text { Very } \\
\text { Satisfied }\end{array}$ & Satisfied & $\begin{array}{c}\text { Neither } \\
\text { satisfied nor } \\
\text { dissatisfied }\end{array}$ & Dissatisfied & $\begin{array}{c}\text { Very } \\
\text { dissatisfied }\end{array}$ \\
\hline 1. & Buffalo & $\bar{O}$ & $\bar{O}$ & 0 & 0 & 0 \\
\hline 2. & Elephant & 0 & 0 & 0 & 0 & 0 \\
\hline 3. & Leopard & O & 0 & 0 & 0 & 0 \\
\hline 4. & Lion & O & 0 & 0 & 0 & 0 \\
\hline 5. & Rhinoceros & 0 & 0 & 0 & 0 & 0 \\
\hline
\end{tabular}




\subsection{The tour guide}

3.1 In the northern tourist circuit of Tanzania, all the package tour operators use tour guides.

How important are the following attributes of tour guides to your satisfaction with tour guiding? (Please tick one option for every statement)

\begin{tabular}{|c|c|c|c|c|c|c|}
\hline & Importance attribute & $\begin{array}{l}\text { Very } \\
\text { important }\end{array}$ & Important & $\begin{array}{l}\text { Not } \\
\text { sure }\end{array}$ & $\begin{array}{l}\text { Not } \\
\text { important }\end{array}$ & $\begin{array}{l}\text { Not } \\
\text { important } \\
\text { at all }\end{array}$ \\
\hline 1 & $\begin{array}{l}\text { Tour guide's knowledge } \\
\text { about wildlife }\end{array}$ & $\mathrm{O}$ & $\mathrm{O}$ & $\mathrm{O}$ & 0 & 0 \\
\hline 2 & $\begin{array}{l}\text { Tour guide's knowledge } \\
\text { about local culture. }\end{array}$ & O & $\mathrm{O}$ & O & O & 0 \\
\hline 3 & $\begin{array}{l}\text { Tour guide's care of } \\
\text { customers' needs. }\end{array}$ & 0 & 0 & 0 & 0 & 0 \\
\hline 4 & $\begin{array}{l}\text { Tour guide's } \\
\text { professional ethics }\end{array}$ & 0 & 0 & 0 & 0 & 0 \\
\hline 5 & $\begin{array}{l}\text { Tour guide's } \\
\text { communication skills. }\end{array}$ & 0 & 0 & 0 & 0 & 0 \\
\hline 6 & $\begin{array}{l}\text { Tour guide has good } \\
\text { language skills. }\end{array}$ & 0 & 0 & 0 & 0 & 0 \\
\hline 7 & $\begin{array}{l}\text { Tour guide's time } \\
\text { management skills }\end{array}$ & 0 & 0 & 0 & 0 & 0 \\
\hline 8 & $\begin{array}{l}\text { Tour guide has good } \\
\text { presentation and } \\
\text { interpretation skills. }\end{array}$ & 0 & 0 & 0 & 0 & 0 \\
\hline 9 & $\begin{array}{l}\text { Tour guide is able to } \\
\text { manage interaction } \\
\text { between tourists and } \\
\text { local communities. }\end{array}$ & 0 & 0 & 0 & 0 & 0 \\
\hline 10 & $\begin{array}{l}\text { Tour guide has a sense } \\
\text { of humour. }\end{array}$ & 0 & 0 & 0 & 0 & 0 \\
\hline 11 & $\begin{array}{l}\text { Tour guide is focussing } \\
\text { on the safety of the tour } \\
\text { members }\end{array}$ & 0 & 0 & 0 & 0 & 0 \\
\hline 12 & $\begin{array}{l}\text { Tour guide is capable of } \\
\text { handling customers' } \\
\text { complaints properly. }\end{array}$ & 0 & 0 & 0 & 0 & 0 \\
\hline
\end{tabular}


3.2 How satisfied are you with these different attributes of the tour guide? (Please tick one option for every statement)

\begin{tabular}{|c|c|c|c|c|c|c|}
\hline & Performance attribute & $\begin{array}{c}\text { Very } \\
\text { satisfied }\end{array}$ & Satisfied & $\begin{array}{c}\text { Neither } \\
\text { satisfied } \\
\text { nor } \\
\text { dissatisfied }\end{array}$ & Dissatisfied & $\begin{array}{c}\text { Very } \\
\text { dissatisfied }\end{array}$ \\
\hline 1 & $\begin{array}{l}\text { Tour guide's knowledge } \\
\text { about wildlife }\end{array}$ & $\mathrm{O}$ & 0 & 0 & $\mathrm{O}$ & $\mathrm{O}$ \\
\hline 2 & $\begin{array}{l}\text { Tour guide's knowledge } \\
\text { about local culture. }\end{array}$ & $\mathrm{O}$ & $\mathrm{O}$ & $\mathrm{O}$ & $\mathrm{O}$ & $\mathrm{O}$ \\
\hline 3 & $\begin{array}{l}\text { Tour guide's care of } \\
\text { customers' needs. }\end{array}$ & 0 & 0 & 0 & 0 & 0 \\
\hline 4 & $\begin{array}{l}\text { Tour guide's professional } \\
\text { ethics }\end{array}$ & $\mathrm{O}$ & $\mathrm{O}$ & $\mathrm{O}$ & $\mathrm{O}$ & $\mathrm{O}$ \\
\hline 5 & $\begin{array}{l}\text { Tour guide's } \\
\text { communication skills. }\end{array}$ & 0 & 0 & 0 & 0 & 0 \\
\hline 6 & $\begin{array}{l}\text { Tour guide has good } \\
\text { language skills. }\end{array}$ & $\mathrm{O}$ & $\mathrm{O}$ & $\mathrm{O}$ & $\mathrm{O}$ & $\mathrm{O}$ \\
\hline 7 & $\begin{array}{l}\text { Tour guide's time } \\
\text { management skills }\end{array}$ & 0 & 0 & 0 & 0 & 0 \\
\hline 8 & $\begin{array}{l}\text { Tour guide has good } \\
\text { presentation and } \\
\text { interpretation skills. }\end{array}$ & $\mathrm{O}$ & $\mathrm{O}$ & $\mathrm{O}$ & $\mathrm{O}$ & $\mathrm{O}$ \\
\hline 9 & $\begin{array}{l}\text { Tour guide is able to } \\
\text { manage interaction } \\
\text { between tourists and local } \\
\text { communities. }\end{array}$ & $\mathrm{O}$ & 0 & $\mathrm{O}$ & $\mathrm{O}$ & $\mathrm{O}$ \\
\hline 10 & $\begin{array}{l}\text { Tour guide has a sense of } \\
\text { humour. }\end{array}$ & $\mathrm{O}$ & $\mathrm{O}$ & $\mathrm{O}$ & $\mathrm{O}$ & $\mathrm{O}$ \\
\hline 11 & $\begin{array}{l}\text { Tour guide is focussing on } \\
\text { the safety of the tour } \\
\text { members }\end{array}$ & 0 & 0 & 0 & 0 & 0 \\
\hline 12 & $\begin{array}{l}\text { Tour guide is capable of } \\
\text { handling customers' } \\
\text { complaints properly. }\end{array}$ & $\mathrm{O}$ & $\mathrm{O}$ & $\mathrm{O}$ & $\mathrm{O}$ & $\mathrm{O}$ \\
\hline
\end{tabular}




\subsection{Demographic information}

4.1 What is your country of origin?

4.2 What is your gender? Male $O$ Female $O$

4.3 What is your age? Please select your age group from the table below.

\begin{tabular}{lcccc}
\hline Age group in years & $18-24$ & $25-44$ & $45-64$ & $65+$ \\
\hline Please select & 0 & 0 & 0 & 0 \\
\hline
\end{tabular}

4.4 Who are you travelling with? (Please select the option that best describes your situation)

\begin{tabular}{ccccc}
\hline I'm travelling & Alone & $\begin{array}{c}\text { With a } \\
\text { spouse or } \\
\text { partner }\end{array}$ & $\begin{array}{c}\text { With Family } \\
\text { and Children }\end{array}$ & With friends \\
\hline O & 0 & 0 & 0 \\
\hline
\end{tabular}

Thank you for taking the time to complete this questionnaire 